\title{
Piloto Baseado em Aprendizagem por Reforço para o Simulador de Corridas TORCS
}

\author{
Vinícius Kiwi Daros \\ Dissertação apresentada \\ ao \\ Instituto de Matemática e Estatística \\ da \\ Universidade de São Paulo \\ para \\ obtenção do título \\ de \\ Mestre em Ciência da Computação
}

Programa:

Mestrado em Ciência da Computação

Orientador:

Prof. Dr. Flávio Soares Corrêa da Silva

Durante o desenvolvimento deste trabalho o autor recebeu auxílio financeiro da CAPES 



\section{Piloto Baseado em Aprendizagem por Reforço para o Simulador de Corridas TORCS}

Esta versão da dissertação contém as correções e alterações sugeridas pela Comissão Julgadora durante a defesa da versão original do trabalho, realizada em 06/08/2015. Uma cópia da versão original está disponível no Instituto de Matemática e Estatística da Universidade de São Paulo.

Comissão Julgadora:

- Prof. Dr. Flávio Soares Corrêa da Silva - IME-USP

- Prof. Dr. Luiz Chaimowicz - UFMG

- Prof. Dr. Wamberto Weber Miranda P. de Vasconcelos - University of Aberdeen 



\section{Resumo}

Corrida de carros é um gênero popular de jogos eletrônicos e um domínio com vários desafios a serem explorados no âmbito da Inteligência Artificial (IA), tendo recebido atenção crescente nos últimos anos. Naturalmente, um desses desafios é criar pilotos virtuais capazes de aprender sozinhos a correr nas pistas.

Neste projeto de mestrado, nós adaptamos e aplicamos técnicas de Aprendizagem por Reforço (Reinforcement Learning) no desenvolvimento de um agente completamente autônomo capaz de correr em pistas de vários formatos dentro do simulador TORCS. Esse jogo de código aberto possui um sistema de física muito elaborado e permite a criação de módulos de IA para controlar os carros, sendo assim um ambiente de testes frequentemente adotado para pesquisas nesse contexto.

O objetivo do nosso agente é encontrar ações de controle do acelerador e freio a fim de gastar o menor tempo possível em cada volta. Para atingir tal meta, ele coleta dados na primeira volta, gera um modelo do circuito, segmenta e classifica cada trecho da pista e, finalmente, dá voltas no percurso até atingir um comportamento consistente.

Além das questões relacionadas à aprendizagem, este trabalho explora conceitos de Sistemas de Controle, em especial controladores PID (Proporcional, Integrativo, Derivativo), usados para a implementação da heurística do manejo do volante. Também abordamos os fundamentos de alguns assistentes de direção, tais como ABS (Anti-lock Braking System) e controle de estabilidade. Esses princípios são de grande importância para tornar o agente capaz de guiar o carro dentro de um ambiente com simulação física tão próxima à realidade. Nesse ponto e no emprego do sensoriamento para a aquisição de dados, nosso trabalho flerta com a área de Robótica Móvel.

Por fim, avaliamos o desempenho de nosso piloto virtual comparando seus resultados com os de controladores baseados em outras técnicas.

Palavras-chave: IA, aprendizagem por reforço, TORCS, jogos, corrida. 


\section{Sumário}

1 Introdução 1

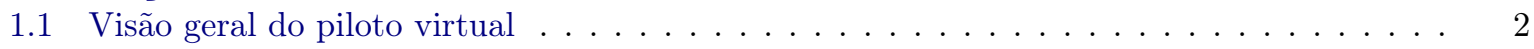

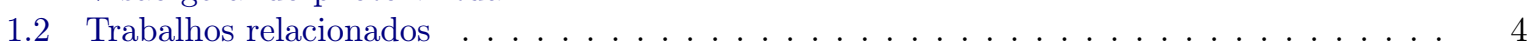

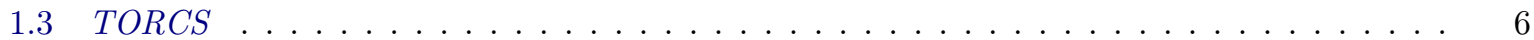

2 Controlador PID 11

2.1 PID - Proporcional Integrativo Derivativo . . . . . . . . . . . . . . . . . . . . 11

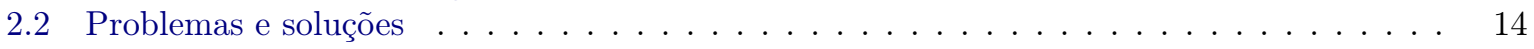

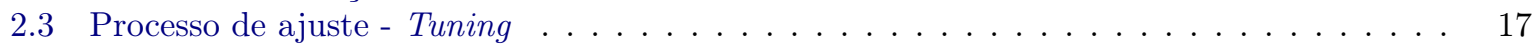

3 Modelagem da pista de corrida $\quad 19$

3.1 Construção de um modelo de pista . . . . . . . . . . . . . . . . . . . . . . . . 19

3.1 .1 Piloto coletor de dados . . . . . . . . . . . . . . . . . . . . . . . 19

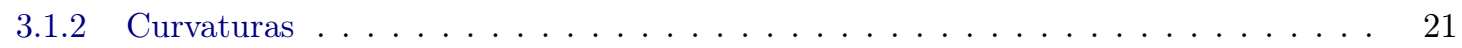

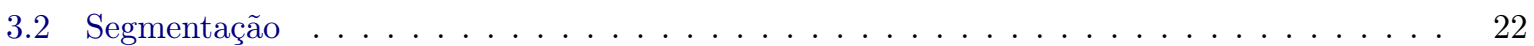

3.3 Classificação . . . . . . . . . . . . . . . . . . . . . . . . . . . 27

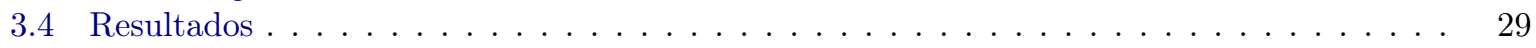

4 Aprendizagem por Reforço 31

4.1 Conceitos fundamentais . . . . . . . . . . . . . . . . . . . . . 31

4.1 .1 Processo de Decisão de Markov . . . . . . . . . . . . . . . . . . . . . 33

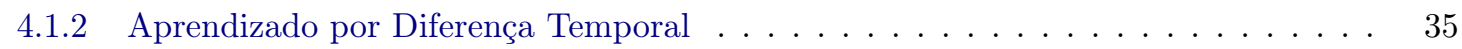

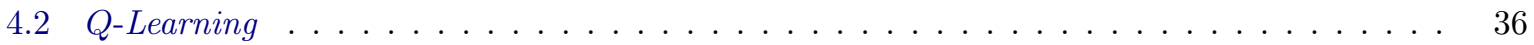

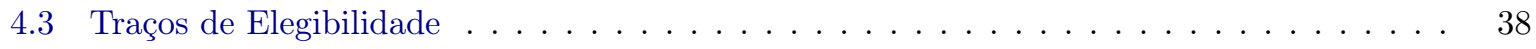

5 O piloto virtual 39

5.1 Preparação da aprendizagem e do carro $\ldots \ldots \ldots \ldots \ldots \ldots \ldots \ldots \ldots$

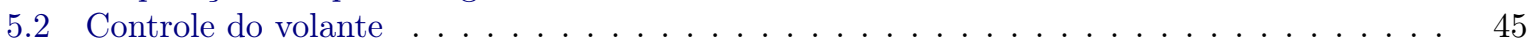

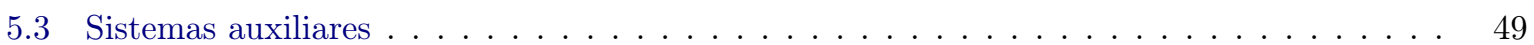

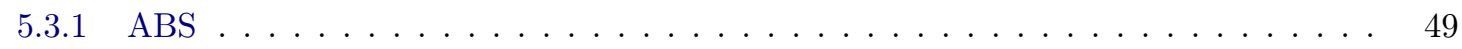

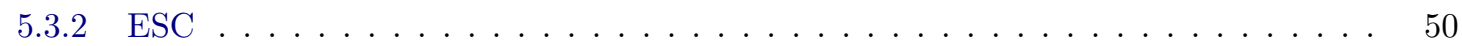

6 Experimentos e análises $\quad 53$

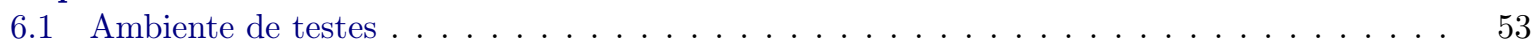

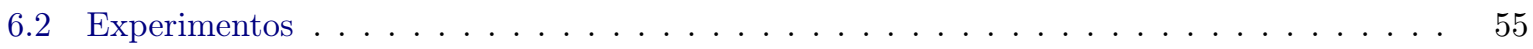

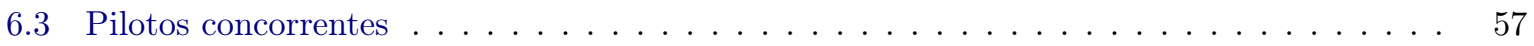

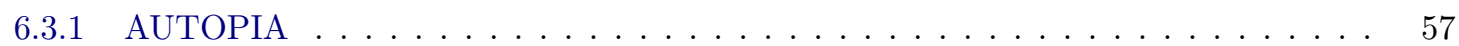

$6.3 .2 \quad$ Mr. Racer . . . . . . . . . . . . . . . . . . . . . . . . . . . . . 58

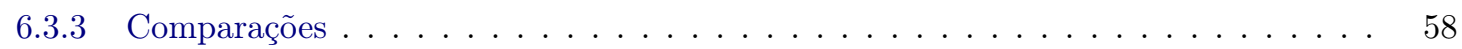

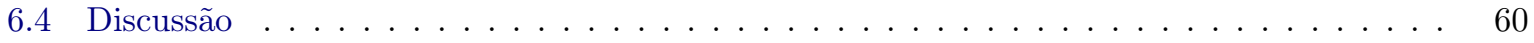

6.4.1 Aprendizado humano vs. aprendizado de máquina $\ldots \ldots \ldots \ldots \ldots$

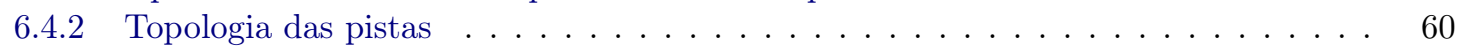

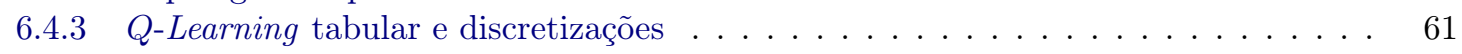

7 Conclusão $\quad 63$

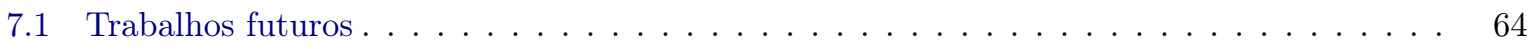


Referências Bibliográficas

Appendices

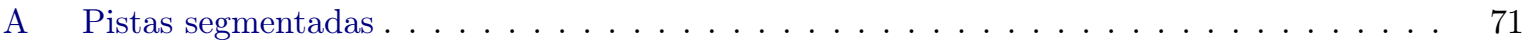

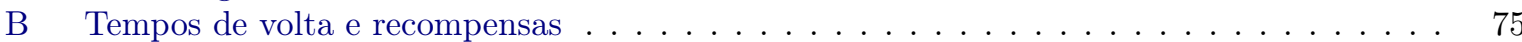




\section{Capítulo 1}

\section{Introdução}

O desenvolvimento de tecnologias aplicadas a automóveis autônomos é uma área que tem despertado o interesse de pesquisadores tanto no meio acadêmico quanto na indústria. Em particular, pilotar carros de corrida é uma tarefa reconhecidamente difícil e pessoas especialistas nessa atividade precisam realizar complexas sequências de ações para levar o carro aos limites de seu desempenho. Esse cenário desafiador é um campo fértil para o emprego de métodos de controle baseados em Inteligência Artificial (IA).

Entretanto, a construção de veículos é um processo demorado e oneroso, fazendo com que os procedimentos de testes tenham alto risco. Em paralelo a essa condição, muitos jogos de corrida modernos se mostram capazes de simular detalhadamente o mundo real e a dinâmica entre carros e pista. Essa conjunção de fatores apresenta a utilização de jogos eletrônicos para teste e desenvolvimento técnicas de aprendizado de máquina como um domínio promissor a ser explorado.

Em meio aos jogos existentes atualmente, o TORCS ${ }^{1}$ (The Open Racing Car Simulator) se mostra um ambiente virtual particularmente interessante para a pesquisa científica. Esse simulador preza pela implementação realista de conceitos físicos e sua arquitetura modular permite facilmente construir e integrar ao jogo controladores responsáveis pela condução dos carros. Por conta disso, o TORCS tem sido amplamente adotado como plataforma de testes por trabalhos encontrados na literatura e por competições realizadas em conferências internacionais sobre IA.

Dentre esses campeonatos, um dos mais renomados é o SCRC (Simulated Car Racing Championship) $\left[\mathrm{LLT}^{+} 10\right]$, onde os projetos submetidos competem entre si em séries de corridas no TORCS. Os trabalhos dos competidores têm se baseado em métodos variados, tais como redes neurais artificiais, algoritmos genéticos e lógica fuzzy. Contudo, a quantidade de publicações envolvendo Aprendizagem por Reforço (Reinforcement Learning ou apenas RL) é notoriamente limitada, valendo mencionar a implementação de um método simples voltado exclusivamente para ultrapassagens [LPLC10]. Também existe a proposta de um aproximador de função valor específico para o contexto de carros de corrida autônomos [AL11] e, embora a motivação desse artigo seja a aplicação em cenários complexos como os oferecidos pelo TORCS, os autores se limitaram a usar um simulador muito mais simples de implementação própria.

Consequentemente, não há relatos significativos sobre o emprego de RL no domínio de corridas simuladas. Algumas suposições a respeito da escassez de experimentos com pilotos virtuais baseados nesse importante ramo da aprendizagem de máquina já foram discutidas [AL11], tais como:

- Comparando-se com técnicas evolutivas, RL é mais sensível às muitas escolhas de parâmetros, tais como taxa de aprendizagem, fator de desconto e funções de recompensa;

- Falta de um modelo preditivo capaz de auxiliar o agente a estimar as mudanças de estado em função da tomada de ações;

\footnotetext{
1 http://www.torcs.org
} 
- Necessidade de se considerar um grande número de características para a formulação do espaço de estados, possivelmente sendo algumas delas contínuas;

- A própria falta de resultados anteriores sobre o desempenho da abordagem nesse domínio.

Dessa forma, um dos objetivos desta dissertação é descrever todas as etapas do desenvolvimento de um controlador baseado em Aprendizagem por Reforço capaz de pilotar um carro virtual em um ambiente complexo que simula a realidade. O objetivo do controlador é correr em diferentes pistas gastando o menor tempo possível em cada volta. Nenhuma informação prévia é disponibilizada e o piloto virtual deve, por si só, descobrir o comportamento que melhor atende à sua meta. A avaliação de desempenho é feita pela comparação entre o tempo médio de volta e os resultados obtidos por competidores do SCRC quando expostos a condições de testes idênticas.

Tipicamente, o comportamento de personagens não jogáveis (NPCs, non-player characters) em jogos de corrida comerciais é projetado com o auxílio de especialistas de domínio [Lec09]. As poucas exceções notáveis às abordagens manuais incluem o Colin McRace Rally ${ }^{2}$ (da empresa Codemasters), onde o comportamento dos NPCs foi definido pelo resultado do treinamento de redes neurais [Han], e a série Forza Motorsport ${ }^{3}$ (da Microsoft), onde técnicas de aprendizado supervisionado foram exploradas para treinar a IA do jogo e computação evolutiva foi aplicada na otimização do traçado a ser seguido [SC09]. Assim, acreditamos que este trabalho também pode beneficiar a criação de NPCs em jogos comerciais ao reduzir a necessidade de peritos de domínio no acompanhamento do projeto.

Além disso, carros autônomos capazes de navegar por ruas e estradas sem a necessidade de motoristas humanos já são uma realidade [Thr]. Entretanto, projetar e efetuar testes com carros reais envolve alta demanda de tempo, pessoal e materiais, sendo portanto um processo de alto custo. Simuladores de robôs dessa categoria seriam então alternativas mais simples, rápidas e baratas para a condução de experimentos. Porém, frequentemente esses simuladores não são bons o suficiente a ponto de ser possível empregar com sucesso no mundo real os controladores treinados nos ambientes virtuais [TLDN07].

Paralelamente a esse fato, alguns jogos atuais proveem implementações de física elaboradas o bastante para atender a essa necessidade, podendo ser o campo de provas ideal para o treinamento de robôs autônomos [TLDN07]. Com isso, outro objetivo deste trabalho é contribuir com essa pluralidade de aplicações dos video games, apresentando soluções que eventualmente possam ser exploradas também no domínio de robótica móvel.

\subsection{Visão geral do piloto virtual}

A fim de transmitir ao leitor uma perspectiva global do controlador desenvolvido em nosso trabalho, apresentamos brevemente nesta seção as principais características do projeto, indicando os capítulos dedicados ao detalhamento dos respectivos tópicos. Posto isso, listamos a seguir os principais aspectos que guiaram nossa proposta de piloto virtual:

- A plataforma de testes escolhida é o TORCS e a implementação do controlador usa a interface padronizada do SCRC;

- O carro sempre corre sozinho na pista, disputando apenas pelo tempo de volta;

- Na primeira volta, o piloto deve coletar dados sobre a pista por meio dos sensores virtuais presentes no carro. Exclusivamente a partir dessas informações, cria-se então um modelo da pista, o qual é segmentado em trechos que recebem classificações individuais;

\footnotetext{
2 http://en.wikipedia.org/wiki/Colin McRae Rally

3 http://en.wikipedia.org/wiki/Forza_Motorsport
} 
- O piloto deve aprender a controlar o acelerador e o freio por meio de técnicas de Aprendizado por Reforço de modo a ser capaz de adaptar-se a novas pistas;

- O manejo do volante é gerenciado em função do posicionamento do carro por meio de heurística;

- Os efeitos de desgaste de pneus, consumo de combustível e danos ao carro não são ativados durante as simulações.

As vantagens fundamentais que nos motivaram a adotar o ferramental de software disponibilizado pela organização do SCRC para a comunicação com o TORCS foram: $(i)$ a possibilidade de expor alguns competidores do campeonato aos mesmos testes enfrentados por nosso controlador, nos permitindo assim comparar resultados; (ii) a interface disponível ao controlador para acessar as informações do ambiente e comandar o carro é análoga aos sensores e atuadores que um robô móvel poderia ter. Em contrapartida, essa escolha também implica em algumas restrições, como por exemplo: $(i)$ cada iteração de processamento do controlador precisa ser rápida o suficiente para se manter sincronizada com a execução da simulação de física, obrigando o aprendizado a funcionar praticamente em tempo real; ( $i i)$ as características do ambiente que não podem ser medidas pelos sensores virtuais também não podem ser usadas pelo controlador.

Na próxima seção, mostramos alguns dos controladores submetidos ao SCRC, bem como outros trabalhos relacionados ao desenvolvimento de carros autônomos reais. Já a última seção deste capítulo é dedicada a apresentar as especificações do TORCS e a interface de sensores e atuadores virtuais.

Como já mencionado, ao longo da primeira volta na pista, nosso piloto virtual apenas coleta dados para reconhecer o circuito. Durante essa atividade, deseja-se manter a velocidade baixa e constante em aproximadamente $40 \mathrm{~km} / \mathrm{h}$. O posicionamento do carro, por sua vez, deve ser mantido ao centro da pista tanto quanto o possível. Assim, nessa tarefa, o volante, acelerador e freio são gerenciados por um mecanismo de controle do tipo PID (Proporcional-Integrativo-Derivativo), cujo funcionamento está explicado no Capítulo 2.

Quando a volta de reconhecimento termina, os dados são processados e o piloto virtual então cria um modelo do formato da pista. Depois de sua construção, esse modelo é segmentado em trechos, os quais são classificados em reta longa, curva leve, curva acentuada, entre outros. Descrevemos no Capítulo 3 os detalhes do método que propomos para efetuar a segmentação e classificação da pista.

A partir da segunda volta, nosso controlador passa a experimentar várias ações distintas ao longo dos trechos da pista, empregando técnicas de Aprendizagem por Reforço na busca pelo comportamento mais veloz. A aprendizagem atua sobre o controle dos pedais do acelerador e freio, sendo que a fundamentação teórica dos conceitos de RL está apresentada no Capítulo 4. Já o Capítulo 5 aborda as adaptações necessárias à implementação do piloto virtual, bem como as particularidades da heurística que propomos para o manejo do volante usando uma série de controladores PID.

Após a exposição dos elementos conceituais e a descrição da construção do controlador, relatamos no Capítulo 6 os procedimentos aplicados para a avaliação de desempenho. Retratamos dois dos mais notáveis participantes do SCRC e comparamos seus resultados com os de nosso piloto. Ainda nesse capítulo, apontamos reflexões sobre algumas questões que se revelaram durante o processo de testes.

Por fim, no Capítulo 7 apresentamos nossas conclusões e últimas considerações sobre este projeto. Entendemos claramente que este texto apresenta apenas os primeiros passos dados em um amplo campo de pesquisa, onde há muito a ser explorado. Assim, encerramos a dissertação indicando algumas oportunidades para trabalhos futuros. 


\subsection{Trabalhos relacionados}

Criar carros que não dependam de motoristas não é uma proposta recente. A literatura sobre o tema é abundante e diversas publicações relatam casos de sucesso. Embora exista uma polarização entre trabalhos relacionados a automóveis reais e aos simuladores, estudos em ambas frentes podem contribuir entre si. Por conta disso, apresentamos brevemente a seguir os projetos mais emblemáticos da história da condução autônoma de veículos. Posteriormente, expomos o levantamento de alguns trabalhos relacionados ao emprego de IA em simuladores de corrida.

\section{Ambientes reais}

As primeiras pesquisas buscando transformar carros convencionais em veículos autônomos datam da década de 80. A Universidade de Carnegie Mellon foi a pioneira nesse segmento, iniciando dois projetos em 1984: Navlab1 [JPKA95] e $A L V$ [WST ${ }^{+}$85, KTW86]. O Navlab1 foi o primeiro de uma série de automóveis desenvolvidos na universidade e consistia em uma van adaptada carregando 5 prateleiras de computadores. Porém seu software era limitado e o carro só se tornou completamente funcional ao final da década, quando conseguiu atingir sua velocidade máxima de $32 \mathrm{~km} / \mathrm{h}$ [JPKA95].

A primeira versão do $A L V$ usava como único sensor apenas uma simples câmera de televisão em preto e branco [WST $\left.{ }^{+} 85\right]$. O trabalho se concentrou em produzir algoritmos para a detecção das faixas central e laterais da pista, além de um método de controle do volante baseado na imagem capturada. A velocidade era mantida constante e baixa. A evolução do projeto incorporou uma gama de sensores, tais como câmeras estéreo coloridas e sonares [KTW86]. O carro ainda se orientava pelas faixas na pista, mas também pela presença de calçadas. Além disso, obstáculos e pedestres eram monitorados e evitados.

Outro precursor da área foi Ernst Dickmanns, da Universidade do Bundeswehr de Munique, quem desenvolveu um sistema computadorizado para controlar a direção, acelerador e freios de uma van da Mercedes-Benz também usando processamento de imagens [Dic07]. Em 1987, o aparato foi capaz de percorrer aproximadamente $20 \mathrm{~km}$, atingindo velocidade máxima de $96 \mathrm{~km} / \mathrm{h}$. Mais tarde, em 1994, os modelos aprimorados VaMP e VITA-2, preparados pelo EUREKA Prometheus Project (PROgraMme for a European Traffic of Highest Efficiency and Unprecedented Safety) [Wil88], conseguiram andar mais de $1000 \mathrm{~km}$ no trânsito normal em uma rodovia de Paris, França.

Em 1995, o VaMP percorreu 1758km em uma viagem entre Munique e Odense, Dinamarca. Aproximadamente $95 \%$ do trajeto foi cumprido de forma totalmente autônoma, incluindo trechos da Autobahn alemã, onde o carro alcançou velocidades superiores a $175 \mathrm{~km} / \mathrm{h}\left[\mathrm{MBF}^{+} 96\right]$.

A primeira grande competição entre projetos de veículos dessa categoria foi organizada em 2004 pela Defense Advanced Research Projects Agency dos Estados Unidos. O chamado DARPA Grand Challenge rapidamente ganhou notoriedade devido ao prêmio de um milhão de dólares à equipe vencedora.

No desafio de $2004^{4}$, os carros dirigidos por computador deveriam atravessar um trecho de aproximadamente $240 \mathrm{~km}$ do Deserto de Mojave (Califórnia, Estados Unidos), porém nenhum dos competidores conseguiu realizar a façanha. No ano seguinte, as especificações e objetivos do desafio não se alteraram e 5 carros foram capazes de cumpri-lo ${ }^{5}$. Já em $2007^{6}$, o cenário passou a ser um percurso em um ambiente urbano controlado e os automóveis precisaram seguir as leis de trânsito além de percorrer o circuito no menor tempo possível. Das 11 equipes na disputa, 6 completaram a tarefa com sucesso.

\footnotetext{
4 http://archive.darpa.mil/grandchallenge04/

5 http://archive.darpa.mil/grandchallenge05/

6 http://archive.darpa.mil/grandchallenge/
} 


\section{Ambientes simulados}

Jogos de corrida tem sido considerados um domínio de testes interessante para a construção e avaliação de técnicas de condução autônoma de veículos baseadas em IA [OPG+12]. Vários autores tem usado o simulador TORCS para elaborar controladores capazes de descobrir sozinhos como correr em pistas variadas.

Um dos candidatos do SCRC bem sucedido nessa tarefa é denominado AUTOPIA [OPA+09, OPG $\left.{ }^{+} 12\right]$. A arquitetura desse competidor é modular e empregou-se lógica fuzzy em conjunto a algoritmos genéticos para determinar a velocidade mais apropriada em cada trecho da pista. Outro controlador muito competitivo é o chamado Mr. Racer [QPR11], fundamentado fortemente em planejamento. Usando exaustivamente todos os sensores de distâncias disponíveis, cria-se um modelo acurado da pista para o planejamento das ações. Em virtude do desempenho notável desses dois controladores, descrevemos mais detalhadamente seu funcionamento no Capítulo 6, onde também comparamos seus resultados com os de nosso piloto virtual.

Outro trabalho baseado em lógica fuzzy mostra uma tentativa de representar o mundo do ambiente simulado por meio dessa técnica [PRSI09]. Os sensores e atuadores do carro são agrupados em conjuntos fuzzy e as regras usadas em cada um dos conjuntos foram definidas manualmente. A evolução dos parâmetros é feita por um algoritmo genético com o objetivo de otimizar o tempo de volta, o dano sofrido e o tempo gasto fora da pista. O desempenho desse controlador foi menos expressivo e os autores mostram uma discussão sobre como a construção dos conjuntos fuzzy limitou a capacidade de se acelerar e frear totalmente.

Uma abordagem mais direta é adotada no projeto COBOSTAR [BL09], onde os dados provenientes dos sensores são mapeados para o controle dos atuadores sem a existência de representações internas. Pela técnica sensory-to-motor, a informação sensorial é usada como entrada para uma função a qual devolve os sinais de comando aos atuadores. Os parâmetros dessa função são otimizados usando a estratégia evolutiva CMA (Adaptação de Matrizes de Covariância). Por essa característica imediatista, o controlador precisa ser treinado em várias pistas distintas a fim de determinar parâmetros genéricos para a função de mapeamento e, com isso, evitar o sobre-ajuste. Em razão dessa característica, o desempenho do carro se limita a ser mediano na maioria dos circuitos.

Entretanto, a competitividade e a busca pela maior eficiência não são os únicos fatores motivando pesquisas nessa área. Existem também estudos com o objetivo de criar NPCs que se comportem de forma semelhante aos jogadores humanos guiando seus carros [MGS10, MGS09]. Para isso, uma série de redes neurais artificiais é treinada com dados recebidos de partidas de jogadores humanos. A partir desse treinamento, as redes neurais respondem às diferentes situações de uma corrida fazendo previsões de como seriam as escolhas de um jogador em relação ao traçado e à velocidade a serem seguidos.

Também existem estudos sobre formalizações das capacidades e limitações relacionadas a condução de carros em pistas de corrida [BCMS08]. O modelo matemático proposto é abrangente e aborda questões como o cálculo das velocidades máximas em cada ponto da pista, a busca pelo melhor traçado e até mesmo um método para estimar o tempo mínimo necessário para se completar uma volta. Apesar de muito poderosa, essa abordagem exige informações muito detalhadas para a construção do modelo, tais como as diversas relações dinâmicas de interação entre o carro e o ambiente. Assim, há poucos trabalhos aproveitando esse formalismo.

Tentando aplicar algumas das conclusões do modelo citado acima, porém reduzindo a quantidade de informações prévias exigidas, vale destacar uma proposta de método evolutivo para encontrar o traçado ideal a ser seguido [CLLB10]. Dada apenas a geometria precisa de uma pista, um algoritmo genético usado em conjunto de simulações no TORCS é capaz de determinar a melhor ponderação entre o caminho de menor curvatura e o caminho mais curto em um circuito. 


\section{$1.3 \quad$ TORCS}

O ambiente de simulação escolhido como plataforma de testes para este trabalho é o TORCS (The Open Racing Car Simulator), um simulador de corridas automobilísticas de código aberto (licença GPL) desenvolvido com o intuito de permitir aos usuários a criação de módulos capazes de controlar o comportamento dos carros virtuais. O emprego do TORCS em projetos acadêmicos apresenta uma série de vantagens em comparação a outros simuladores $\left[\mathrm{OPG}^{+} 12\right]$. Algumas delas são:

- Ele possui qualidades de um simulador avançado, semelhante a jogos comerciais recentes, porém possibilita grande variedade de personalizações;

- Há um sofisticado mecanismo de física, no qual a aderência dos pneus à pista, efeitos aerodinâmicos, consumo de combustível, dano sofrido e diversos outros fatores influenciam o comportamento e desempenho do carro;

- Há representação gráfica em 3D da corrida, permitindo o acompanhamento visual da simulação;

- A arquitetura do software é altamente modularizada, facilitando a tarefa de implementar e integrar controladores para o jogo.

Embora o TORCS não tenha a mesma qualidade visual com gráficos de última geração dos jogos comerciais, o visualizador 3D permite acompanhar o comportamento do controlador na pista por de vários ângulos diferentes, como exemplificado na Figura 1.1. Ademais, também é possível usar apenas o simulador, sem o componente gráfico, acelerando a execução de testes. Essa característica é fundamental para a realização de baterias de experimentos em várias pistas com centenas de voltas em cada.
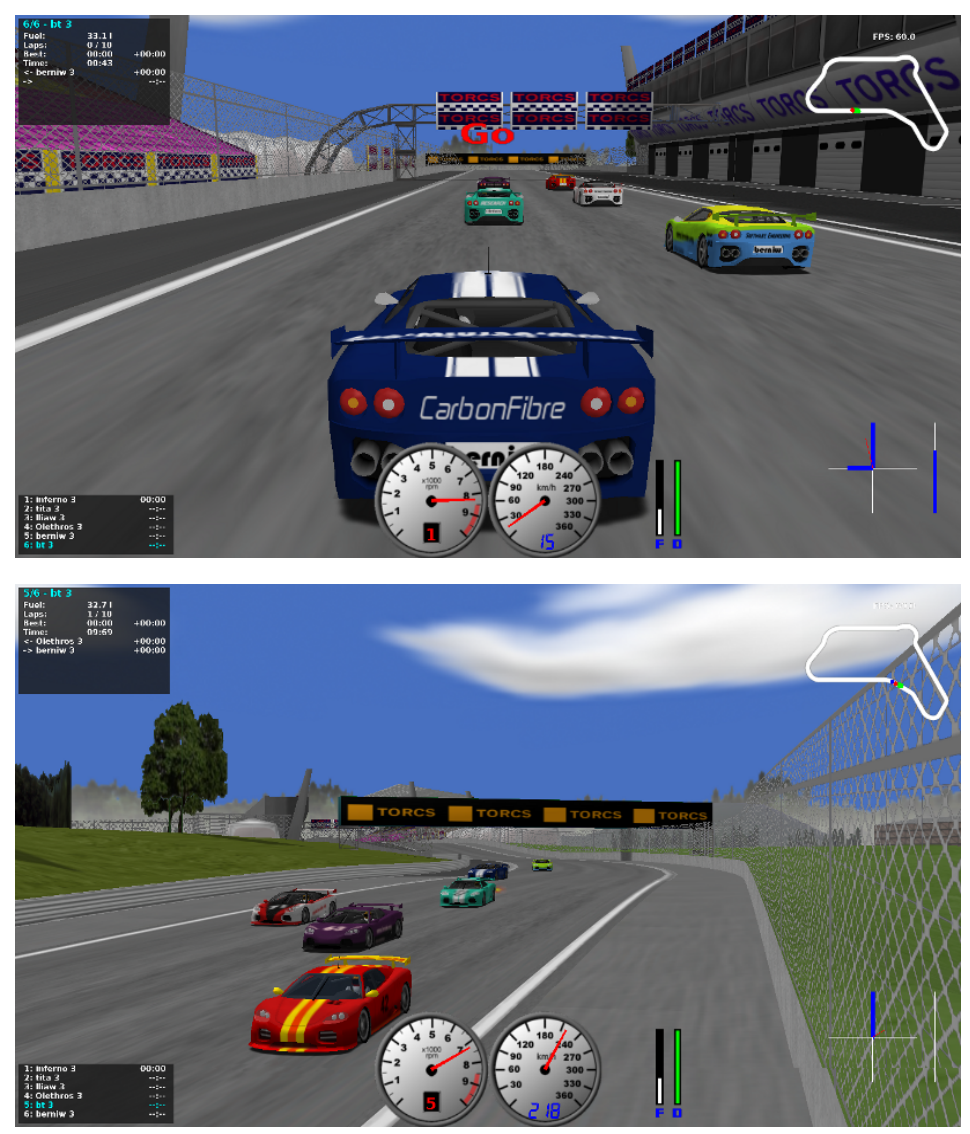

Figura 1.1: Imagens de uma corrida no TORCS. 
Por padrão, o TORCS permite aos controladores acessar uma enorme quantidade de informações da simulação, pois elas são compartilhadas entre todos os módulos acoplados ao jogo. Assim, qualquer piloto virtual poderia analisar diretamente as estruturas de dados da pista, por exemplo. Além disso, a atualização da simulação de física fica bloqueada enquanto os controladores não respondem quais ações farão, podendo impedir o sistema de trabalhar em tempo real.

Essas duas questões afastam a condição de jogo do cenário que um robô móvel enfrentaria no mundo real, onde as informações disponíveis ao robô são restritas e eventos acontecem em seu próprio ritmo. Ademais, controladores com longas atividades de processamento a cada iteração poderiam tornar as partidas de disputa direta inviavelmente prolongadas.

A fim de lidar com essas adversidades e tornar o TORCS uma ferramenta funcional e justa para competições, os autores do SCRC (Simulated Car Racing Championship) desenvolveram uma adaptação para o jogo seguindo o modelo cliente-servidor [scr12]. O servidor está acoplado diretamente ao TORCS e os controladores devem implementar a interface de cliente. A comunicação é feita por troca de mensagens em intervalos regulares de $20 \mathrm{~ms}$, dos quais apenas $10 \mathrm{~ms}$ são reservados para os controladores efetuarem seus processamentos.

Com isso, o controlador não tem acesso indiscriminado às informações da partida e a observação do ambiente é feita por meio de sensores virtuais presentes no carro. Esses sensores são capazes de realizar medições variadas, sendo atualizados pelo servidor de acordo com o estado do ambiente a cada passo da simulação. Na Figura 1.2 mostramos uma representação visual de alguns desses sensores e, na Tabela 1.1, apresentamos sua listagem completa, juntamente com descrições individuais.

Depois da atualização dos sensores, o controlador possui um intervalo de $10 \mathrm{~ms}$ para determinar qual será sua ação e ajustar os parâmetros passados aos atuadores do carro. Encerrado o período de processamento, o servidor consulta o valor atribuído a cada atuador e retransmite ao TORCS os comandos associados. Caso o cliente não termine seus cálculos há tempo, o servidor dá continuidade à simulação usando a última ação definida. Na Tabela 1.2 há a descrição dos atuadores disponíveis.

O campeonato SCRC tem sido realizado em conferências internacionais, tais como EVO* [evo12], ACM GECCO [gec12] e IEEE CIG [cig12]. Em cada etapa, são feitas baterias de experimentos compostas por três estágios: $(i)$ aquecimento; $(i i)$ qualificação; e (iii) corridas. Durante o aquecimento, cada piloto virtual é colocado sozinho na pista para explorar o circuito a fim de coletar informações que poderão ser usadas nos próximos estágios. Em seguida, os pilotos, ainda sozinhos, correm contra o relógio com o objetivo de percorrer a maior distância dentro do limite de tempo. Por fim, os melhores qualificados disputam corridas juntos, onde o vencedor é o primeiro que conseguir cruzar a linha de chegada. Ao término de cada corrida, os controladores recebem pontos de acordo com sua classificação final, seguindo os moldes da Fórmula 1. Aquele que acumular mais pontos ao encerramento da última conferência ganha o campeonato.

Vale salientar que as pistas usadas em todas as corridas do torneio não são distribuídas com o TORCS. Ou seja, o primeiro contato entre os pilotos virtuais e os circuitos da competição acontece no aquecimento. Com isso, fica evidente que os desenvolvedores não têm possibilidade de ajustar previamente parâmetros específicos para as pistas do campeonato e, portanto, os controladores precisam ter a capacidade de se adaptar a circuitos desconhecidos. 
Tabela 1.1: Sensores disponíveis

\begin{tabular}{|c|c|}
\hline Nome & Descrição \\
\hline angle & $\begin{array}{l}\text { Ângulo entre a direção do carro e a direção do eixo da pista. Valores negativos indicam } \\
\text { que o carro está apontando para a direita do eixo da pista e valores positivos para a } \\
\text { esquerda. }\end{array}$ \\
\hline curLapTime & Tempo decorrido desde o início da volta atual. \\
\hline damage & Quantidade de dano sofrido pelo carro. \\
\hline distFromStart & Distância entre o carro e a linha de largada ao longo do eixo da pista. \\
\hline distRaced & Distância percorrida pelo carro desde o início da corrida. \\
\hline fuel & Indica o nível de combustível. \\
\hline gear & Indica qual marcha está engatada. \\
\hline lastLap Time & Tempo gasto para completar a volta anterior. \\
\hline opponents & $\begin{array}{l}\text { Vetor de } 36 \text { sensores que detecta a distância (de } 0 \text { a } 100 \text { metros) até um oponente. } \\
\text { Cada sensor cobre um setor de } 10^{\circ} \text {, de }-\pi \text { a } \pi \text {, em torno do carro. }\end{array}$ \\
\hline racePos & Posição na corrida com relação aos outros carros. \\
\hline rpm & Número de rotações por minuto do motor. \\
\hline speed $X$ & Velocidade do carro ao longo do eixo longitudinal do carro. \\
\hline speed $Y$ & Velocidade do carro ao longo do eixo transversal ao carro. \\
\hline track & $\begin{array}{l}\text { Vetor de } 19 \text { sensores de proximidade posicionados na frente: cada sensor indica a } \\
\text { distância entre a frente do carro e a extremidade da pista. Cada sensor tem inclinação } \\
\text { própria, indo de }-\pi / 2 \text { a }+\pi / 2 \text {, definida na configuração inicial do carro. A distância é } \\
\text { dada em metros e o alcance dos sensores é de } 200 \text { metros. Quando o carro está fora } \\
\text { da pista (ou seja, quando trackPos é menor que }-1 \text { ou maior que } 1 \text { ), esses sensores } \\
\text { não são confiáveis. }\end{array}$ \\
\hline trackPos & $\begin{array}{l}\text { Distância entre o carro e o eixo da pista. O valor é normalizado com respeito à largura } \\
\text { da pista: } 0 \text { quando o carro está sobre o eixo, }-1 \text { quando estiver sobre a borda direita } \\
\text { da pista e } 1 \text { quando estiver sobre a borda esquerda. Valores menores que }-1 \text { e maiores } \\
\text { que } 1 \text { indicam que o carro está fora da pista. }\end{array}$ \\
\hline wheelSpinVel & Vetor de 4 sensores representando a rotação de cada roda. \\
\hline
\end{tabular}

Tabela 1.2: Atuadores disponíveis

\begin{tabular}{|c|c|}
\hline Nome & Descrição \\
\hline accel & Pedal virtual do acelerador (0 significa sem aceleração e 1 é aceleração total) \\
\hline brake & Pedal virtual do freio ( 0 significa sem freio e 1 é frenagem total). \\
\hline gear & $\begin{array}{l}\text { Engata a marcha especificada: }-1 \text { para ré, } 0 \text { para neutro (ponto morto) e de } 1 \text { a } 6 \text { para as } \\
\text { demais. }\end{array}$ \\
\hline steer & $\begin{array}{l}\text { Valor de }-1 \text { a }+1 \text { indicando o quanto o volante está virado (completamente para esquerda e } \\
\text { direita respectivamente). Inclinação total corresponde a } 0,785398 \text { radianos. }\end{array}$ \\
\hline neta & Para uso de controle da corrida: 0 não faz nada e 1 solicita ao servidor o reiníc \\
\hline
\end{tabular}




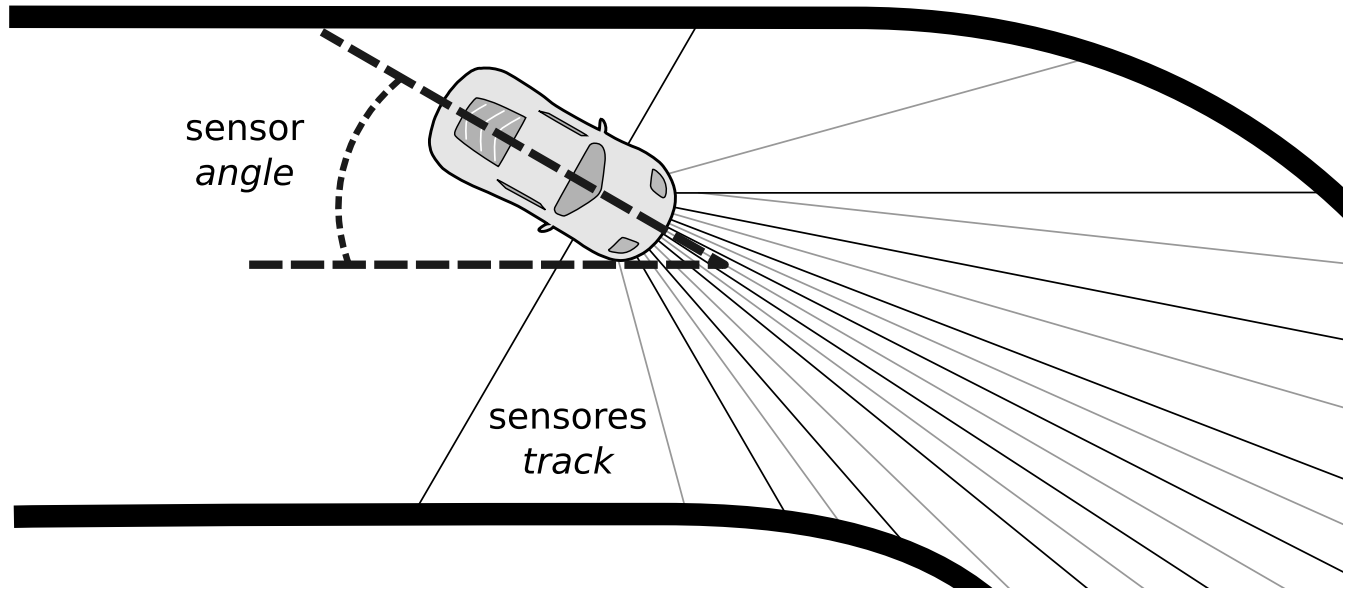

(a) Representação do sensor de inclinação em relação ao eixo da pista (angle) e dos sensores de distância até as bordas da pista (track).

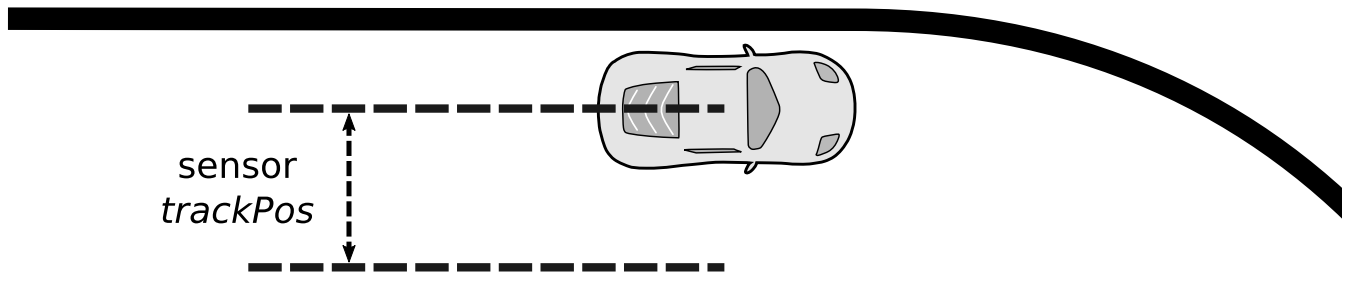

(b) Representação do sensor de distância em relação ao eixo da pista (trackPos).

Figura 1.2: Alguns dos sensores mais usados pelos controladores. A lista completa de todos os sensores disponíveis, bem como seus detalhes, encontra-se na Tabela 1.1. 


\section{Capítulo 2}

\section{Controlador PID}

Para algumas das atividades que o piloto virtual precisa realizar durante as sessões de testes, o exato comportamento desejado já é conhecido. Nessa categoria estão, por exemplo, posicionar o carro ao centro da pista, manter uma velocidade constante, atacar uma curva, entre outras. Nesses contextos, torna-se mais interessante aplicar métodos relacionados à Teoria de Controle do que a Aprendizado de Máquina. Em particular para essas atividades, implementamos controladores do tipo PID (Proporcional-IntegrativoDerivativo), que são o tema deste capítulo.

O capítulo se inicia com uma breve introdução sobre sistemas de controle e os princípios do PID. Adiante analisamos algumas situações nas quais o controlador apresenta comportamentos indesejados e como contorná-las. Por fim, é abordado o processo de ajuste de parâmetros necessário para personalizar o PID para cada caso de uso.

\subsection{PID - Proporcional Integrativo Derivativo}

Na teoria de controle, um sistema é visto como uma combinação de componentes usada para cumprir determinado objetivo. Quando um sistema toma a medição de uma grandeza, a compara com um valor de referência desejado e usa essa diferença como meio de controle, usa-se a denominação sistema de controle com retroação [Oga00]. Sistemas desse tipo são agrupados em duas categorias:

\section{Sistemas de controle de malha aberta:}

Os sistemas com retroação que produzem saída usando um sinal de entrada que se refere exclusivamente à medição de determinada grandeza são chamados de sistemas de malha aberta. A Figura 2.1 mostra como é o esquema geral de um sistema desse tipo.

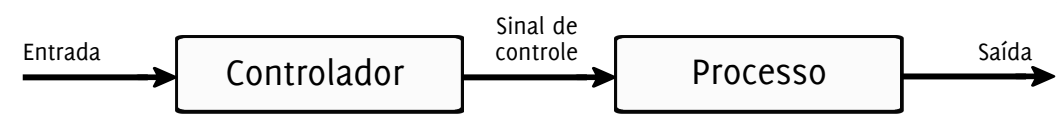

Figura 2.1: Representação em blocos de um sistema de malha aberta.

\section{Sistemas de controle de malha fechada:}

Sistemas de malha fechada, por sua vez, além de considerarem o valor da medição, também tomam o próprio sinal de saída como parte da entrada. Com isso, tem-se realimentação do sistema, permitindo monitorar a diferença entre o valor medido e o resultado da saída devolvida, como ilustrado pela Figura 2.2. Essa diferença é chamada de erro e geralmente os sistemas de malha fechada buscam minimizar esse valor. 


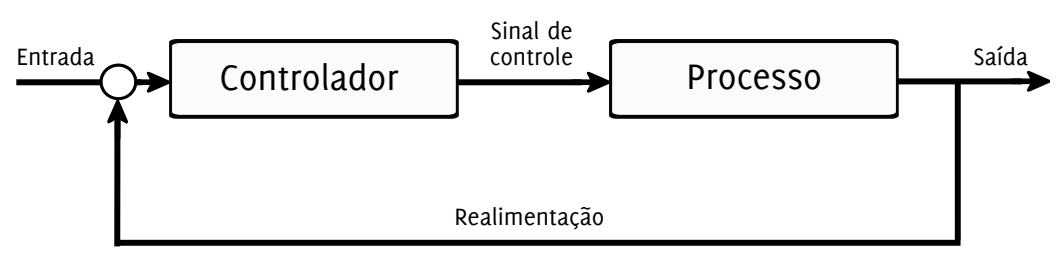

Figura 2.2: Representação em blocos de um sistema de malha fechada.

Observação: Muitas vezes os sistemas de controle são chamados apenas de controladores. Por praticidade e para seguir a convenção, adotaremos essa nomenclatura até o fim deste capítulo. Porém, no restante da dissertação o termo controlador é usado ao nos referirmos aos pilotos virtuais.

O controlador Proporcional-Integrativo-Derivativo, que é um sistema de malha fechada, é notoriamente o algoritmo mais utilizado em aplicações de controle [ÅH95]. O princípio por trás desse controlador se resume a monitorar o valor de uma variável de interesse (denominado por process value, ou simplesmente PV), avaliar a diferença entre PV e um determinado valor de referência (setpoint, ou apenas SP) e produzir saídas que ajustam o processo externo ao controlador a fim de minimizar o erro entre PV e SP.

A sigla PID se refere aos três termos que compõe a Equação (2.1), a qual rege o cálculo da resposta do controlador.

$$
u(t)=K_{p} e(t)+K_{i} \int_{0}^{t} e(\tau) d \tau+K_{d} \frac{d}{d t} e(t)
$$

Onde,

PV: Process Value - variável cujo valor é monitorado e serve de entrada para sistema de controle;

SP: Setpoint - valor de referência até onde se deseja levar PV;

$u(t)$ : Sinal de saída do PID no instante $t$;

$e(t)$ : $\quad$ Erro no instante $t$, sendo que erro $=S P-P V$;

$K_{p}$ : Constante de ganho do termo proporcional;

$K_{i}$ : Constante de ganho do termo integrativo;

$K_{d}$ : Constante de ganho do termo derivativo;

Pode-se observar que o PID depende basicamente de três termos, sendo que a magnitude da contribuição de cada um deles é controlada pelas constantes de ganho $K_{p}, K_{i}$ e $K_{d}$. Os termos exercem influências distintas sobre o comportamento do sinal de resposta. Assim sendo, para conseguir ajustar o controlador de modo a resolver determinado problema atendendo às restrições impostas pelo contexto de uso, é preciso primeiro compreender as relações entre os termos e as características do sinal de saída.

\section{Termo Proporcional}

O termo Proporcional está diretamente ligado à diferença entre o valor medido PV e o patamar de referência SP desejado. Em outras palavras, o componente Proporcional responde francamente ao erro do tempo presente. Essa característica está intimamente vinculada à "responsividade" (ou "sensibilidade") do controlador, isto é, à rapidez com que o sistema responde às mudanças da variável externa ou do setpoint.

Em certos cenários, quando o processo externo ao controlador é consideravelmente estável, um controlador puramente Proporcional ( $\operatorname{com} K_{i}=K_{d}=0$ ) pode ser suficiente para garantir que PV alcance o setpoint de maneira satisfatória. Entretanto, o desempenho dos controladores Proporcionais é limitado, principalmente em lidar com erros de pequena amplitude ao se atingir o estado estacionário. Também vale observar que altos parâmetros de ganho proporcional refletem em grandes variações na saída, criando oscilações e podendo até tornar o sistema instável. 


\section{Termo Integrativo}

O termo Integrativo é calculado com base na área sob a curva de erro, ou seja, o erro acumulado. Consequentemente, além da magnitude, a duração do período em que PV esteve longe do valor desejado também é relevante. Por essa razão, frequentemente interpreta-se o componente Integrativo como relacionado ao "passado" ou ao "histórico" de erro.

O uso do fator integrativo ajuda a superar a deficiência do componente Proporcional em anular o erro residual no estado estacionário, pois mesmo para erros pequenos o valor da integral continua aumentando. Assim, eventualmente a saída do controlador continua levando o sistema em direção ao setpoint até que o erro torne-se nulo de fato.

Contudo, acompanhando o raciocínio anterior, é possível perceber que em algumas situações o fator Integrativo continuará empurrando a saída do controlador em um sentido mesmo depois de PV ultrapassar o setpoint. Esse acontecimento recebe o nome de overshoot (ou exagero sobre o alvo) e é um dos efeitos colaterais que o uso do Integrativo pode ocasionar. Longos períodos passados em erro faz com que o termo Integrativo induza permanecer em erro oposto.

Além disso, dada sua característica acumulativa, é fácil notar que esse termo possui a tendência de tornar-se excessivamente grande. Por conta disso, geralmente $K_{i}$ é definida com valores consideravelmente inferiores às demais constantes. Portanto o componente Integrativo é usado como um fator de resposta lenta, embora ele contribua para acelerar a escalada de PV em direção à SP desde o início.

\section{Termo Derivativo}

O termo Derivativo atua em resposta à taxa de variação do erro em relação ao tempo. Por conta disso, sua reação a mudanças tanto em PV quanto em SP são imediatas, característica que torna esse componente consideravelmente sensível a alterações ruidosas no erro. Em contrapartida, o Derivativo se anula na presença de erros constantes, mesmo quando eles apresentam alto valor.

Devido a esse aspecto de responder à tendência do erro, o termo derivativo é interpretado como uma previsão do erro futuro. Tal propriedade se contrasta com os efeitos produzidos pelo Proporcional e Integrativo, pois faz com que o Derivativo seja o único termo capaz de combater o overshoot. Isso acontece porque, à medida que PV se aproxima do setpoint, o Proporcional vai perdendo força até que em certo momento (antes de PV ultrapassar SP) o Derivativo se torna o termo dominante, fazendo com que o PID passe a responder de modo a tentar reduzir a derivada, ou seja, tornar o erro constante. Vale notar que, assim como o Proporcional, o termo Derivativo pode contribuir para que o sistema atinja o estado estacionário sem que o erro seja completamente anulado (seja com PV abaixo do setpoint, ou mesmo acima do setpoint), ressaltando assim o papel do componente Integrativo.

\section{Algoritmo inicial}

Tendo como base os conceitos apresentados nas seções anteriores, principalmente a Equação (2.1), é possível construir o Algoritmo 1 do sistema de controle PID. É preciso ressaltar que a abordagem apresentada omite qualquer tipo de controle de tempo, simplesmente por pressupor que as medições da variável de processo PV e as atualizações da saída são realizadas em intervalos discretos e regulares, caracterizando assim um controlador discreto com retroação [Cor00].

Acompanhando o algoritmo é possível entender mais dois fatores atrativos desse tipo de controlador: o PID consegue ter robustez e flexibilidade quanto aos cenários de aplicação ao mesmo tempo em que (i) possui implementação simples e (ii) demanda baixo poder computacional. Pela junção dessas características o PID se mostra um algoritmo de controle muito favorável ao uso em sistemas embarcados e em microcontroladores. 
Apesar de já ser funcional para a maioria das situações, há casos nos quais o Algoritmo 1 apresenta certos comportamentos indesejados. Por isso, essa pode ser entendida como uma versão inicial do controlador. Logo adiante são mostrados mais detalhes sobre os casos em que essa primeira implementação não é satisfatória, bem como uma versão adaptada do algoritmo.

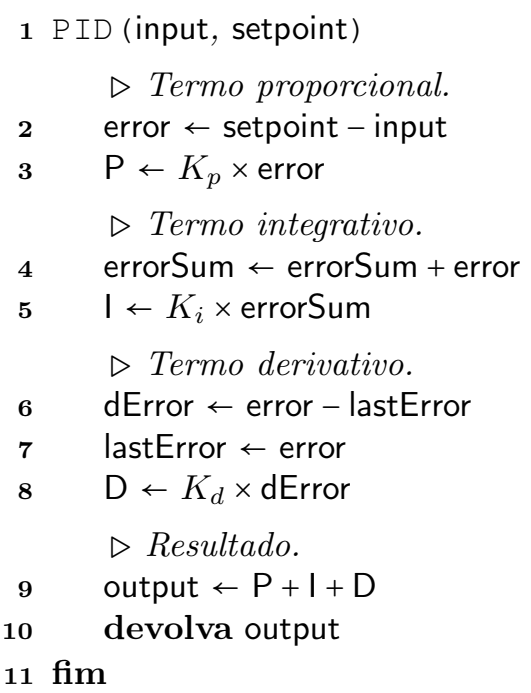

Algoritmo 1: Algoritmo simples de PID assumindo que o intervalo entre as chamadas é constante.

\subsection{Problemas e soluções}

Como dito anteriormente, apesar da formulação apresentada pelo Algoritmo 1 ser funcional, ela está sujeita a produzir algumas anomalias na saída. Em muitos contextos, tais anomalias causam pouca ou nenhuma alteração indesejada no processo externo ao controlador, passando completamente desapercebidas. Entretanto, quando a saída é usada em controles delicados ou sensíveis, como o volante, essas anormalidade podem se tornar muito problemáticas. Para exemplificar, basta imaginar o que aconteceria se, durante uma curva, a saída do PID produzisse um pico e o piloto girasse abruptamente o volante provavelmente um acidente seria inevitável.

A seguir veremos duas questões que proporcionam a ocorrência de picos ou atrasos na resposta do PID e também como resolvê-las. Essas correções foram adicionadas ao algoritmo inicial, resultando na versão descrita pelo Algoritmo 2, a qual foi usada na implementação do piloto virtual.

\section{Derivative kick}

Considerando que um dos objetivos do PID é diminuir a diferença entre os valores da variável PV e o patamar de referência SP, é natural considerar que durante o uso do controlador SP sofrerá mudanças. Porém quando o valor de SP muda significativamente de uma só vez, o erro é alterado instantaneamente e a derivada dessa alteração acaba sendo bem alta - a rigor, seria infinita uma vez que $d t$ tenderia a zero.

Entretanto, em implementações digitais do PID, os intervalos de operação são regidos por um relógio (clock) e, em especial nos controladores discretos, são regulares. Portanto $d t$ na prática não fica nulo de fato e, por sua vez, o Derivativo nunca chega a ser computado como infinito. Embora esse caso extremo nunca aconteça, ainda assim o Derivativo assume um valor desproporcionalmente alto no instante em que há o "salto" de SP. Esse pico de resposta é chamado de derivative kick (ou coice derivativo, em tradução livre) e está ilustrado na Figura 2.3a. É possível contornar esse problema atacando apenas o instante quando setpoint é alterado. 

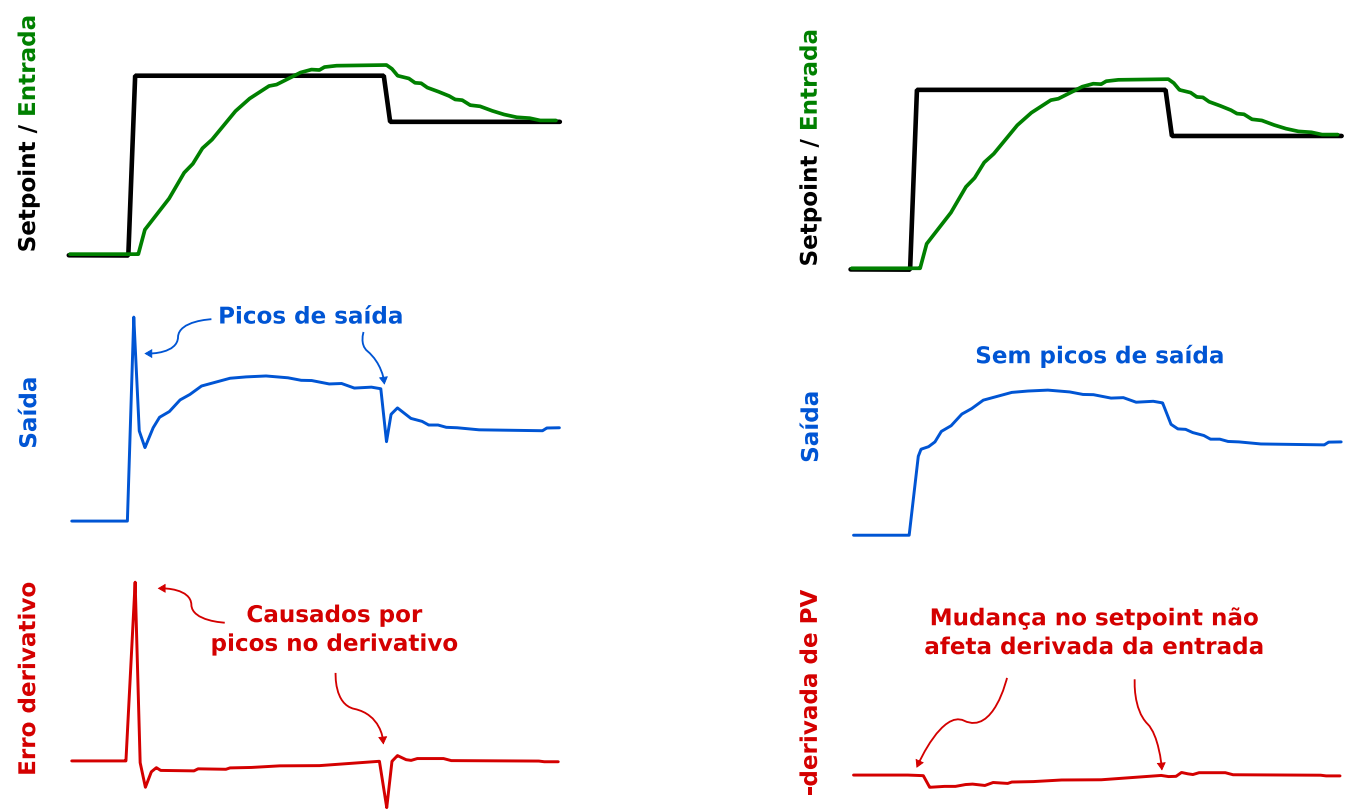

(a) Termo derivativo considerando SP.

(b) Termo derivativo calculado por PV.

Figura 2.3: Exemplificação de derivative kick e sua solução.

Sabemos que:

Portanto, quando SP é constante, temos:

$$
\frac{d \mathrm{Erro}}{d t}=\frac{d \mathrm{SP}}{d t}-\frac{d \mathrm{PV}}{d t}
$$

$$
\frac{d \text { Erro }}{d t}=-\frac{d \mathrm{PV}}{d t}
$$

Pela Equação (2.2), vemos que enquanto o setpoint permanecer inalterado podemos usar o negativo da derivada de PV no componente Derivativo sem alterar o comportamento do controlador. Por sua vez, nos instantes nos quais SP varia, o Derivativo não é afetado e a saída não mais apresenta picos. Esse cenário está ilustrado na Figura 2.3b. Portanto, para eliminar os picos indesejados basta calcular o termo Derivativo em função da variável de processo PV, não em função do erro. Essa adaptação se reflete nas operações das linhas 6 a 9 do Algoritmo 2.

\section{Saturação do componente integrativo (Integrator windup)}

A saída do PID normalmente é ligada a algum dispositivo capaz de realizar alterações no processo e consequentemente influenciar o valor de PV. Esses dispositivos de atuação praticamente sempre possuem algum tipo de limite ou restrição de suas capacidades. Por exemplo, cada motor tem um limite máximo de quanta força consegue gerar.

A formulação de PID vista no Algoritmo 1 ignora completamente quaisquer limites para a saída. Portanto, num cenário hipotético, onde a saída controlasse diretamente a porcentagem da potência que um motor deveria usar, eventualmente o PID poderia devolver um valor maior que 100\%. Mas certamente o motor não conseguiria realizar um trabalho usando mais que $100 \%$ de sua potência. Nessa situação, há uma disparidade entre o valor que o PID "pensa" que está sendo usado no atuador e o valor que de fato está sendo aplicado, afinal o atuador permanecerá no seu limite independentemente da saída do controlador (como visto na Figura 2.4a). 

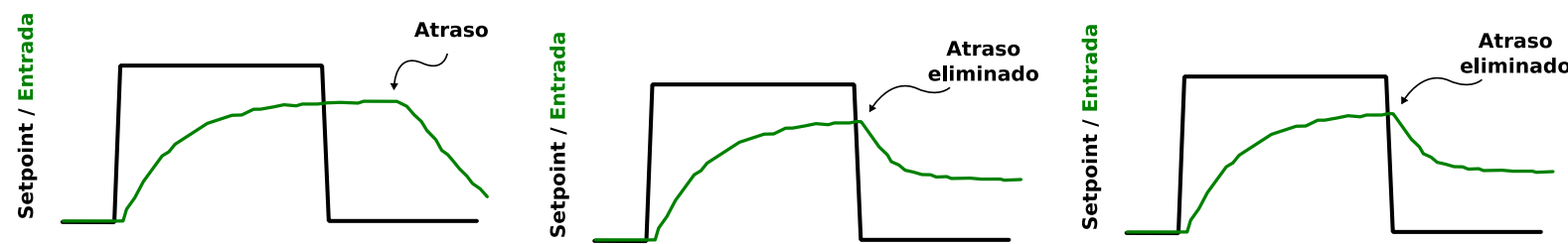

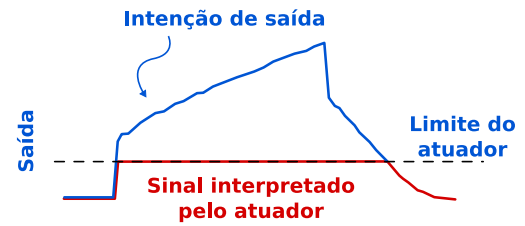

(a) Saída do PID maior que o limite máximo do atuador.

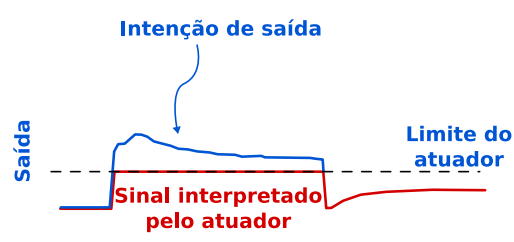

(b) Termo integrativo limitado.

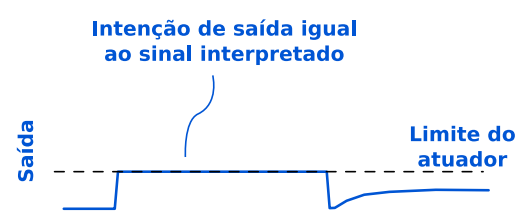

(c) Integrativo e saída do PID limitados.

Figura 2.4: Problema de integrator windup e as duas etapas de solução.

No caso de controladores com o componente Integrativo, o erro acumulado continuará crescendo independentemente da saída devolvida ao processo. Com isso, esse termo pode eventualmente tornandose exageradamente grande. Essa situação implica que o processo não se estabilizará enquanto o erro não permanecer por um longo período com sinal oposto ao acumulado.

A solução desse problema é feita em duas etapas simples. A primeira consiste em apenas repassar para o PID o intervalo dos valores máximo e mínimo do atuador. Com essa informação, quando o termo integrativo atinge esses limites de saturação, interrompe-se a soma (ou subtração) do acumulador mantendo o valor do termo dentro do intervalo operacional do atuador. Como consequência disso, assim que o erro assume um valor com sinal oposto ao acumulado, o acumulador passa a diminuir e como resultado elimina-se o atraso na reação do controlador.

Acompanhando a Figura 2.4b, vemos que embora a técnica anterior já faça o PID responder prontamente à alterações em SP, a saída ainda continua apresentando valores maiores que o limite do atuador. Isso se deve ao fato de que, embora o Integrativo esteja controlado, o Proporcional e o Derivativo ainda podem contribuir no resultado final. Portanto a segunda etapa da solução consiste em simplesmente filtrar a saída de modo a mantê-la dentro das restrições, resultando no comportamento ilustrado pela Figura 2.4c.

Uma observação a ser feita é que, se apenas aplicássemos a segunda etapa da solução, a saída do PID se manteria controlada de fato, porém o termo Integrativo continuaria crescendo indiscriminadamente. Dessa forma, se manteriam o atraso na reação e a exigência de um longo período com erro oposto ao acumulado para o controlador atingir o estado estacionário.

\section{Algoritmo corrigido}

Incorporando as melhorias apresentadas à implementação inicial do PID, chegamos ao Algoritmo 2. Essa foi a versão integrada ao piloto virtual. Porém não basta ter em mãos o algoritmo do controlador, ainda é preciso definir as constantes $K_{p}, K_{i}, K_{d}$ a fim de que o PID se comporte como o desejado para cada contexto. Mostramos na próxima seção como determinar os valores para cada constante. 


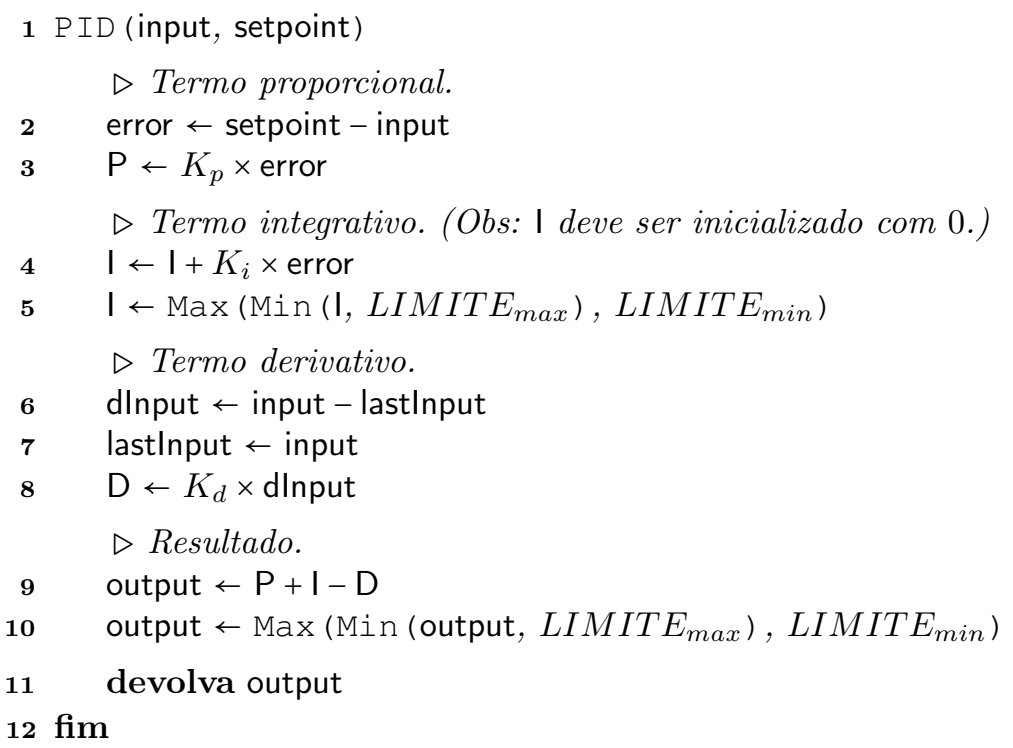

Algoritmo 2: Algoritmo final de PID com as modificações citadas.

\subsection{Processo de ajuste - Tuning}

Pela Equação (2.1) vemos que a saída do PID é fundamentalmente dependente das constantes $K_{p}, K_{i}$ e $K_{d}$. Portanto, definir esses valores basicamente molda o comportamento do controlador perante às alterações na variável de processo e no setpoint. O procedimento feito para determinar o ganho em cada um dos termos é chamado de tuning (ou processo de ajuste).

$\mathrm{Na}$ literatura da área de controle, encontra-se métodos formais para se fazer o ajuste do PID de modo a atender rigorosamente às especificações de cada caso de uso. Por exemplo, o método de Ziegler-Nichols [ZN42] se apoia na análise dos parâmetros de resposta do sistema para testes específicos, permitindo assim calcular as constantes de modo que a resposta do controlador sempre gere efeitos dentro de limites determinados como aceitáveis.

Cada processo de ajuste demanda algum tipo específico de informação sobre a dinâmica do processo onde deseja-se aplicar o PID. Dessa forma, a escolha do método depende de quão prático é conseguir as informações necessárias através de ensaios com o sistema e do quão rigorosamente é preciso seguir as exigências sobre a saída.

Embora o rigor e a exatidão desse tipo de método sejam grandes pontos positivos, em contrapartida é necessário preparar ensaios e medições para conseguir aplicá-los. Muitas vezes essas preparações demandam tão trabalho e os requerimentos de resposta não são muito rígidos. Nesses casos, métodos de ajuste complexos se mostram pouco práticos.

Na Tabela 2.1 vemos de forma simplificada quais são as implicações de se aumentar cada uma das constantes de ganho. Baseando-se apenas nesse conhecimento, é possível fazer ciclos iterativos alternando entre alterar os parâmetros e verificar o comportamento resultante do sistema. Apesar desse processo de ajuste manual consistir basicamente em tentativa e erro, ele é frequentemente usado em cenários simplificados, pois é possível rapidamente chegar a configurações que produzam resultados satisfatórios.

Para os controladores PID presentes no piloto virtual, ajustamos manualmente as constantes. A seguir mostraremos um procedimento para realizar o processo de ajuste de forma eficiente. 
Tabela 2.1: Efeitos ao se alterar as constantes de ganho do PID [LAC06].

\begin{tabular}{|c|c|c|c|c|c|}
\hline & $\begin{array}{l}\text { Tempo de } \\
\text { ascensão }\end{array}$ & $\begin{array}{l}\text { Sobrepassagem } \\
\text { (overshoot) }\end{array}$ & $\begin{array}{c}\text { Tempo de } \\
\text { estabilização }\end{array}$ & $\begin{array}{c}\text { Erro no } \\
\text { estado } \\
\text { estacionário }\end{array}$ & Estabilidade \\
\hline Incrementar $K_{p}$ & Diminui & Aumenta & $\begin{array}{l}\text { Aumenta } \\
\text { pouco }\end{array}$ & Diminui & Piora \\
\hline Incrementar $K_{i}$ & Diminui pouco & Aumenta & Aumenta & Diminui muito & Piora \\
\hline Incrementar $K_{d}$ & Diminui pouco & Diminui & Diminui & Pouco muda & Melhora \\
\hline
\end{tabular}

\section{Método de ajuste manual}

Com o auxílio da Tabela 2.1, cada alteração nas constantes de ganho pode ser feita de forma mais consciente do que por meros palpites. Além disso, basta seguir uma metodologia simples de como fazer essas alterações para ajudar a minimizar o número de testes necessários até que o controlador produza o comportamento desejado. Primeiramente deve-se deixar todas as constantes com valor zero. Depois, os passos a serem seguidos em cada iteração de ajuste são:

1. Aumentar $K_{p}$ aos poucos até que a saída do controlador se torne oscilatória (deve-se ter cuidado para não tornar o sistema instável ao se aumentar demasiadamente o valor de $K_{p}$ );

2. Aumentar $K_{d}$ até reduzir a oscilação (ou até não haver mais overshoot, eliminando completamente a oscilação);

3. Aumentar $K_{i}$ até que o erro no estado estacionário seja anulado tão rápido quanto se desejar.

Uma vez terminado um ciclo de ajuste, é perfeitamente válido reajustar os valores das constantes, independentemente de ordem. Afinal, cada processo tem suas peculiaridades e muitas vezes será preciso fazer alterações sutis a fim encontrar o melhor ajuste fino. 


\section{Capítulo 3}

\section{Modelagem da pista de corrida}

Apesar de nosso carro virtual estar munido com uma ampla gama de sensores, nenhum deles fornece de imediato dados sobre a pista de corrida como um todo. Embora essa informação não esteja disponível a princípio, ela é de grande valia caso se deseje elaborar um controlador que não seja simplesmente reativo aos sensores. Construir um modelo da pista possibilita a identificação de trechos com características similares, o que pode ser aproveitado no processo de aprendizagem, além de permitir eventualmente a exploração de técnicas de planejamento.

Neste capítulo, apresentamos um método de como construir uma representação da pista a partir da consulta a apenas um pequeno subconjunto dos sensores disponíveis no carro virtual. Além disso, propomos uma técnica para segmentar esse modelo da pista em trechos e classificá-los de acordo com suas particularidades. Esses tópicos compõem um trabalho apresentado no simpósio SBGAMES 2014 [DdS14], porém o presente capítulo contém refinamentos na abordagem do tema, produzindo melhores resultados.

\subsection{Construção de um modelo de pista}

Durante a primeira volta, nosso piloto virtual coleta dados da pista para montar um modelo do circuito, isto é, uma representação do formato da pista como um todo. Esse modelo é usado posteriormente nas etapas de segmentação e classificação a fim de facilitar o processo de aprendizagem. A seguir, descrevemos como nosso agente usa seus sensores para construir tal modelo.

\subsubsection{Piloto coletor de dados}

De forma semelhante a um robô móvel em um ambiente desconhecido a ser explorado, nosso piloto virtual percorre a primeira volta em cada circuito coletando dados por meio de seus sensores, listados anteriormente na Tabela 1.1. Esses dados são processados de modo a se produzir um modelo do formato da pista. Assim, durante a primeira volta, o agente realiza praticamente apenas três atividades:

- Manter o carro centralizado sobre o eixo da pista;

- Manter a velocidade baixa e constante (em torno de $40 \mathrm{~km} / \mathrm{h}$ );

- Coletar e armazenar os dados dos sensores a cada 5 metros percorridos.

Para manter o carro ao centro da pista, o piloto virtual pode se basear nas leituras dos sensores angle e trackPos. Retomando a Figura 1.2a, vemos que o sensor angle mede o ângulo formado entre a direção do carro e o eixo da pista. Entretanto, mesmo que esse ângulo seja nulo, ainda assim o carro pode não 


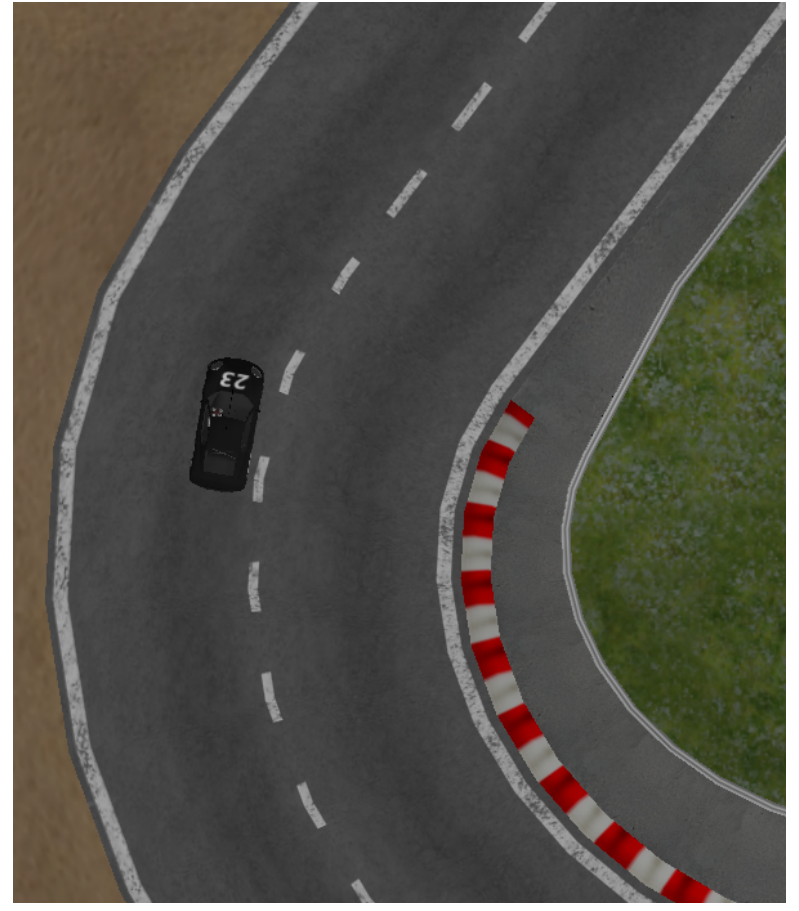

(a) Controle do volante com base na Equação (3.1).

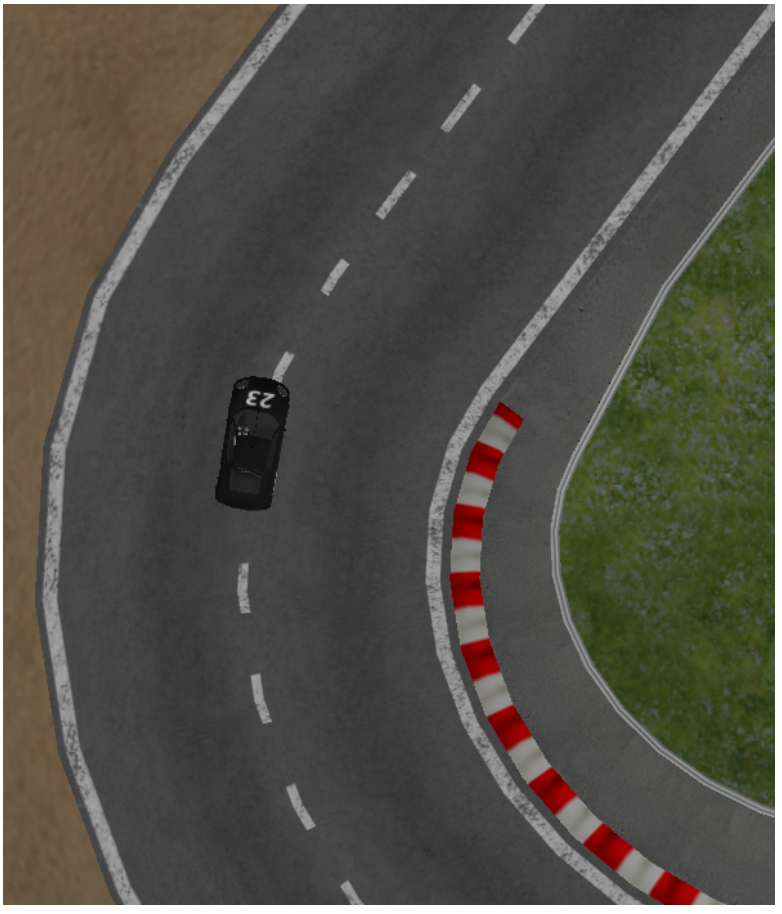

(b) Controle do volante com PID.

Figura 3.1: Diferença de posicionamento ao se passar pelo hairpin da pista street-1.

estar posicionado como o desejado. Um exemplo dessa situação está ilustrado na Figura 1.2b, onde vemos que o carro está alinhado, porém afastado do trajeto central. Na mesma imagem, também vemos que a distância desse afastamento é medida pelo sensor trackPos.

Quando o carro está na posição ideal, as medições de ambos sensores estarão em zero. Portanto, o valor steer de quanto se precisa esterçar o volante deve ser determinado de modo a se contrapor a medições não nulas. Uma forma simples de calcular steer é através da Equação (3.1), onde steerLock é uma constante do carro a qual indica o ângulo máximo de esterção do volante.

$$
\text { steer }=\frac{\text { angle }- \text { trackPos } \times \text { steer Lock }}{\text { steerLock }}
$$

Segundo a Tabela 1.2, o atuador do volante só pode receber valores de entrada no intervalo $[-1,1]$. Embora o termo trackPos seja limitado pelo mesmo intervalo, angle, por sua vez, pode assumir valores com módulo maior que steerLock. Por conta disso, depois do cálculo de steer, é preciso ter o cuidado de saturar o valor a ser repassado para o atuador.

Embora a Equação (3.1) seja simples e funcional, ela não leva em conta o fato de carro não ser capaz de se reposicionar instantaneamente de acordo com o pretendido. Como resultado, é possível verificar durante as simulações que o carro não se mantém satisfatoriamente ao centro da pista. Um flagrante desse efeito pode ser visto na Figura 3.1a, a qual mostra o piloto virtual conduzindo o carro por um hairpin (curva do tipo grampo) da pista street1. Como essa pista apresenta uma faixa tracejada ao centro, nota-se claramente o quanto o posicionamento do carro fica defasado em relação ao ideal.

Esse comportamento é indesejado, pois a análise dos dados para a criação do modelo de cada pista (processo explicado na próxima seção) é feita assumindo que as medições foram realizadas a partir de pontos perfeitamente centralizados. Por essa razão, faz-se necessário um método de controle mais robusto para gerenciar o atuador do volante de modo a manter o carro alinhado ao centro da pista o mais precisamente possível. 
Dada essa necessidade, os comandos do volante de nosso agente são regidos por um controlador PID que recebe o valor do sensor trackPos e tenta posicionar o volante de modo a minimizar essa medida. Isso produz um resultado nitidamente melhor em comparação ao uso da Equação (3.1), como pode-se verificar na Figura 3.1b.

Quanto ao controle da velocidade, ingenuamente, pode-se pensar que manter o acelerador com pressão constante seja suficiente para também manter a velocidade em um mesmo patamar. Entretanto, o simples ato de contornar as curvas já faz o carro ir mais devagar caso não haja uma compensação no acelerador. Além disso, as pistas possuem aclives e declives, os quais também influenciam diretamente a velocidade do carro. Em virtude disso, usamos outro controlador PID para gerenciar o acelerador e o freio durante a volta de leitura de dados. Por esse método, o carro é mantido com velocidade praticamente constante, variando entre 39 e $40 \mathrm{~km} / \mathrm{h}$.

Já a gravação dos dados em intervalos regulares é a atividade mais simples. O monitoramento da distância é feito pelo acompanhamento das leituras do sensor distFromStart, o qual informa o quanto se percorreu na pista a partir da linha de largada. Assim que se inicia a primeira volta, o piloto virtual registra os dados dos sensores disponíveis. A partir daí, verifica-se a cada instante a diferença entre distFromStart e o ponto do último registro. Quando a diferença é maior ou igual a 5 metros, faz-se então uma nova gravação. Ao término da volta, os dados armazenados são usados nas etapas seguintes de análise, além de serem exportados em arquivos para eventual verificação posterior.

\subsubsection{Curvaturas}

Coletados todos os dados referentes a uma volta completa pela pista, podemos usá-los para montar uma representação do percurso. Cada elemento desses dados em questão é o conjunto dos valores dos sensores no momento da medição, que ocorre aproximadamente a cada 5 metros. Portanto, tomando-os aos pares, é possível extrair informações para descrever pequenas fatias da pista, as quais chamaremos de segmentos. Assim, temos que a diferença de valores em distFromStart revela o comprimento exato do segmento, mas também é preciso descobrir se esse segmento faz parte de uma reta ou se o carro mudou de direção entre as duas medições em foco.

Para conseguir fazer essa distinção, pode-se consultar steer e verificar o quanto o volante estava esterçado nas leituras inicial e final. Se ao menos um dos valores não for nulo, então o carro virou no intervalo entre as medições. Nesse caso, é importante descobrir o quanto o carro virou, ou seja, a curvatura do segmento. Essa informação não está contida diretamente em nenhum dos sensores disponíveis e para consegui-la é preciso realizar uma série de operações.

Uma simplificação que adotamos foi interpretar o carro seguindo o modelo da bicicleta [Gil92] ilustrado na Figura 3.2. Na ilustração, WB (wheelbase) é a distância entre os eixos das rodas, $\delta$ é o ângulo em que o volante está esterçado e $R$ é o raio da curva, o qual queremos calcular. Por esse modelo, quando $\delta$ assume valores pequenos, o raio da curva pode ser aproximado pela Equação (3.2).

$$
R=\frac{W B}{\operatorname{tg}(\delta)} \simeq \frac{W B}{\operatorname{sen}(\delta)}
$$

Tendo o raio da curva, pela Equação (3.3) encontramos o ângulo $\alpha$ do arco percorrido pelo carro ao andar por esse segmento. O termo $r$ é a constante do raio das rodas dianteiras, $\omega$ é o valor do sensor wheelSpin Vel de velocidade angular da roda externa à curva, $\Delta_{t}$ é o intervalo entre as medições do início e fim do segmento e $T$ é a constante $T R A C K$ representando a distância entre as rodas do mesmo eixo.

$$
\alpha=\frac{r \times \omega \times \Delta_{t}}{R+\frac{T}{2}}
$$




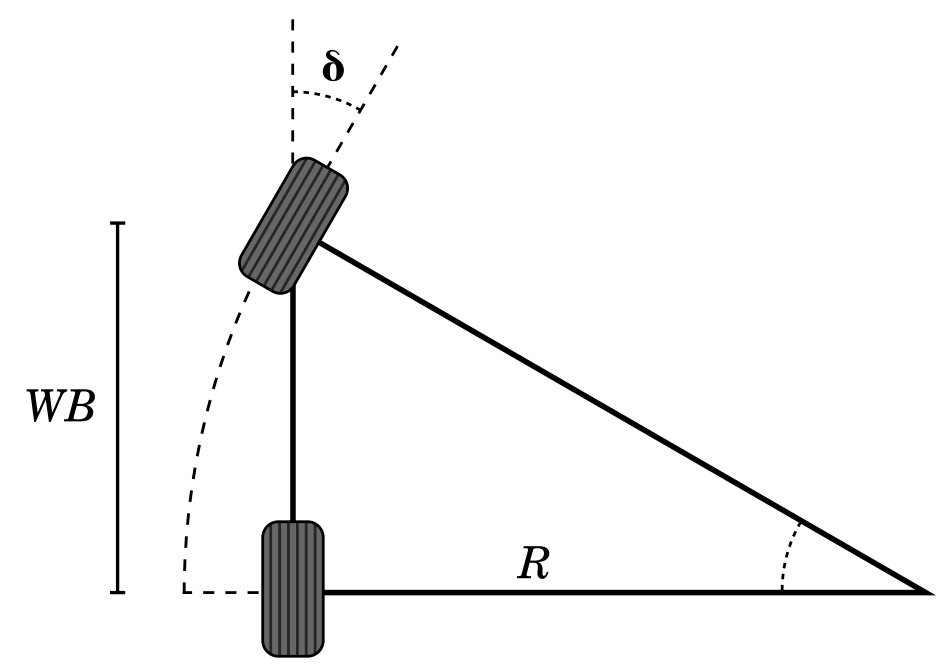

Figura 3.2: Modelo de bicicleta usado para simplificar o carro.

Repetindo esse processo para todos os pares de dados adjacentes, cada fatia da pista passa a ser descrita por um segmento composto por: ( $i$ ) um comprimento, próximo a 5 metros; e (ii)uma curvatura, referente ao ângulo coberto pelo arco que o carro fez. Contudo, ao longo das etapas descritas há arredondamentos e imprecisões tanto em decorrência do intervalo entre medições, quanto pelo posicionamento não ideal do carro no instante de cada coleta. Por esse motivo, a concatenação desses segmentos não forma um circuito fechado. Esse efeito já foi apresentado em outros trabalhos [MGS10], porém não caracteriza um problema, pois o modelo da pista não é usado pelo controlador para determinar seu posicionamento.

Apesar disso, considerando pistas que não apresentem cruzamentos, sabemos que a soma de todos os ângulos do circuito deveria resultar em $2 \pi$. Com essa suposição, podemos calcular a proporção entre $2 \pi$ e a soma dos ângulos definindo assim um fator de correção. Multiplicando todas as curvaturas por esse fator, conseguimos um modelo cujas extremidades tenham a mesma direção - embora não necessariamente estejam alinhadas, como visto na Figura 3.3. Nas mesmas ilustrações estão representadas as divisões dos segmentos.

\subsection{Segmentação}

Como vimos na seção anterior, o modelo formado pelos segmentos de 5 metros é capaz de remontar as pistas de modo aceitável. Entretanto a informação contida em cada um desses segmentos é pouco expressiva e não há vantagem alguma em lidar com uma representação tão fragmentada. Ao observar o desenho de um circuito, é fácil para uma pessoa distinguir onde começa e termina cada reta, quão fechada é cada curva e quando um trecho é longo ou curto. Para um piloto, esse entendimento é muito importante, pois a informação do tipo de trecho em que se está e do(s) trecho(s) seguinte(s) tem influência direta na decisão de qual ação executar. Dessa forma, aglutinar os segmentos em trechos relativamente uniformes traz as seguintes vantagens:

- Simplifica-se o modelo. Por exemplo, a pista g-track-1 vista na Figura 3.3b pode ser representada por apenas 12 trechos em vez de 400 segmentos;

- A descrição por trechos é mais eficiente, transmitindo informações de forma concisa e significativa. Por exemplo, o fato dos primeiros 70 segmentos de g-track-1 formarem uma reta de 350 metros é uma informação simples e valiosa;

- Facilita-se a leitura, compreensão e interpretação dos dados. 


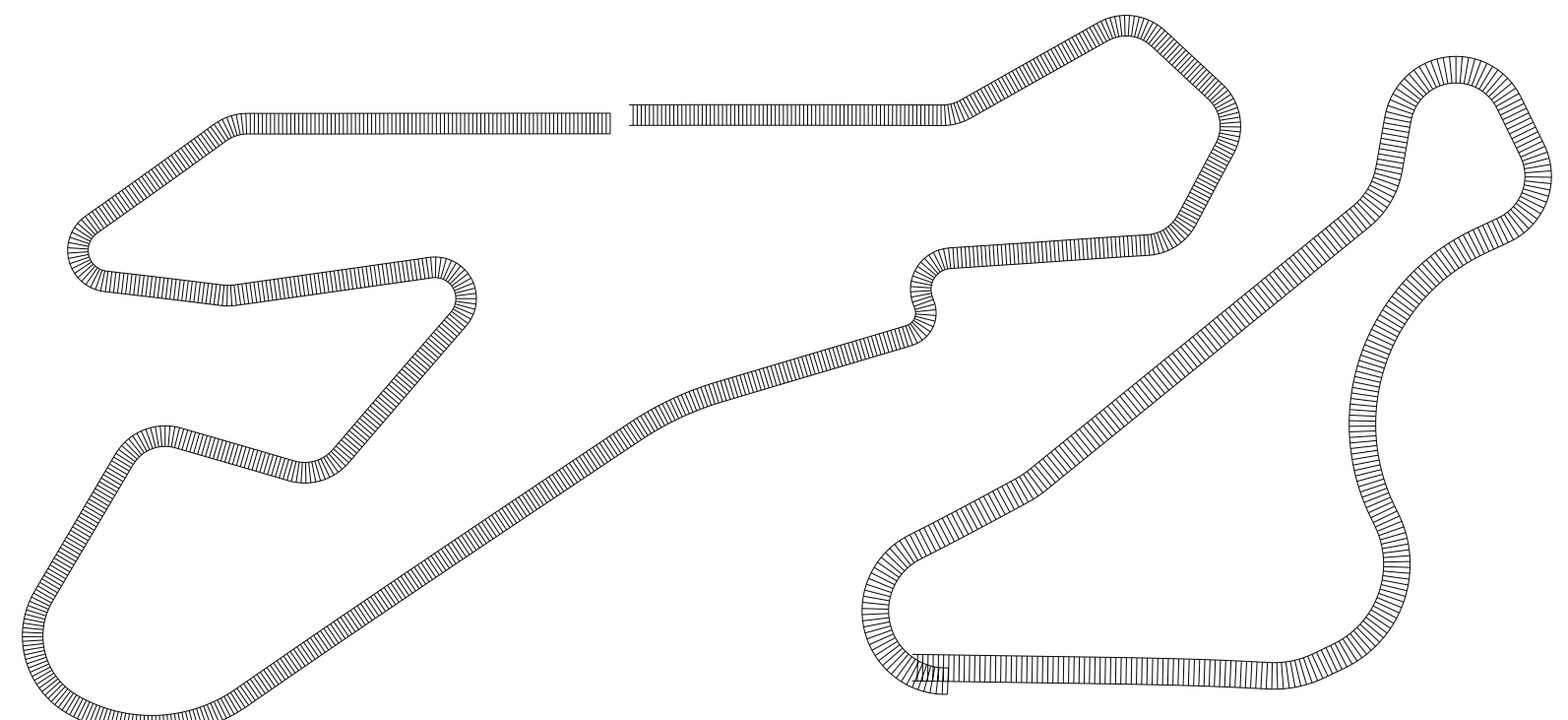

(a) Pista e-track-3.

(b) Pista g-track-1.

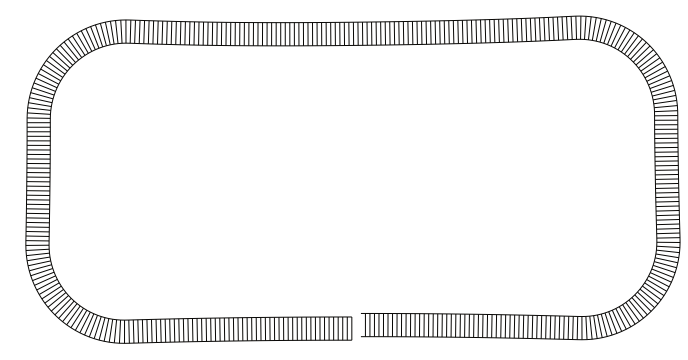

(c) Pista a-speedway.

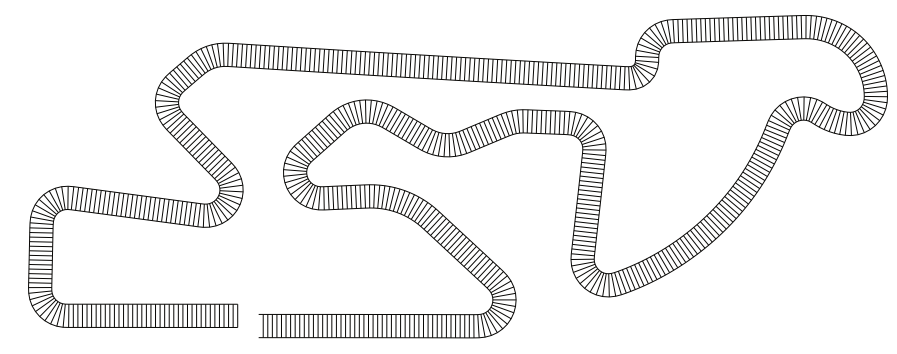

(d) Pista e-track-2.

Figura 3.3: Modelos de pista com divisórias dos segmentos.

Para realizar a segmentação, isto é, determinar os pontos nos quais um trecho termina e outro começa, propomos um método que avalia as variações das curvaturas dos segmentos como oscilações de um sinal. Na Figura 3.4 estão representados os ângulos de curvatura dos segmentos das pistas g-track-1 e a-speedway, cujos modelos já foram mostrados na Figuras 3.3b e 3.3c respectivamente. Nos gráficos, o eixo das abscissas indica a distância do segmento até a linha de largada e o eixo das ordenadas se refere aos ângulos de curvatura. Vale notar que ângulos negativos indicam curvas para a direita e curvas para a esquerda tem ângulos positivos. Comparando-se com as figuras, é fácil observar que os trechos de curva nas pistas tem paralelo com patamares nos gráficos. Porém, também é possível perceber que há regiões aparentemente homogêneas na pista que possuem oscilações consideráveis no sinal.

Nosso objetivo com o segmentador é filtrar o sinal original de modo a encontrar os patamares que representam trechos homogêneos na pista mesmo com a existência de oscilações. O método que desenvolvemos para tratar esses sinais é descrito pelo Algoritmo 3, o qual recebe os vetores distâncias e ângulos de tamanho $n$ (que representam o sinal da pista) e devolve duas novas listas com as distâncias e ângulos representando o sinal contendo apenas os pontos referentes aos patamares encontrados. Dessa forma, tomando dois pontos consecutivos desse novo sinal, ou eles estão alinhados (indicando um patamar) ou há uma diferença significativa de ângulo entre eles (indicando um "salto"). 

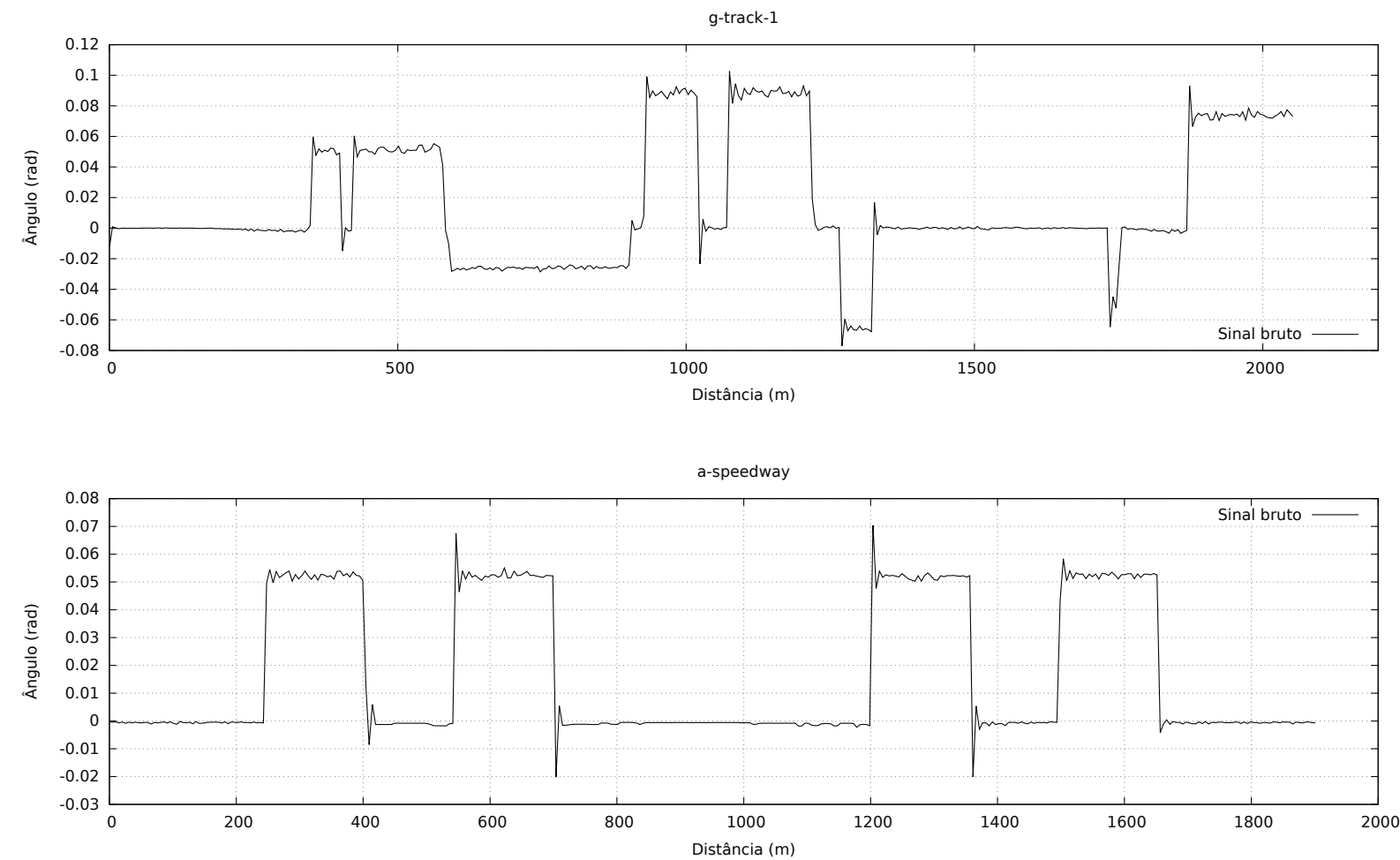

Figura 3.4: Representação dos ângulos de curvatura das pistas g-track-1 e a-speedway representados como sinais ao longo da distância percorrida.

O primeiro passo realizado pelo algoritmo é passar o vetor ângulos por um filtro de média ponderada para atenuar os picos locais do sinal original. Assim, para cada ângulo $a_{i}$, filtroDeMédia () devolve $a_{i}^{\prime}$ de acordo com a regra (3.4).

$$
a_{i}^{\prime}= \begin{cases}\frac{a_{i-1}+2 a_{i}+a_{i+1}}{4} & , i \in[1, n-2] \\ a_{i} & , \text { caso contrário. }\end{cases}
$$

Na sequência, é definido o limiar acima do qual a diferença entre dois ângulos é considerada significativa, um "salto". Esse limiar é proporcional ao desvio padrão das diferenças entre ângulos consecutivos. Para nossos testes, o fator ESCALA usado foi 4 . Em seguida, o ponto inicial $(0,0)$ é adicionado ao novo sinal e inicia-se a iteração sobre os pontos do sinal.

A função éSalto ( ) identifica se: ou a diferença entre o ângulo atual e o ângulo base é suficientemente grande; ou esses dois ângulos estão em curvas de direções opostas; ou um dos ângulos faz parte de uma reta e o outro de uma curva. Nesses casos, éSalto() devolve verdade. Quando um salto é encontrado, distlnício e angInício indicam o ponto do início do salto. Já distFim e angFim marcarão o fim do salto e início de um patamar.

A função éPatamar () devolve verdade quando os ângulos imediatamente à frente de $i$ tem valores próximos. Durante a busca ao fim do salto, há a possibilidade de dois ângulos consecutivos terem sinais diferentes, indicando duas curvas para direções opostas em sequência. Quando isso acontece, as distâncias de início e fim do salto são reajustadas para que o salto cruze o eixo das abscissas no ponto onde há a inversão das curvas. Caso o valor absoluto de angInício seja menor que MAX_RETA, o arredondamos para zero, indicando que o patamar encontrado é o início de uma reta. A constante MAX_RETA representa a curvatura máxima que um trecho pode ter e ainda ser considerado uma reta. Em nossos experimentos, seu valor foi definido como 0.008 . 


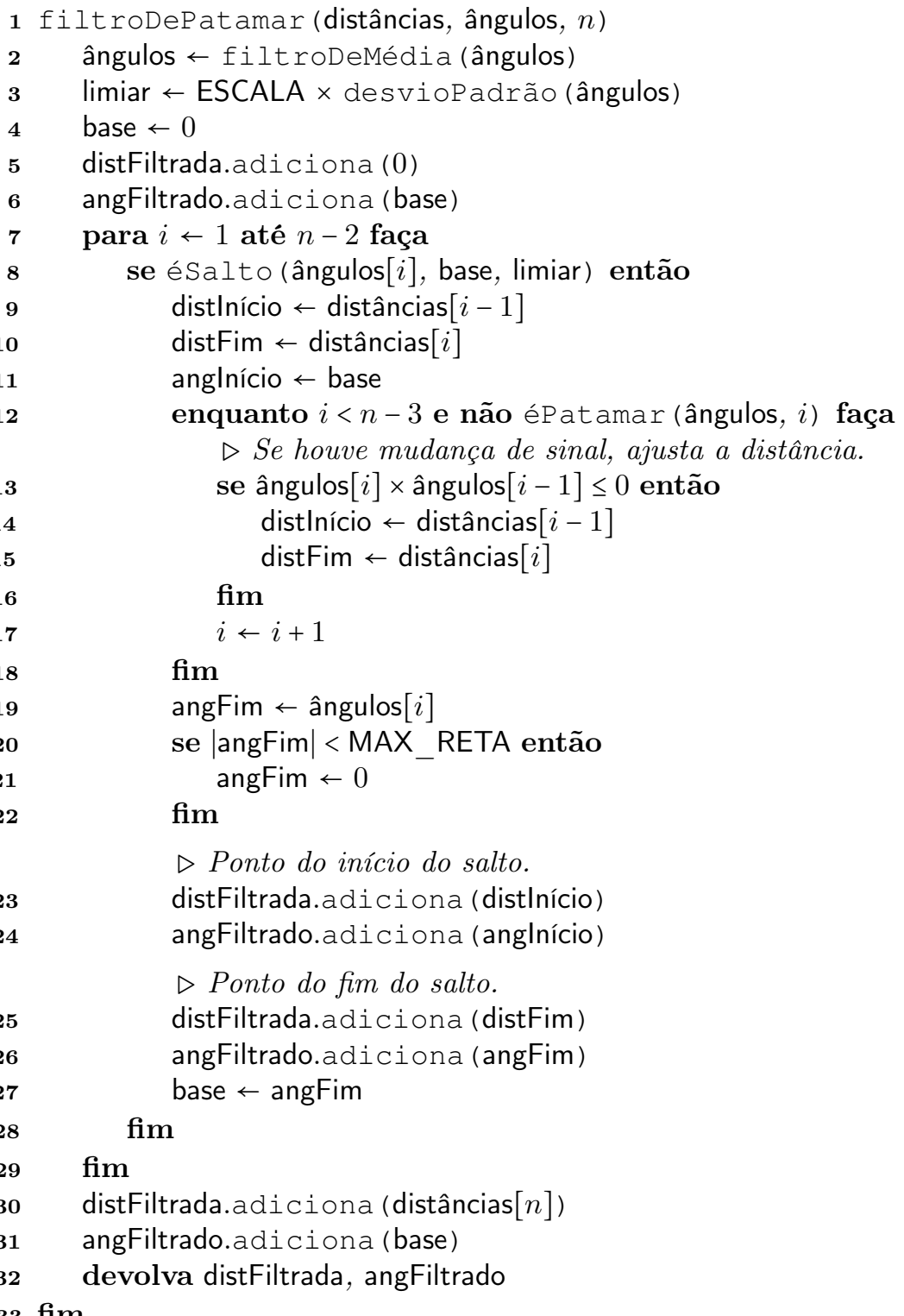

Algoritmo 3: Método de segmentação, onde $n$ é o tamanho dos vetores distâncias e ângulos. 

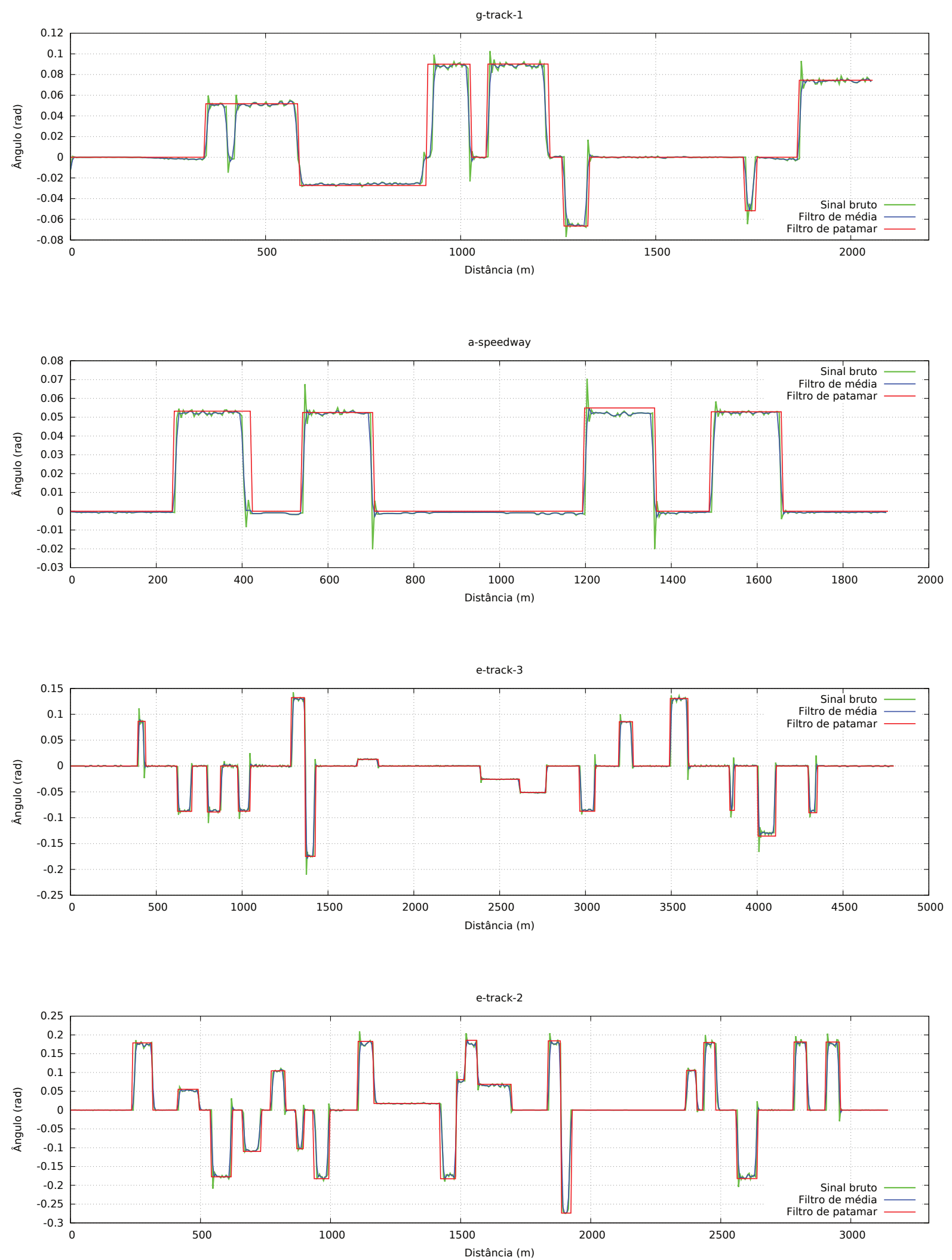

Figura 3.5: Exemplos de comparação entre os sinais de algumas pistas. 


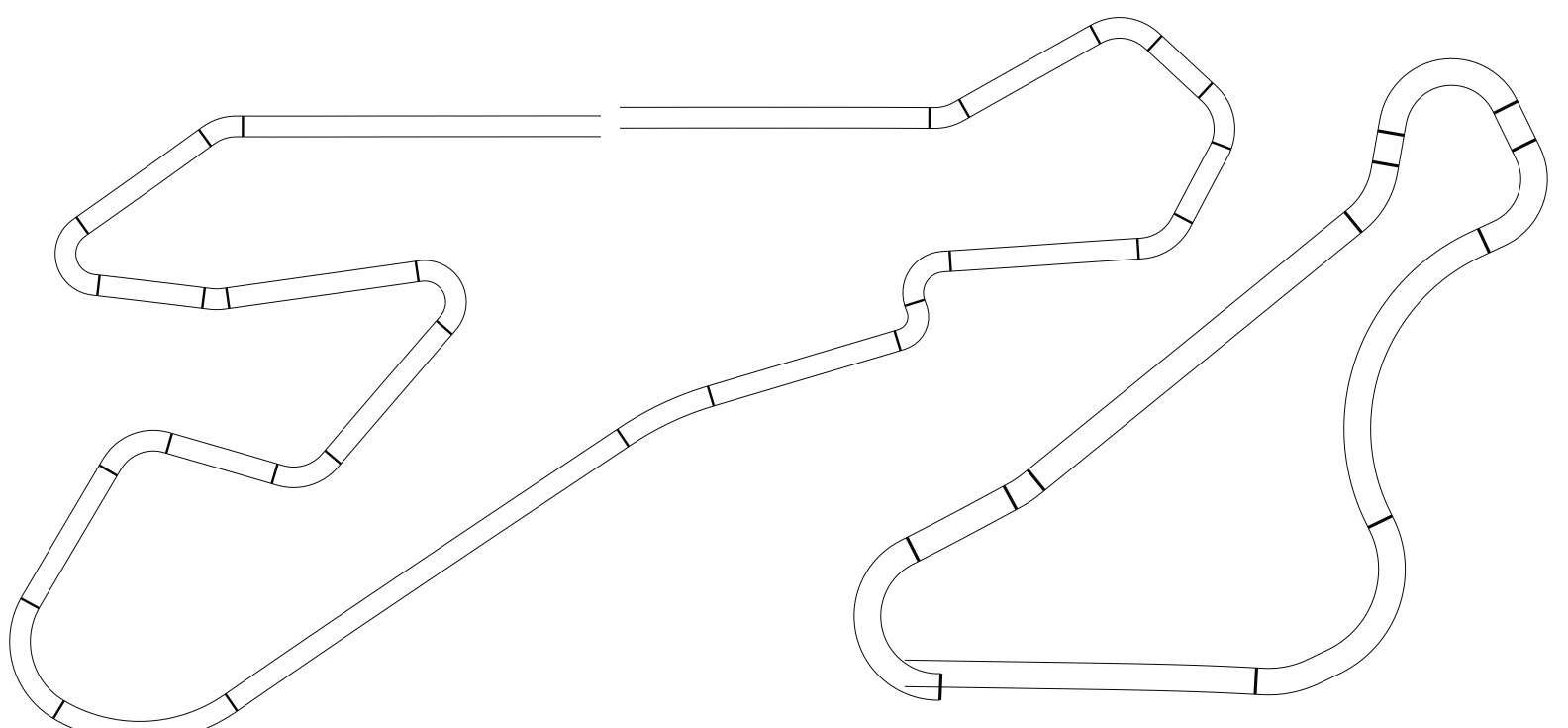

(a) e-track-3

(b) g-track-1

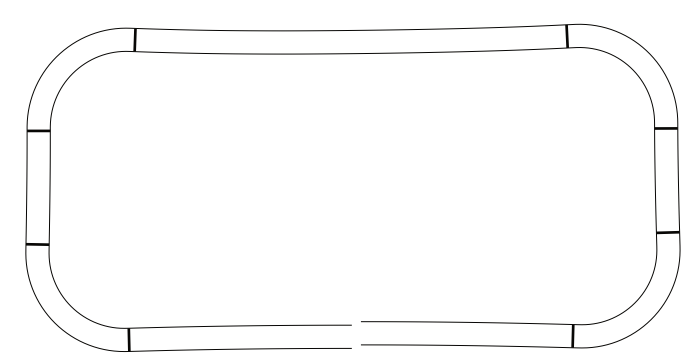

(c) a-speedway

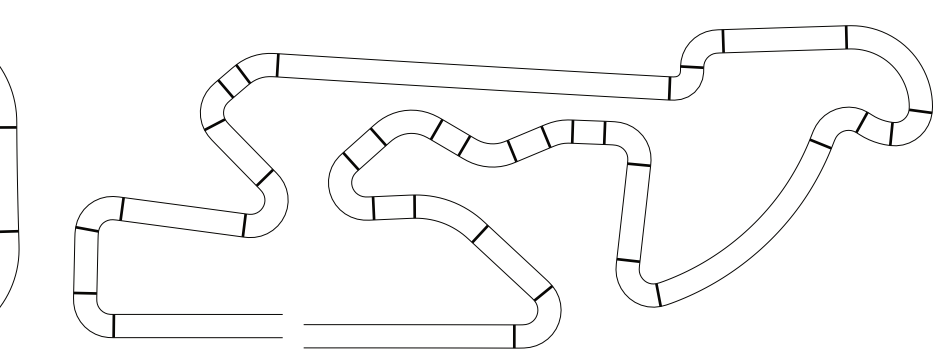

(d) e-track-2

Figura 3.6: Marcação da segmentação das pistas.

Ao término da execução do algoritmo, cada salto precede um patamar, o qual é uma região uniforme da pista. Nos gráficos da Figura 3.5 estão mostradas as comparações entre os sinais originais, com filtro de média ponderada e com filtro de patamar das pistas apresentadas na Figura 3.3. Como resultado, a segmentação dessas pistas está indicada na Figura 3.6, onde as marcações apontam as divisões dos trechos em decorrência dos saltos encontrados.

Vale notar que a pista g-track-1 termina coincidentemente com o fim do último segmento. Por essa razão, há uma marcação no final da última curva, na linha de chegada da Figura 3.6b. Nas demais pistas, não há tal marcação, pois a linha de chegada está posicionada no meio de retas, de modo que o piloto virtual interpreta que as porções antes e depois desse ponto fazem parte do mesmo trecho.

\subsection{Classificação}

Depois da segmentação, cada trecho passa a ser descrito por três atributos: $(i)$ comprimento; (ii) raio; e (iii) ângulo $\alpha$. O comprimento é simplesmente a distância entre o início e o fim do trecho. O raio indica quanto uma curva é fechada, lembrando que é possível considerar as retas como tendo raio infinito. Por fim, $\alpha$ indica o ângulo coberto pelo carro ao percorrer uma curva.

Esses três atributos são suficientes para descrever as características principais dos trechos e, por conta disso, podem ser usados como parâmetros de distinção. Assim, após a etapa de segmentação, o agente analisa cada trecho da pista e o classifica seguindo a árvore de decisão descrita no Algoritmo 4. 
Nosso classificador agrupa trechos em 11 classes distintas. Embora não haja necessidade de rotular as categorias, atribuímos a cada uma delas um nome de modo a facilitar a compreensão da classificação. As retas foram dividias em curta, média e longa. As curvas, da mais fechada para a mais suave, são hairpin (grampo), cotovelo, acentuada, moderada e leve, sendo que as três últimas categorias ainda foram subdivididas em curta e longa.

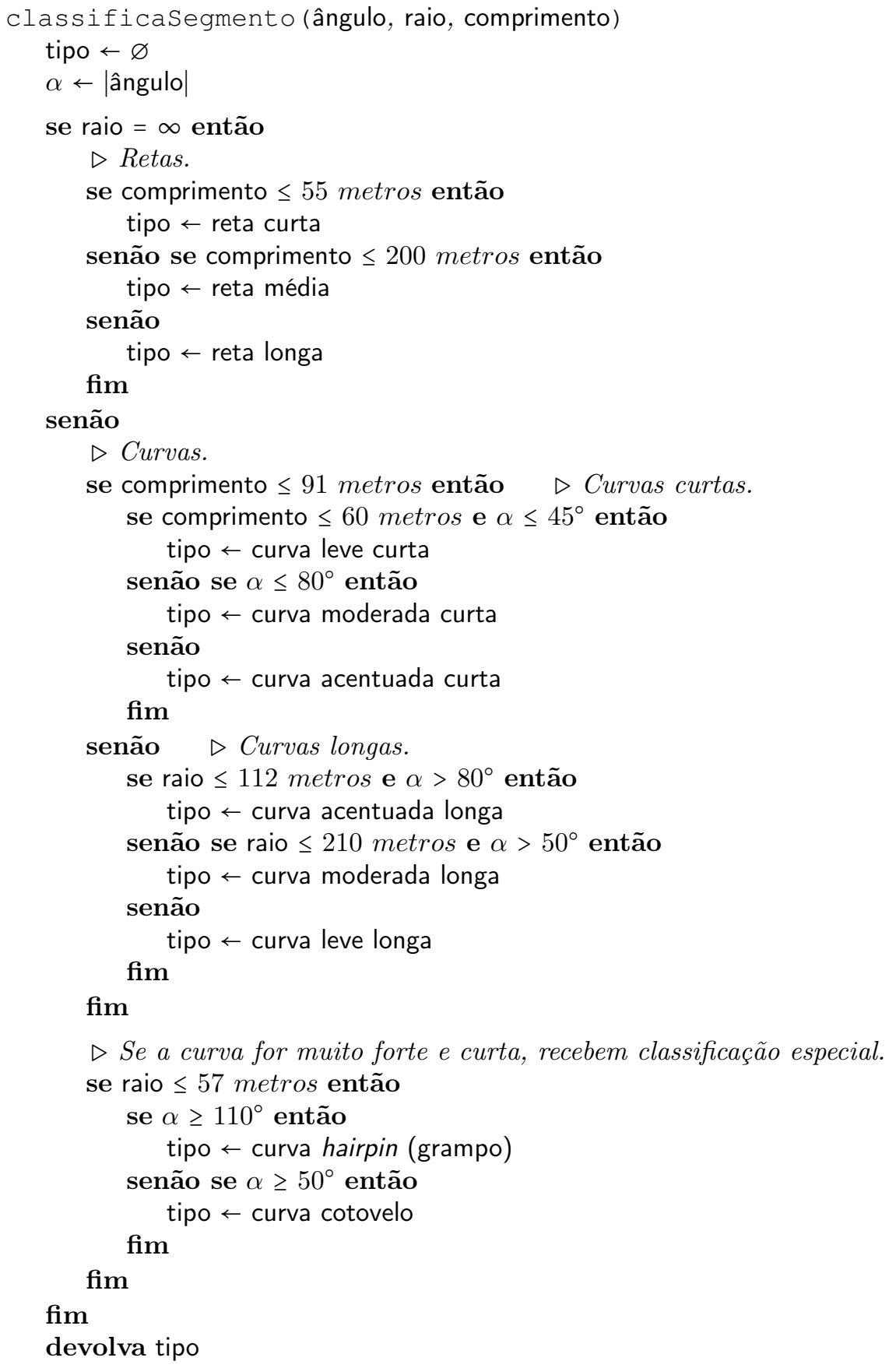

9 fim

Algoritmo 4: Método de classificação. 


\subsection{Resultados}

Usando o TORCS como ambiente de testes, realizamos experimentos nas 16 pistas de asfalto que acompanham o simulador. Os resultados das etapas de segmentação e classificação foram satisfatórios, como exemplificado pela Figura 3.7. Os resultados provenientes das demais pistas estão apresentados no Apêndice A.

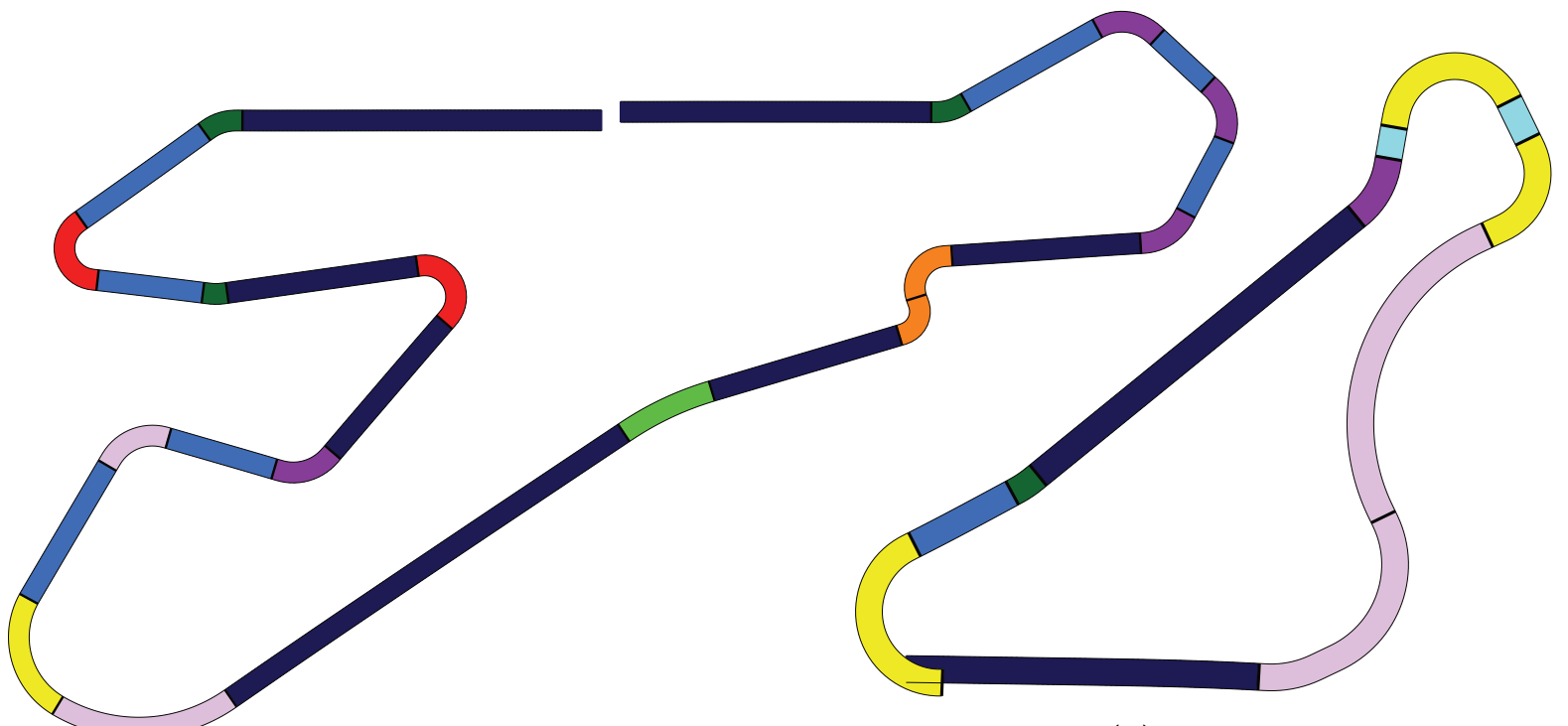

(a) e-track-3

(b) g-track-1.

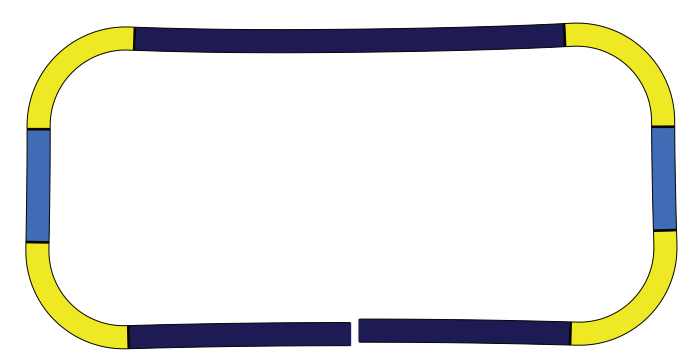

(c) a-speedway.

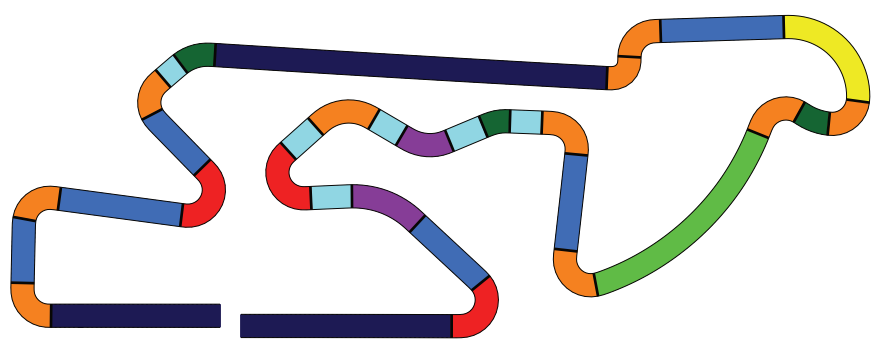

(d) e-track-2.

\section{Reta curta}

Reta média

Reta longa

Curva hairpin (grampo)

Curva cotovelo

Curva acentuada curta

Curva acentuada longa

Curva moderada curta

Curva moderada longa

Curva leve curta

Curva leve longa

Figura 3.7: Exemplos de resultados do processo de coleta de dados, segmentação e classificação. 


\section{Capítulo 4}

\section{Aprendizagem por Reforço}

A maioria dos métodos de aprendizado de máquina se baseia em ensinar ao aprendiz quais ações tomar através de exemplos que relacionam situações a comportamentos "corretos" [SB98]. Em contraste a essa abordagem, pela Aprendizagem por Reforço (Reinforcement Learning, ou apenas RL), o aprendiz descobre quais ações são as mais vantajosas ao experimentá-las enquanto interage com o ambiente.

Dada a enorme quantidade de situações distintas possivelmente presentes em uma corrida, elaborar um bom conjunto de exemplos seria tão dispendioso a ponto de ser inviável. Além disso, definir tais exemplos exige que já se conheça a melhor ação para cada circunstância, mas em nosso caso é essa relação que desejamos descobrir.

Por essa razão, adotamos Aprendizagem por Reforço neste projeto e essa técnica é o tema deste capítulo. Na primeira seção, introduzimos os conceitos fundamentais sobre RL, apresentando as principais terminologias, a relação entre RL e Processos de Decisão de Markov e encerrando com noções de Aprendizagem por Diferença Temporal. Na seção seguinte, abordamos o algoritmo Q-Learning e, por fim, concluímos o capítulo tratando brevemente sobre os Traços de Elegibilidade.

\subsection{Conceitos fundamentais}

Intuitivamente, o processo de aprendizado natural envolve as seguintes etapas: $(i)$ realizar uma ação para interagir com o ambiente; ( $i i)$ avaliar as consequências; ( $i i i)$ melhorar a tomada de decisão; e ( $i v$ ) repetir esses passos até se conseguir um resultado satisfatório. Por exemplo, para aprender a acertar uma flecha no alvo usando um arco, um iniciante geralmente atira a primeira vez, verifica o quanto e em qual direção a flecha ficou afastada do centro do alvo, estima o quanto precisa mudar o posicionamento do arco e a força na corda e, em seguida, executa novas tentativas.

Esses aspectos de tentativa e erro e busca por recompensa a longo prazo estão enraizados na Aprendizagem por Reforço, sendo essas as características mais importantes e que mais distinguem esse método de aprendizagem de máquina dos demais[SB98]. Uma forma conveniente de introduzir o tema é definindo a terminologia de seus principais componentes:

\section{Agente:}

É a entidade que está tentando aprender algo. O agente tem de ser capaz de realizar ações e observar (total ou parcialmente) o estado do ambiente. No nosso caso, o piloto virtual é o agente;

\section{Ambiente:}

Tudo com o que se interage, mas que não é o agente; 


\section{Ações:}

São as diferentes formas de como o agente pode interagir com o ambiente. Por exemplo, acelerar, frear e virar o volante;

\section{Estados:}

São os indicadores da situação na qual o agente se encontra em dado instante. Cada estado pode ser determinado por um conjunto de características. Em nosso contexto, mas com um cenário muito simplificado, poderíamos considerar o estado do carro apenas como um par velocidade e tipo de trecho no qual se está.

\section{Política:}

É a função que mapeia estados a ações. Isto é, para cada estado possível, a política indica qual ação deve ser tomada. É a politica que determina o comportamento do agente. Seguindo com os exemplos, se o estado do carro fosse o par " $200 \mathrm{~km} / \mathrm{h}$ " e "curva fechada", a política poderia indicar "frear" como ação a ser executada;

\section{Recompensa $^{1}$ :}

Quando o agente realiza uma ação, pode lhe ser dada uma recompensa de acordo com o efeito causado, isto é, de acordo com o estado ao qual se chega. Por exemplo, se o carro sair da pista, seria interessante atribuir uma recompensa negativa (punição) para a ação responsável por isso;

\section{Função Valor:}

Indica o quanto se espera ganhar a partir de um dado estado. Assim, é possível tomar decisões que envolvem a escolha de ações com baixa recompensa imediata mas proporcionam grande ganho no futuro. Continuando com os exemplos contextualizados, digamos que sair da pista gere uma punição, porém chegar em primeiro lugar tenha grande recompensa. Então, talvez a função valor indique que sair da pista e cortar a curva seja vantajoso caso isso garanta a vitória.

Ter um agente atuante na busca pelo melhor comportamento é um aspecto de distinção da RL em relação a outras técnicas, sendo que os métodos mais empregados nas pesquisas em aprendizado de máquina são baseados em aprendizado supervisionado [SB98]. Nesse modelo, é preciso se ter um supervisor externo com total conhecimento sobre a tarefa a ser cumprida a fim de se produzir um conjunto de exemplos. Cada exemplo é um par de entrada e saída, sendo que a entrada é um sinal de informações que o agente poderia receber e a saída é a resposta que se espera que o agente devolva perante àquela entrada.

No aprendizado supervisionado portanto, o agente recebe passivamente um conjunto de dados de treinamento e é só depois dessa exposição a exemplos que ele pode ser usado para tomar decisões. Com isso, as fases de treinamento e de aplicação são muito bem delineadas e não se misturam. Contudo, diferentemente dos métodos supervisionados, na Aprendizagem por Reforço o agente precisa coletar informações durante a execução das ações, interagindo ativamente com o ambiente. Em resposta a cada ação, o agente recebe o estado em que se encontra e uma recompensa. Dessa forma, as fases de treinamento e aplicação se mesclam em uma só [MRT12].

Uma vez que o objetivo do agente é maximizar sua recompensa total acumulada, seria intuitivo definir a política simplesmente como "escolha a ação de maior valor esperado". Mas para conseguir descobrir quão boa é uma ação a longo prazo, antes é preciso executá-la e avaliar seu resultado. Ou seja, se o agente sempre escolher as ações que já conhece e sabe que dão boas recompensas, ele nunca descobrirá se

\footnotetext{
1 No processo de aprendizagem, cada "recompensa" pode ser positiva, negativa ou até mesmo nula. Portanto, é preciso ter cautela para não interpretar essa palavra apenas com seu significado favorável. Em contrapartida, a palavra "punição" sempre está associada a recompensas estritamente negativas.
} 
outras ações são melhores. Em contrapartida, se a escolha sempre for feita visando a busca de novas informações, a recompensa acumulada tende a não ser tão grande quanto poderia. Esse é o dilema da busca por novas descobertas contra o aproveitamento do que já se sabe (exploration-exploitation). Para o agente ter sucesso, é preciso balancear esses dois objetivos conflitantes. Uma das formas de conseguir isso é adotar uma política $\varepsilon$-gulosa: com probabilidade $\varepsilon$, se escolhe uma ação aleatória e, com probabilidade $1-\varepsilon$, se escolhe a ação de maior valor esperado (decisão gulosa).

No geral, a rotina de aprendizagem de um agente se baseia em: verificar o estado atual; consultar a política; executar a ação indicada pela política; verificar o novo estado; e, por fim, atualizar o valor da recompensa da ação realizada. Na prática, isso significa que o agente precisa armazenar a relação entre estado-ação e a recompensa. O método para fazer esse armazenamento, bem como a atualização dos dados, será apresentado nas seções seguintes.

\subsubsection{Processo de Decisão de Markov}

É recorrente modelar o ambiente de aprendizagem e as interações feitas nele como um Processo de Decisão de Markov (Markov Decision Process, ou apenas MDP). Em particular, a maioria dos problemas de RL são modelados como MPDs finitos, isto é, com espaços de estado e ação finitos e discretos [SB98]. A definição de um MDP é dada pela quina $\left(S, A, P_{s a}, R, \gamma\right)$.

$S: \quad$ É o conjunto de estados;

$A: \quad$ É o conjunto de ações;

$P_{s a}$ : É a distribuição da probabilidade de transição de estados. Assim, $P_{s a}\left(s^{\prime}\right) \geq 0$ é a probabilidade de se chegar ao estado $s^{\prime}$ a partir de $s$, executando a ação $a$;

$R: \quad$ É a função de recompensa imediata, que associa cada estado a um valor tal que $R: S \mapsto \mathbb{R}$

$\gamma: \quad$ É o fator de desconto, indicando a atenuação que o valor de recompensas futuras recebe por ser avaliado no tempo presente, sendo que $\gamma \in[0,1]$.

Esse modelo atende à Propriedade de Markov, pois tanto a escolha da próxima ação a ser tomada quanto a recompensa a ser recebida dependem apenas da informação do estado atual. Com isso em mãos, vamos supor que um agente tenha partido do estado inicial $s_{0}$ e percorrido o seguinte "caminho":

$s_{0} \quad s_{1} \quad s_{2} \quad s_{3} \quad \ldots$

Para avaliar quão bem esse agente cumpriu sua tarefa, podemos adotar como medida de desempenho as recompensas recebidas ao longo da jornada. Assim, sua recompensa total acumulada seria dada pela soma:

$$
R\left(s_{0}\right)+R\left(s_{1}\right)+R\left(s_{2}\right)+R\left(s_{3}\right)+\ldots
$$

Agora, supondo que o agente esteja em $s_{0}$ e planejando qual sequência de ações tomar, há um certo grau de incerteza sobre as recompensas futuras. Quanto mais distante do presente for a ação, menor será o valor percebido de sua recompensa por conta dessa incerteza. Para essa ponderação, usamos o fator de desconto $\gamma$. Assim, a estimativa da soma de recompensas fica:

$$
R\left(s_{0}\right)+\gamma R\left(s_{1}\right)+\gamma^{2} R\left(s_{2}\right)+\gamma^{3} R\left(s_{3}\right)+\ldots
$$


Portanto, o objetivo do agente é encontrar uma política $\pi: S \mapsto A$ a qual escolha um conjunto de ações $\left(a_{0}, a_{1}, a_{2}, \ldots\right)$ tal que se tenha a maior expectativa de ganho. Em outras palavras, deseja-se maximizar a esperança da recompensa total acumulada.:

$$
E\left[R\left(s_{0}\right)+\gamma R\left(s_{1}\right)+\gamma^{2} R\left(s_{2}\right)+\gamma^{3} R\left(s_{3}\right)+\ldots\right]
$$

A sequência anterior de etapas é apenas uma construção informal para ilustrar como é possível associar um valor a cada estado tendo como base a recompensa que se pode conseguir a partir dele. Na literatura [MRT12], essa associação é apresentada como a função valor $V^{\pi}(s)$, descrita na Equação (4.1). A função valor é interpretada como a recompensa total esperada partindo do estado $s \in S$.

Vale notar que há na equação um pequeno abuso de notação para indicar que a escolha de ações é feita seguindo a política $\pi$. Além disso, embora a teoria de MDPs se estenda a espaços de estados e ações contínuos, frequentemente sua aplicação é feita em contextos discretos, como no caso deste projeto. Assim sendo, é razoável enxergar $V$ como um vetor com tantas posições quanto o número de estados.

$$
V^{\pi}=E\left[\sum_{t=0} \gamma^{t} R\left(s_{t}\right) \mid \pi, s_{0}=s\right]
$$

O fato da função valor satisfazer algumas relações recursivas particulares é uma propriedade fundamental para a Aprendizagem por Reforço [SB98]. Dessas relações, a Equação de Bellman descrita na Equação (4.2) é aquela que alicerça a principal técnica de aprendizagem usada neste trabalho, o Q-Learning, apresentada mais adiante neste mesmo capítulo.

$$
V^{\pi}(s)=R(s)+\gamma \sum_{s^{\prime}} P_{s \pi(s)}\left(s^{\prime}\right) V^{\pi}\left(s^{\prime}\right)
$$

Onde,

$$
\begin{array}{ll}
R(s): & \text { É a recompensa imediata por chegar ao estado } s ; \\
P_{s \pi(s)}\left(s^{\prime}\right): & \text { É a probabilidade de chegar em cada } s^{\prime} \text { a partir de } s, \text { seguindo a política } \pi, \text { lembrando } \\
& \text { que } \pi(s) \text { devolve uma ação; } \\
V^{\pi}\left(s^{\prime}\right): & \text { É o valor esperado de cada } s^{\prime} ;
\end{array}
$$

Com a Equação (4.2) e dada uma política fixa, se consegue calcular o valor esperado de cada estado através de um sistema linear com $n$ equações e $n$ incógnitas, sendo $n$ o número de estados distintos. Nessa linha de raciocínio, um próximo passo seria buscar o maior valor esperado possível de cada estado, considerando todas as políticas permitidas ao problema. Esse seria o valor ótimo $V^{*}$, tal como definido na Equação (4.3).

$$
V^{*}(s)=\max _{\pi} V^{\pi}(s)
$$

Consequentemente, pode-se adaptar a Equação de Bellman resultando em uma versão alternativa para $V^{*}$, como visto na Equação (4.4).

$$
V^{*}(s)=R(s)+\gamma \max _{a} \sum_{s^{\prime}} P_{s a}\left(s^{\prime}\right) V^{*}\left(s^{\prime}\right)
$$

Tendo calculado todos os valores de $V^{*}(s)$ para cada estado $s$, é possível determinar qual estado vizinho possui a maior esperança de recompensa. Portanto, podemos construir uma política que sempre devolve a ação que leva ao estado vizinho de maior valor. Essa seria uma política ótima, simbolizada por $\pi^{*}$, e seguiria a Equação (4.5). 


$$
\pi^{*}(s)=\underset{a}{\arg \max } \sum_{s^{\prime}} P_{s a}\left(s^{\prime}\right) V^{*}\left(s^{\prime}\right)
$$

Contudo, a Equação (4.4) não é linear por conta do operador max. Além dessa questão, essa sequência lógica nos conduziria a avaliar todas as possíveis políticas a fim de encontrar $\pi^{*}$, o que claramente é inviável. Por conta disso, uma forma de solucionar o problema é usar um método iterativo para calcular os valores de $V(s)$ de modo a aproximá-los a $V^{*}(s)$ e, por consequência, chegar a $\pi^{*}$.

Esse método é chamado de value iteration (iteração de valor) e está descrito no Algoritmo 5 . O valor de cada estado é seguidamente sobrescrito de acordo com a Equação (4.4). Como $V^{*}(s)$ satisfaz a Equação de Bellman, é provado que a sequência de iterações faz qualquer $V$ arbitrariamente escolhido convergir para $V^{*}$ [MRT12]. As iterações são repetidas até que algum indicador de convergência seja satisfeito. É possível impor um número máximo de repetições, porém uma forma simples de avaliar a convergência é verificar a maior alteração feita em $V$ durante cada iteração e comparar essa medida com um valor limite. Se nenhuma mudança foi maior que esse limite, então pode-se assumir que houve convergência.

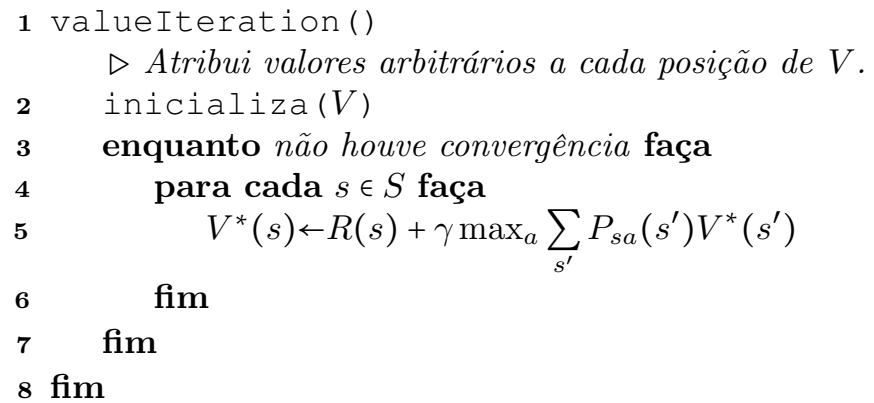

Algoritmo 5: Método iterativo para calcular $V^{*}$.

Embora a iteração de valor seja simples e efetiva, ela depende fortemente de se conhecer a distribuição de probabilidades $P_{s a}$ de transição entre estados. Em outras palavras, é necessário ter um modelo preciso de como o ambiente se comporta. Essa é uma suposição muito forte e difícil de atender quando se lida com aplicações reais ou simulações próximas à realidade. Por esse motivo, o cálculo iterativo de $V$ precisa se estendido de modo a perder essa dependência. Isso será tratado na próxima seção.

\subsubsection{Aprendizado por Diferença Temporal}

Em vários cenários reais, ou que simulam a realidade como em nosso caso, a distribuição de probabilidades de transição entre estados $P_{s a}$ é muito complexa, ou muito grande, ou simplesmente completamente desconhecida. Por qualquer que seja o motivo, é comum não ser proveitoso tentar definir $P_{s a}$.

Nesses casos, uma alternativa para o cálculo das estimativas $V(s)$ de valor de cada estado é o conceito de Aprendizagem por Diferença Temporal (Temporal Difference Learning, ou apenas TD). Essa abordagem consiste em calcular a diferença de valores entre dois estados visitados consecutivamente e usar essa variação para atualizar $V$. A operação de atualização de $V(s)$ com base no valor do estado seguinte $s^{\prime}$ está descrita mais precisamente na Equação (4.6).

$$
\begin{aligned}
V(s) & \leftarrow(1-\alpha) V(s)+\alpha\left[r+\gamma V\left(s^{\prime}\right)\right] \\
& =V(s)+\alpha \underbrace{\left[r+\gamma V\left(s^{\prime}\right)-V(s)\right]}_{\text {diferença temporal dos valores de } V}
\end{aligned}
$$


O termo $\alpha$ representa a taxa de aprendizado, sendo normalmente $0 \leq \alpha \leq 1$. Quanto maior for essa taxa, mais peso é dado às experiências recém adquiridas. Já para pequenos valores de $\alpha$, menos o aprendizado recente afeta o "conhecimento" acumulado. Quando $\alpha=0$, o aprendizado cessa completamente. Esse valor não precisa ser fixo e uma técnica utilizada é diminuí-lo gradualmente. Assim, a Equação (4.6) serve de base para o Algoritmo 6, usualmente denominado $T D(0)$.

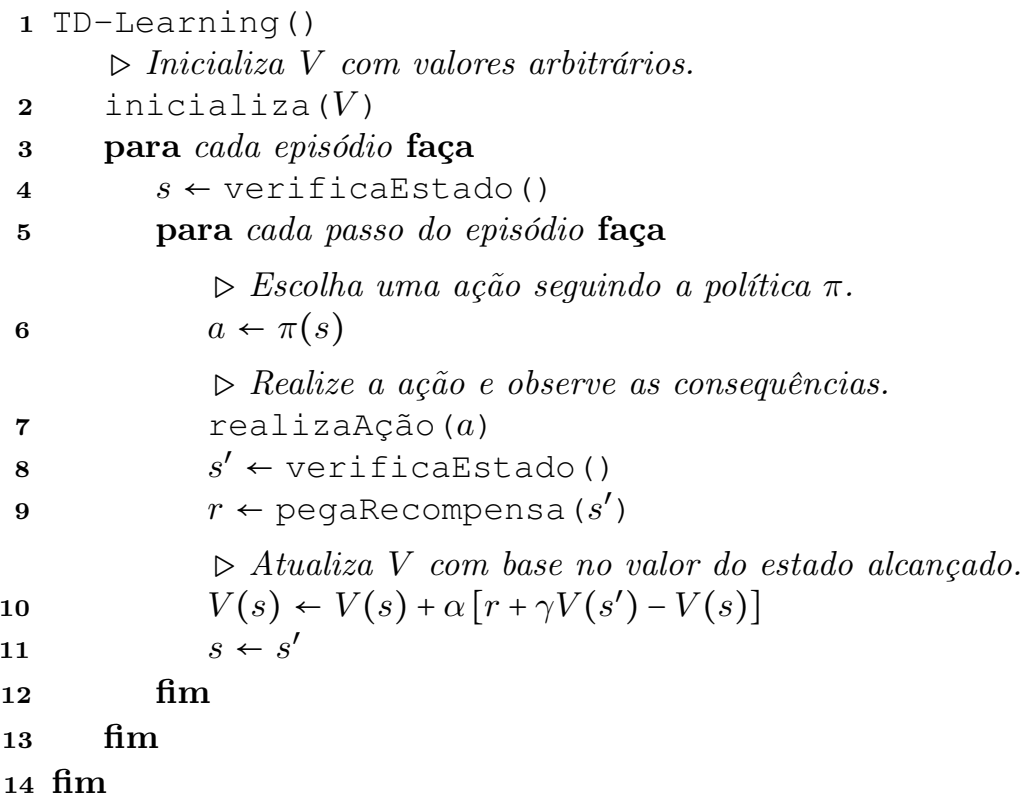

Algoritmo 6: Aprendizagem por diferença temporal.

Da mesma forma que o método de iteração por valor, novamente a inicialização de $V$ pode ser arbitrária. Porém, o TD não itera por todos os estados, mas sim por passos em cada episódio ${ }^{2}$. Por meio do método verificaEstado(), o agente observa em qual estado se encontra e indica ao ambiente sua reação através de realizaAção $(a)$, sendo $a$ a ação dada pela política $\pi$. Cada estado pode estar associado a uma recompensa e essa verificação é feita por pegaRecompensa ( ) .

\section{$4.2 \quad$ Q-Learning}

Vimos que a função valor associa estados a valores. Entretanto, esse conceito pode ser ampliado de maneira a não considerar como entrada apenas o estado, mas sim um par estado-ação. Com essa alteração, temos então a função $Q(s, a)$, a qual indica a esperança de recompensa total por realizar a ação $a$ no estado $s$.

O emprego da função $Q$ em conjunto da abstração de aprendizagem por diferença temporal é a essência do Q-Learning [Wat89], que é a técnica ao redor da qual este projeto foi elaborado. A principal mudança que o Q-Learning (ou simplesmente QL) introduz em relação ao TD está no passo de atualização dos valores de $Q$, pois é nesse ponto onde acontece o aprendizado.

A sequência de operações para a atualização de $Q$ acontece da maneira descrita a seguir: Em determinado instante, o agente está em um estado $s$. Escolhe-se a ação a a partir da política em uso. Após a execução de $a$, o agente chega ao estado $s^{\prime}$ e avalia quão boa é sua situação, recebendo portanto a recompensa $r^{\prime}$. A atualização da estimativa de valor do par $(s, a)$ é feita então com base no maior ganho estimado que se pode conseguir a partir de $s^{\prime}$. Os passos acima são descritos mais formalmente pelo Algoritmo 7 e a atualização de $Q$ segue a regra (4.7).

\footnotetext{
2 Dá-se o nome episódio para cada ciclo de aprendizagem. Um episódio se encerra quando o agente atinge algum estado terminal do ambiente, interrompendo o processo de interação.
} 


$$
Q(s, a) \leftarrow Q(s, a)+\alpha\left[r^{\prime}+\gamma \max _{a^{\prime}} Q\left(s^{\prime}, a^{\prime}\right)-Q(s, a)\right]
$$

Lembrando que $\alpha$ é a taxa de aprendizado, vista no TD. Já o parâmetro $\gamma$ é o fator de desconto, escolhido usualmente tal que $0 \leq \gamma<1$. Esse fator indica quanto peso se dá a expectativa de recompensa futura em relação à recompensa atual. Para $\gamma=0$, diz-se que o agente é míope, pois o ganho a longo prazo passa a ser ignorado. Por outro lado, quanto mais próximo de 1 está o fator, menos a recompensa momentânea influencia na construção da política.

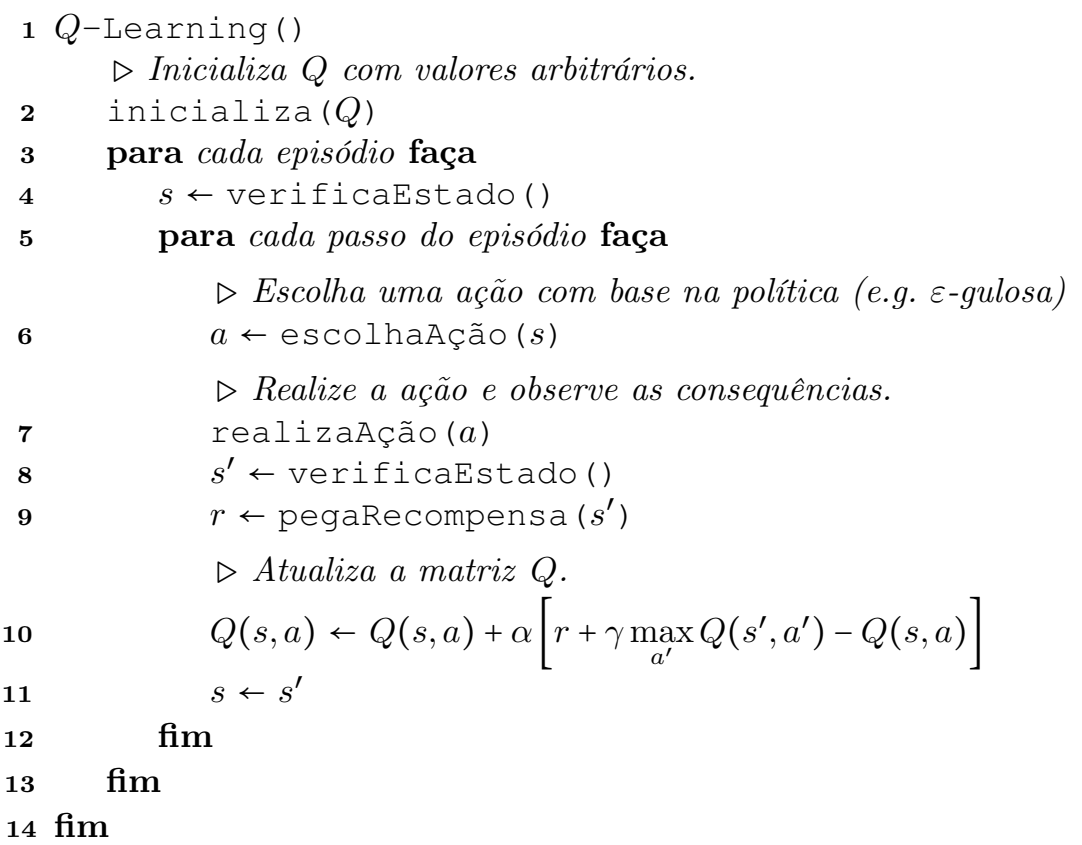

Algoritmo 7: Q-Learning.

Pode-se notar pelo Algoritmo 7 que a melhor ação $a^{\prime}$ escolhida pelo operador max na linha 10 não necessariamente será escolhida para ser executada na iteração seguinte. Ou seja, a estimativa da função valor não está vinculada à política vigente durante o processo de aprendizagem, mas sim à comparação entre todas as possíveis ações $a^{\prime}$. Por essa característica, o $Q$-Learning é categorizado como sendo um algoritmo off-policy.

Com isso, é possível demonstrar que esse algoritmo é capaz de fazer $Q$ convergir para $Q^{*}$ através de qualquer política arbitrária, contato que garantidamente se visite todos os possíveis pares $(s, a)$ infinitas vezes [MRT12]. Na prática, evidentemente essa condição nunca é satisfeita. Assim, uma opção recorrentemente usada nos problemas de Aprendizagem por Reforço é adotar uma política $\varepsilon$-gulosa, mencionada anteriormente, de modo a tentar assegurar que o processo não se prenda a máximos locais.

A título de completude de informação, vale mencionar que também existem algoritmos ditos onpolicy. Neles, os valores de $Q$ são atualizados levando em conta o valor da ação escolhida pela política. $\mathrm{O}$ representante mais renomado desse grupo de algoritmos é o SARSA [RN94] (originalmente chamado de Q-Learning modificado e posteriormente rebatizado [Sut96]). Apesar de muito semelhante ao QL, o agente baseado no SARSA tende a apresentar um comportamento mais cauteloso por conta de seu processo de aprendizado considerar a política em uso, a qual pode tomar decisões ótimas mas eventualmente também faz escolhas exploratórias. Em contrapartida, o $Q$-Learning sempre altera $Q$ em função da melhor escolha, mesmo que ela não seja seguida durante a execução. 
Para ilustrar melhor essa diferença, vamos imaginar que ambos métodos estejam seguindo uma política $\varepsilon$-gulosa $\operatorname{com} \varepsilon=1$, fazendo todas as ações serem escolhidas por sorteio. Nesse caso, os agentes de ambos os algoritmos se comportariam aleatoriamente, porém o SARSA estaria calculando a estimativa de valor da política aleatória enquanto o os cálculos de QL ainda estariam estimando $Q^{*}$.

\subsection{Traços de Elegibilidade}

Pela própria formulação do processo de Aprendizagem por Diferença Temporal, é evidente que, embora o agente construa uma ampla perspectiva em relação ao futuro por meio das estimativas de recompensa a longo prazo, a visão sobre o passado é extremamente limitada. Mais precisamente, essa visão é tão curta a ponto de entender que a causa de se estar no estado atual é exclusivamente relacionada ao estado-ação imediatamente anterior. Em alguns domínios de aplicação, isso é perfeitamente razoável, como no caso de busca de caminhos por um ambiente de posições discretas. Contudo, em cenários onde existam efeitos mais duradouros, como inércia por exemplo, nem sempre a última ação executada é a única responsável pela situação atual.

Para ilustrar melhor como a tarefa de pilotar um carro se enquadra nesse cenário complexo, vamos imaginar a seguinte situação: o piloto percorre toda a extensão de uma reta com aceleração máxima e, ao entrar na curva em sequência, ele pisa no freio mas mesmo assim o carro sai da pista. Certamente a última ação realizada antes do acidente, pisar no freio, não deveria receber punição, pois a real causa do acidente foi não ter acelerado no fim da reta em vez de frear. Ou seja, seguindo o TD como visto anteriormente, além da ação errada receber a punição, nem mesmo parte dessa punição seria para a ação mal escolhida.

Uma forma de contornar essa falta de "memória" é criar alguma espécie de histórico de modo que frações das recompensas de eventos chave sejam repassadas não só para a última ação escolhida, mas também para as anteriores. Os traços de elegibilidade (eligibility traces, ou apenas ETs) são um mecanismo para cumprir esse papel. No traço, os pares estado-ação associados ao evento em questão são marcados como elegíveis para serem influenciados pelas atualizações do passo de aprendizado.

Praticamente toda técnica baseada em TD pode ser combinada com ETs, produzindo assim um método mais genérico e tornando o aprendizado mais eficiente [SB98]. Na literatura os ETs são apresentados como uma estrutura paralela à representação de $Q$, sendo que cada par $(s, a)$ está relacionado a um indicador de elegibilidade. Cada vez que algum evento de interesse acontece, esse indicador é então incrementado. Quando um estado terminal é atingido, por exemplo, apenas os pares elegíveis são responsabilizados recebendo os créditos ou punições pelo ocorrido.

Essa foi apenas uma visão geral sobre o conceito de traços de elegibilidade. Não nos aprofundaremos em detalhes mais técnicos neste capítulo, pois a forma canônica do uso de traços é um método simplista demais para lidar com as necessidades de nosso piloto virtual. Por conta desse fato, embora tenhamos nos inspirado na essência dos ETs, nossa adaptação exigiu alterações tão consideráveis que nos afastamos da estrutura convencional de integração dos traços a Aprendizagem por Reforço. Assim sendo, deixamos para o Capítulo 5 o tratamento das particularidades de nossa abordagem e o algoritmo para sua aplicação. 


\section{Capítulo 5}

\section{O piloto virtual}

Nesse capítulo, nós abordamos os detalhes sobre a construção do piloto virtual. Na primeira seção, detalhamos os estados e ações que compõem a matriz $Q$, além das adaptações feitas no algoritmo $Q$-Learning para a adequação às iterações de simulação e o uso de histórico de escolhas. Ainda nessa seção, explicamos como é feita a decisão das trocas de marcha e o alinhamento dos sensores do carro. A segunda seção é dedicada ao funcionamento do controle do volante e os detalhes da heurística elaborada para esse propósito. Por fim, na terceira e última seção explicamos os sistemas auxiliares embutidos no carro.

\subsection{Preparação da aprendizagem e do carro}

Os dois elementos chave da Aprendizagem por Reforço são o agente, que é a entidade atuante e protagonista do processo, e o ambiente, que é o meio com o qual o agente interage. Portanto, modelar o problema de aprendizagem consiste em determinar:

- as ações que o agente pode executar;

- os estados que ele será capaz de identificar;

- as recompensas, ou punições, dadas ao se chegar em cada estado;

- o método de atualização da matriz $Q$ com os valores estimados de cada par (estado, ação).

Neste trabalho, o ambiente é o simulador de corridas TORCS e o agente é o módulo controlador do piloto virtual. Os acidentes, sair da pista ou parar o carro, são considerados estados terminais e há punições caso eles ocorram. Para todos os demais estados, a recompensa dada é nula. Essa abordagem estritamente punitiva é um método interessante de favorecer a escolha de pares (estado, ação) ainda não testados, pois é pouco dependente do parâmetro de exploração $\varepsilon$.

A diante, apresentamos em detalhes a construção da matriz $Q$ com base na definição dos estados e ações. Em seguida, especificamos a atualização dos valores da matriz através de uma abordagem própria de traços de elegibilidade.

\section{Matriz $Q$}

A grande meta do processo de Aprendizagem por Reforço é encontrar uma boa política, a qual definirá o comportamento do agente. Uma vez que a política é descrita pela matriz $Q$, pois essa é uma tabela que aponta a melhor ação a ser tomada em cada estado, pode-se entender que os valores da matriz são o resultado da aprendizagem. 
Construímos nossa matriz como sendo o produto cartesiano do espaço de estados (linhas) com o espaço de ações (colunas). Essa composição forma uma grade com 220 linhas e 5 colunas. O valor de cada posição é inicializado com zero e, ao fim da simulação, um arquivo com os valores finais é produzido.

\section{Estados}

O espaço de estados é formado pela combinação de 4 propriedades do ambiente que o piloto virtual é capaz de avaliar, sendo que cada uma pode assumir uma quantidade diferente de valores. Essas propriedades são: 11 tipos de trecho; 5 intervalos de velocidade; 2 tipos de característica dos trechos seguintes; e 2 indicações se o carro está no fim do trecho atual. Nas Tabelas 5.1, 5.2, 5.3 e 5.4 mostramos respectivamente a interpretação dada às possibilidades dessas propriedades.

Tabela 5.1: Lista das classificações que os trechos podem receber.

\begin{tabular}{l}
\hline \multicolumn{1}{c}{ Tipos de trechos } \\
\hline Reta curta \\
Reta média \\
Reta longa \\
Curva grampo \\
Curva cotovelo \\
Curva fechada curta \\
Curva fechada longa \\
Curva moderada curta \\
Curva moderada longa \\
Curva leve curta \\
Curva leve longa \\
\hline
\end{tabular}

Tabela 5.2: Faixas de velocidade usadas para determinar o estado no qual o carro se encontra.

\begin{tabular}{rll}
\hline \multicolumn{2}{c}{$\begin{array}{c}\text { Velocidade } \\
(\mathrm{km} / \mathrm{h})\end{array}$} \\
\hline 0 & $\sim$ & 50 \\
50 & $\sim$ & 90 \\
90 & $\sim$ & 120 \\
120 & $\sim 180$ \\
180 & $\sim$ & $\infty^{+}$ \\
\hline
\end{tabular}

Tabela 5.3: Tipos nos quais o conjunto de trechos seguintes se encaixa.

\begin{tabular}{c}
\hline Sequência \\
\hline Lenta \\
Rápida \\
\hline
\end{tabular}

Tabela 5.4: Parâmetro que indica se o carro está próximo ao fim do trecho.

O tipo de trecho é dado pelo posicionamento do carro ao longo do modelo da pista montado na primeira volta, quando se faz o escaneamento com os sensores track. A informação sobre o perto do fim é avaliada da mesma forma. A velocidade é medida diretamente pelo sensor correspondente.

Já para o agente saber qual é a característica principal da sequência de trechos à frente, é preciso consultar um vetor de lookahead (antevisão) processado ao fim da primeira volta, momento no qual os tipos de todos os trechos já foram identificados. As regras para preencher cada posição desse vetor são:

1. Se o próximo trecho for grampo, ou cotovelo, ou curva fechada curta, a sequência é lenta;

2. Caso contrário, se o tipo seguinte for reta curta ou curva leve, mas acompanhado de grampo, ou cotovelo, ou curva fechada curta, então também registra-se sucessão lenta;

3. Para as demais configurações, indica-se sequência rápida.

\section{Ações}

Em contraposição à grande quantidade de estados, o espaço de ações foi dividido em apenas 5 alternativas, sendo elas:
(i) acelerar 100\%;
(ii) acelerar 60\%;
(iii) neutro;
(iv) frear $40 \%$;
(v) frear $100 \%$. 
Enquanto o acelerador é acionado, não se aplica nenhuma pressão no acelerador e vice-versa. Já a ação neutra equivale a simultaneamente não acelerar e não frear.

Os valores intermediários de acelerador e freio, $60 \%$ e $40 \%$ respectivamente, foram escolhidos assimetricamente com base na observação de que o pedal do freio é mais "sensível" que o do acelerador. Isto é, para produzir uma frenagem intensa é preciso menos pressão no pedal do que o exigido por uma aceleração intensa.

\section{Adaptação do Q-Learning}

Anteriormente, no Capítulo 4, apresentamos o Algoritmo 7 com a versão clássica do Q-Learning. Naquele formato, a execução das instruções é interrompida para o agente efetuar a ação escolhida e realizar a leitura do ambiente, identificando o novo estado no qual se encontra (linhas de 7 a 9). Essa abordagem, entretanto, não pode ser aplicada diretamente em ambientes de simulação ou jogos como o TORCS, que são programas interativos. Geralmente, programas dessa natureza são regidos por um laço de atualização de estados chamado game loop. Cada iteração desse laço consiste basicamente em:

1. Transmitir o estado atual da simulação a todos os elementos;

2. Receber de cada elemento seu comportamento dado o estado transmitido;

3. Atualizar o estado da simulação com base na reação dos elementos.

Sendo o piloto virtual um elemento de simulação, ele não pode ativamente executar uma ação (como sugerido pela chamada realizaAção () na linha 7 do Algoritmo 7). Em vez disso, o agente pode apenas determinar qual será seu comportamento em resposta ao estado atual, comunicar essa escolha ao motor de simulação e deixar que o motor em si (nesse caso, o TORCS) efetue a ação e compute as alterações no ambiente simulado.

Dada essa característica intrínseca à aplicação em um ambiente virtual, elaboramos a adaptação apresentada no Algoritmo 8. Esse novo método pode ser chamado em toda iteração de simulação e recebe como parâmetro o estado atual $s^{\prime}$ no qual o agente se encontra. Faz-se a atualização da matriz $Q$ referente ao par estado anterior $s$ e ação anterior $a$. Após essa atualização, uma nova ação $a$ é escolhida em resposta ao estado atual $s^{\prime}$, que passa a ser guardado como estado anterior $s$, e por fim $a$ é devolvida ao motor de simulação.

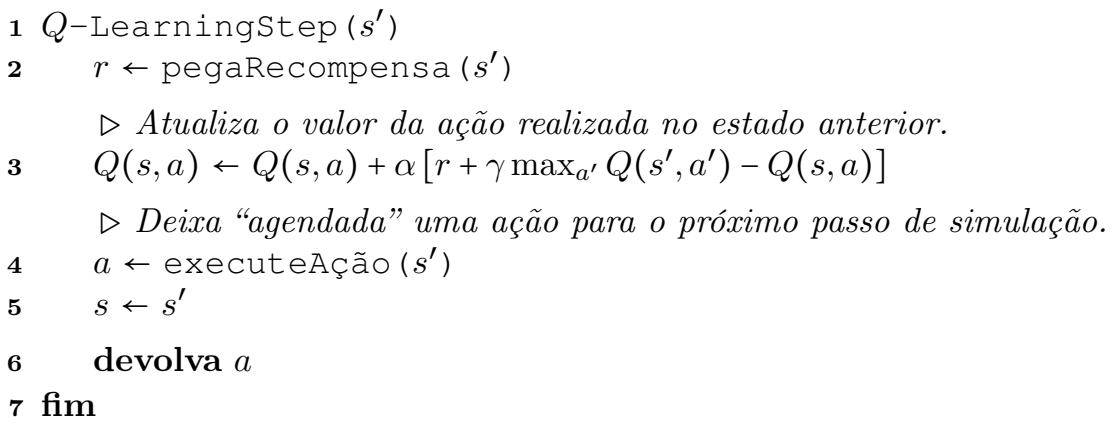

Algoritmo 8: Q-Learning adaptado para se encaixar em uma função chamada a cada passo de execução da simulação.

É importante notar que a rotina do Algoritmo 8 é chamada em todo passo de simulação, porém as variáveis $s$ e $a$ não estão inicializadas na primeira vez em que a matriz $Q$ seria atualizada. Por isso, é preciso ter o cuidado de fazer uma escolha de ação e leitura de estado uma iteração antes da primeira chamada de $Q$-Learningstep. Além disso, da mesma forma que descrito no Capítulo 4 , a matriz $Q$ precisa ser inicializada antes do início do ciclo iterativo. 


\section{Q-Learning com traços de elegibilidade}

O conceito de traços de elegibilidade, apresentado no Capítulo 4, é usado para expandir o Q-Learning de modo a fazer com que a recompensa de uma ação seja refletida também no histórico recente das últimas ações realizadas. No caso do nosso piloto virtual, usamos o conceito mas não exatamente o método de implementação.

O traço é usado principalmente para tentar identificar as causas dos acidentes, pois nem sempre o resultado da última ação antes de sair da pista é de fato razão desse acontecimento. Para exemplificar, imagine a seguinte sequência:

1. Carro no meio de uma longa reta (acelerando 100\%);

2. No fim da reta, o piloto continua escolhendo a ação de acelerar;

3. Na entrada da curva, o piloto passa a frear;

4. Mesmo freando, por conta da alta velocidade, o carro não consegue fazer a curva e sai da pista.

No cenário acima, evidentemente o grupo de ações responsáveis pelo acidente é o escolhido durante o final da reta (deveria ter sido frear em vez de acelerar). Entretanto, a última ação antes do acidente foi frear. Assim, sem o traço, a ação "frear na entrada da curva" receberia toda a punição pelo acidente e o "acelerar no final da reta" se manteria sem alteração.

Para atribuir as punições corretamente, criamos dois traços: um para as ações antes dos pontos de freada e outro para ações durante e depois das curvas. O emprego deles é descrito no Algoritmo 9. O método escolheAção ( ) automaticamente preenche esses históricos a cada vez que é chamado, inserindo a ação escolhida em traçoFrenagem ou em traçoLivre. Já a tarefa de verificar se o carro encontra-se em uma Área de Frenagem, ou seja perto do final de uma reta e próximo à uma curva, fica a cargo de estáNaAF ( ) .

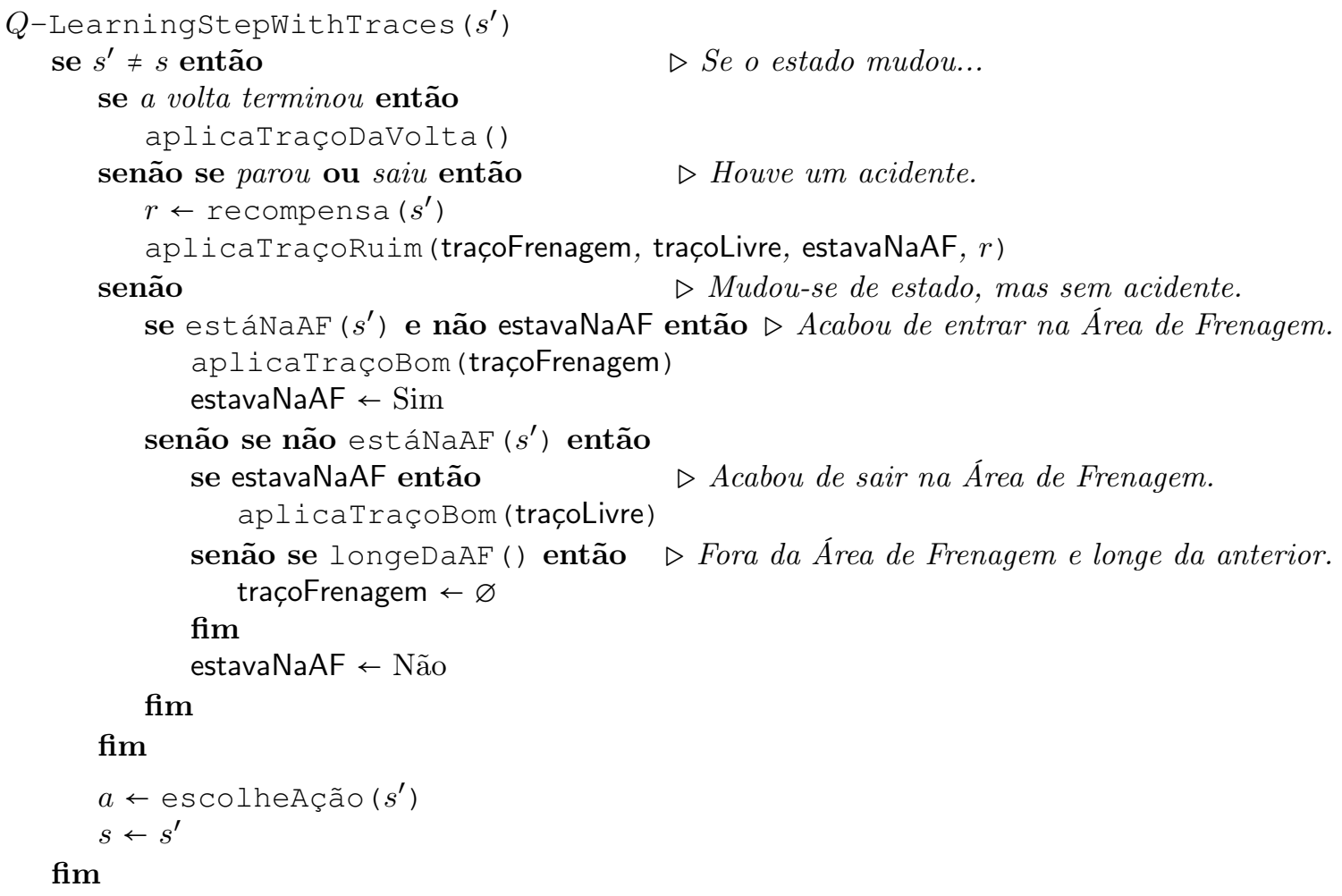

Algoritmo 9: QL trace. 
O aplicaTraçoDeVolta () é chamado toda vez que uma volta acaba. Essa rotina avalia se a volta foi "limpa", isto é, livre de acidentes. Em caso positivo, se a volta foi mais rápida que a melhor volta registrada até o momento, então os pares (estado, ação) da nova melhor volta são guardados. Já quando a volta atual não se tornou a melhor volta, cada escolha feita que não esteja no histórico da volta mais rápida recebe uma pequena punição. Além disso, depois que o processo exploratório for encerrado, essa rotina também passa a atribuir pequenas recompensas às escolhas realizadas durante a volta mais rápida. Desse modo, a aprendizagem tende a convergir para uma política muito próxima à usada na melhor volta $^{1}$.

O aplicaTraçoBom() só tem efeito depois que a exploração terminou. Se não houve acidentes enquanto o traço estava sendo acumulado, para cada par (estado, ação) distinto presente no traço, dá-se um pequeno estímulo a acelerar mais (ou frear menos, se for o caso). Dessa forma, depois que a exploração acaba, o piloto progressivamente passa a tentar escolher ações mais arriscadas. Se acelerar mais não for a melhor escolha por causar acidentes ou não diminuir o tempo de volta, os mecanismos de punição por acidente e por não fazer a melhor volta se encarregam de não "forçar" essa ação ruim. Ao fim da rotina, o traço recebido sempre é esvaziado, independentemente se a exploração acabou ou não.

A aplicação dos traços em caso de acidente é uma das partes mais importantes do nosso processo de aprendizagem. O comportamento ideal do piloto é desconhecido e as únicas informações concretas que temos sobre o problema é que almejamos que o agente gaste o menor tempo possível em cada volta e que algumas situações (acidentes) definitivamente precisam ser evitadas. Portanto, modelar corretamente o sistema de punições é crítico. Se não houver punição para atitudes que levam aos casos indesejados, o piloto terá um comportamento inadmissível. Porém, se a punição se estender erroneamente a ações não diretamente responsáveis pelo mal comportamento, o aprendizado pode resultar em uma política que não alcança o objetivo proposto.

Por esse motivo, a rotina aplicaTraçoRuim() detalhada no Algoritmo 10 é tão crucial. Dado que ela é chamada toda vez que um acidente acontece (sair da pista ou parar o carro), a proposta é percorrer os traços tentando identificar as ações causadoras do acidente e, com isso, punir apenas elas.

Quando o carro para, é relativamente fácil encontrar as causas. Basta identificar se ele estava ou não na área de frenagem e buscar no traço correspondente a ação de frear mais intensa e puni-la. Já quando o carro sai da pista, as variações aumentam e identificar a(s) ação(ões) problemática(s) se torna mais complexo. Abaixo estão os três principais cenários nessa categoria.

- A situação mais comum é o carro entrar rápido demais em uma curva e não conseguir seguir o traçado, saindo da pista;

- Outro cenário recorrente é o carro entrar na curva com velocidade e posicionamento corretos, mas acelerar demais no meio do trecho e perder o controle da direção;

- A terceira situação mais frequente acontece quando o piloto consegue chegar ao limite da velocidade durante a curva, percorre toda sua extensão, mas não é capaz de estabilizar o carro no início do trecho seguinte, que normalmente é uma reta.

No Algoritmo 10, a avaliação feita em causouAcidente () tenta identificar se a ação foi acelerar demais no fim das curvas ou acelerar demais antes de estabilizar. A chamada a avaliaRisco () verifica se a ação esta na lista das ações da melhor volta. Em caso positivo e essa ação estiver envolvida em mais que 4 acidentes, ela então é removida da lista - e consequentemente, deixa de ser reforçada pelo aplicaTraçoDaVolta ().

\footnotetext{
${ }^{1}$ A política final pode não ser exatamente a mesma da usada na melhor volta, pois ações muito arriscadas (com alta relação a acidentes) são gradualmente removidas do histórico da melhor volta.
} 


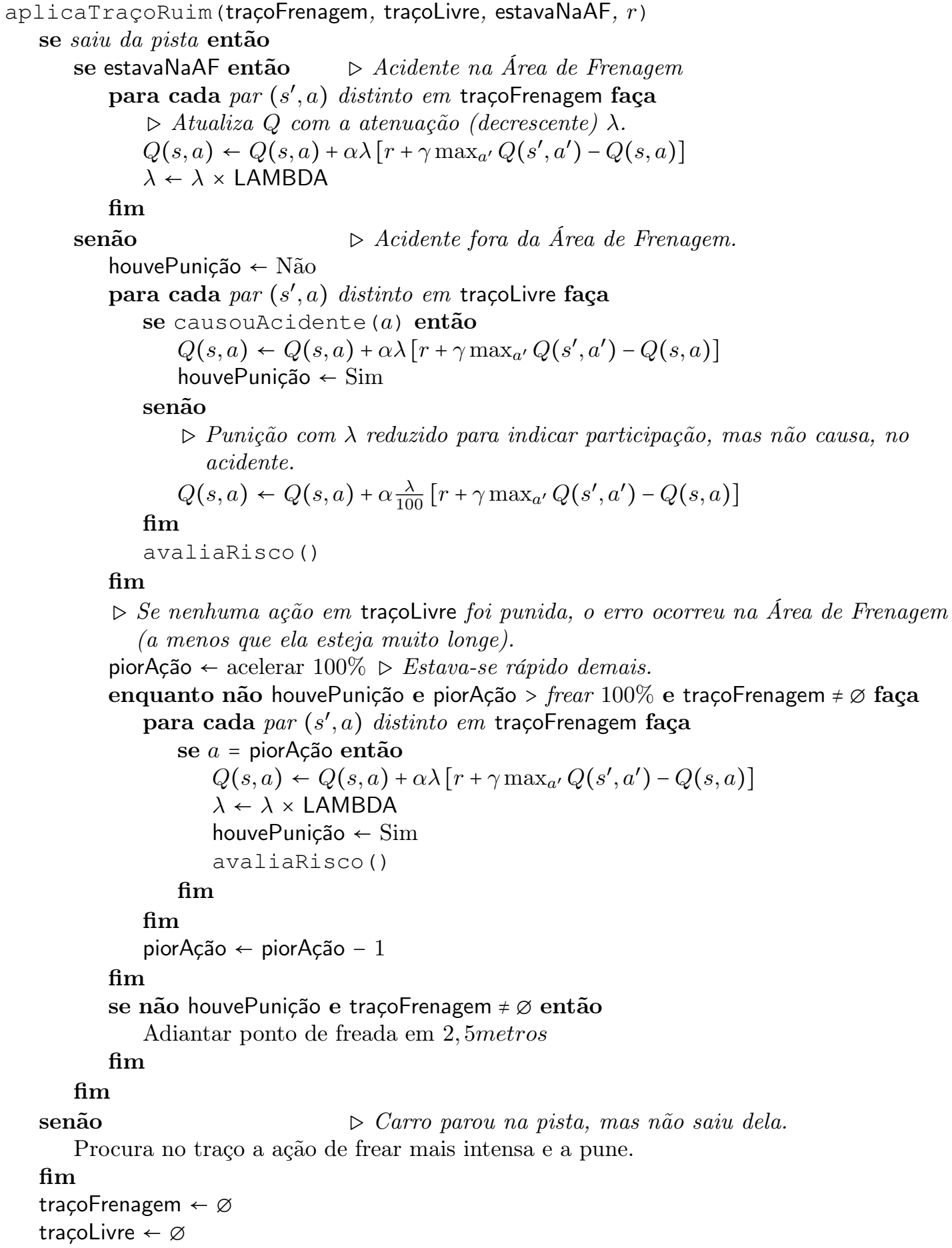

$\triangleright$ Se nenhuma ação em traçoLivre foi punida, o erro ocorreu na Área de Frenagem (a menos que ela esteja muito longe).

piorAção $\leftarrow$ acelerar $100 \% \triangleright$ Estava-se rápido demais.

enquanto não houvePunição e piorAção > frear $100 \%$ e traçoFrenagem $\neq \varnothing$ faça para cada par $\left(s^{\prime}, a\right)$ distinto em traçoFrenagem faça se $a=$ piorAção então

Procura no traço a ação de frear mais intensa e a pune.

fim

traçoFrenagem $\leftarrow \varnothing$

traçoLivre $\leftarrow \varnothing$

40 fim

Algoritmo 10: Punição em acidentes. 
A condição da linha 31 só é satisfeita quando se sai da pista mesmo tendo escolhido todas as ações tomadas de traçoFrenagem como sendo frear $100 \%$. Nesse caso, é preciso começar a frear mais cedo, isto é, mais longe do final do trecho que antecede a curva. Assim sendo, marca-se a alteração no vetor auxiliar que guarda a distância do ponto de freada para cada tipo de trecho.

Com todas essas alterações, nos afastamos do formato tradicional do Q-Learning. Em vez de um traço de elegibilidade único, usamos dois históricos independentes e alternantes. Além disso, "escondemos" as atualizações da matriz $Q$ dentro da avaliação dos traços. Essas modificações são apenas um conjunto de camadas construído com base nos conceitos originais, contudo a essência e os mecanismos da Aprendizagem por Reforço se mantiveram.

\section{Mudanças de marcha}

Quando se está pisando no acelerador, o número de rotações por minuto do motor (rpm) aumenta, assim como a velocidade do carro. Porém chega uma hora na qual é preciso trocar a marcha para a seguinte a fim de manter o aumento de velocidade. Da mesma forma, é preciso reduzir a marcha quando o rpm cai.

Tabela 5.5: Valores máximo e mínimo de rpm de cada marcha.

\begin{tabular}{lcccccc}
\hline marcha & $\mathbf{1}$ & $\mathbf{2}$ & $\mathbf{3}$ & $\mathbf{4}$ & $\mathbf{5}$ & $\mathbf{6}$ \\
\hline máximo & 7000 & 8000 & 8000 & 8500 & 9000 & $\boldsymbol{\infty}^{+}$ \\
mínimo & - & 3500 & 4000 & 4000 & 4500 & 4500 \\
\hline
\end{tabular}

Isso é feito para se manter o rpm numa faixa tal que a conversão da potência do motor em torque nas rodas é a mais eficiente possível. Com isso, o carro demora menos para ganhar velocidade. Os limites superior e inferior de rpm que usamos para efetuar automaticamente a troca de marchas são mostrados na Tabela 5.5.

\section{Alinhamento dos sensores track}

Retomando a Tabela 1.1, vemos que o carro dispõe de um sensor, chamado track, com 19 medidores de distância. Cada um desses instrumentos pode ter uma inclinação própria e funcionam como trenas que medem a distância entre o carro e o extremo da pista.

A definição das inclinações é importante, pois impacta diretamente no controle do volante durante os ataques às curvas - afinal, o piloto virtual só "enxerga" pelas leituras dos sensores e esse é o único modo de estimar o ápice das curvas. Na Figura 5.1, está ilustrada

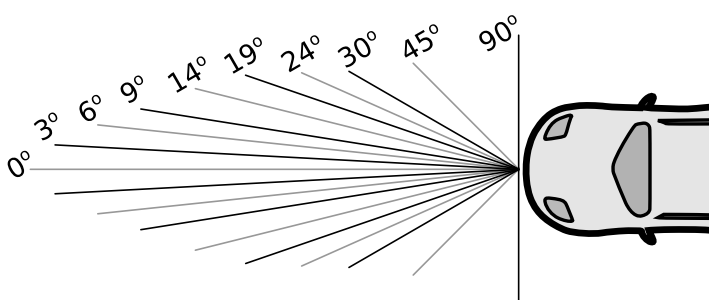

Figura 5.1: Alinhamento dos sensores track na inicialização das configurações do carro. a disposição adotada.

\subsection{Controle do volante}

Conduzir o carro de forma a conseguir manter a maior velocidade possível é uma competência essencial que todo piloto precisa desenvolver. Embora essa habilidade possa ser adquirida através de muito treino, existe uma série de fundamentos teóricos que permitem definir a melhor forma de posicionar o carro na pista. Para isso, porém, é preciso levar em consideração uma grande soma de fatores, tais como a geometria do circuito de corrida, a dinâmica da interação entre o carro e a pista, aerodinâmica, aderência em cada trecho, entre outros [BCMS08]. 
Quando o carro está fazendo uma curva, ele se mantém na trajetória desejada devido à força centrípeta gerada pelo atrito do pneu com o solo. Essa força $F_{c}$ é proporcional à velocidade $v$ do carro (além de sua massa $m$ ) e inversamente proporcional ao raio $r$ da curva, como mostrado na Equação (5.1).

$$
F_{c}=\frac{m v^{2}}{r}
$$

Contudo, a interação entre o pneu e a pista tem um limite máximo de força que consegue gerar. Quando a velocidade é alta e demanda uma força maior do esse limite, o carro "escapa", ou seja, perde aderência e não consegue fazer a curva. Assim sendo, para se conseguir aumentar a velocidade nas curvas é preciso tentar aumentar o raio do trajeto. Em outras palavras, busca-se o caminho de menor curvatura (MCP - minimum curvature path). Entretanto, esse percurso pode ser desnecessariamente mais longo que o caminho de menor comprimento (SP - shortest path) e o ganho em velocidade pode não superar o acréscimo de tempo necessário para percorrer a distância extra.

Tendo isso em vista, uma das formas de se buscar a trajetória que proporciona o menor tempo de volta é tentar encontrar uma ponderação entre os caminhos mais curto e de menor curvatura [CLLB10, BCMS08]. Em [BCMS08], essa ponderação é calculada como uma combinação linear de MCP e SP. Além disso, o tempo de volta é estimado através de um modelo formal. Já em [CLLB10], a ponderação é computada usando um algoritmo genético, sendo que os candidatos à solução evoluem com base no resultado de simulações no TORCS.

No entanto, para aplicar soluções dessa natureza ao manejo do volante, seria necessário: $(i)$ Desenvolver um módulo do piloto virtual dedicado a seguir traçados descritos pelos "pontos de caminho" (way points) resultantes; (ii) Adaptar nossa coleta de dados para criar um modelo de pista compatível com essas necessidades das técnicas; (iii) Além, claro, de implementar as técnicas em si.

Essas tarefas somadas demandariam um considerável esforço mas não estariam alinhadas com a proposta de nosso projeto. Em função disso, optamos por elaborar uma heurística própria para o controle do volante. Essa opção, além de apresentar um método alternativo aos que já existem, nos dá oportunidade de colocar em uso os controladores PID descritos no Capítulo 2. Na próxima seção, são apresentados detalhes da heurística que elaboramos.

\section{Heurística de controle do volante}

A cada passo de execução do simulador, o piloto virtual precisa decidir o quanto virará o volante. Para tomar essa decisão, nossa heurística demanda apenas um conjunto relativamente pequeno de informações, o que é uma vantagem em comparação às abordagens citadas anteriormente, além de facilitar sua adaptação e aplicação em outros ambientes de uso.

A informação indispensável que usamos é o tipo do trecho onde o carro está a cada instante, o que se consegue a partir do modelo proveniente da segmentação e classificação da pista (explicado no Capítulo 3 ). Além disso, dependendo da situação na qual o piloto virtual se encontra, dados complementares também são necessários. A seguir, estão explicados esses distintos cenários bem como o comportamento gerado em resposta a cada um deles e os parâmetros usados em seus respectivos controladores PID.

\section{Preparação para próxima curva}

Quando o carro está em um trecho de reta seguido de curva moderada ou forte, a fim de reduzir a curvatura do trajeto, ele deve se manter no extremo da pista oposto à direção da próxima curva (ponto A na Figura 5.2). Essa estratégia também pode ser usada em trechos que não sejam retas, mas que tenham baixa curvatura (como curvas fáceis longas). Para se posicionar dessa forma, emprega-se o controlador chamado preparePID, que usa o sensor trackPos (Tabela 1.1) como entrada e \pm 0.75 (com sinal dependendo do lado da curva) como setpoint. 


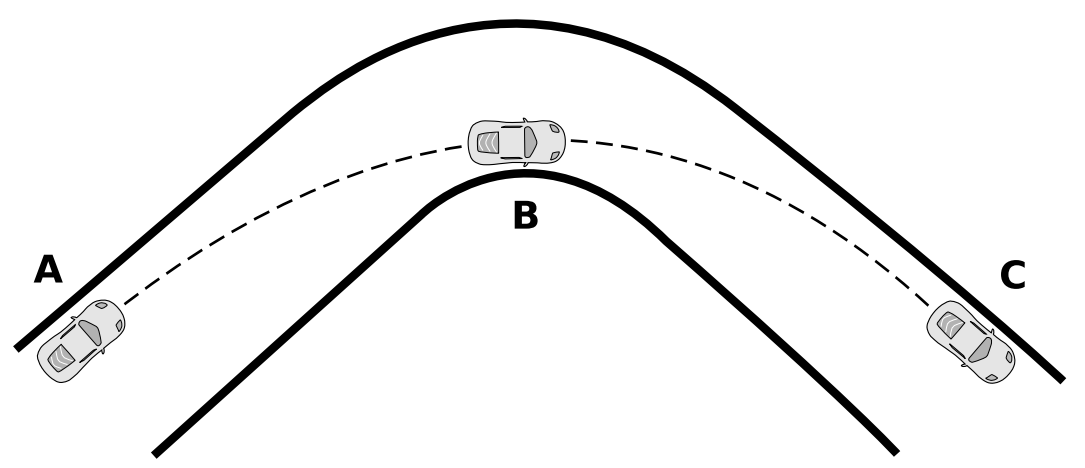

Figura 5.2: Etapas do ataque à curva. A: entrada; B: ápice; C: saída.

\section{Ataque à curva}

Diz-se que um piloto ataca a curva quando (estando na posição correta de preparação) direciona o carro de modo a apontá-lo para o ápice da curva (ponto B na Figura 5.2). Essa atitude resulta em uma trajetória que parte de um extremo da pista, a cruza e culmina no extremo oposto em um movimento que tangencia a curva.

Para realizar essa manobra em função do ângulo entre a direção do carro e a tangente da curva, usamos o controlador attackPID. Como o objetivo é alinhar o carro com a tangente da curva, o setpoint é fixado em zero. Já a direção alvo, a princípio, seria dada pelo ângulo de inclinação do sensor track (Tabela 1.1) que devolvesse a maior distância livre. Entretanto, isso faria com que o centro do carro passasse exatamente sobre o ponto de tangência da curva e, consequentemente, duas rodas ficariam para fora da pista. Para corrigir isso e manter as quatro rodas dentro dos limites do percurso, passamos como entrada do controlador um ângulo corrigido descontando $75 \% 2$ da largura do carro. Assim, a entrada corrigida é dada por:

$$
\text { entrada }=\alpha_{\text {sensor }}-\operatorname{direção~} \times \arctan \left(\frac{0,75 T}{\text { dist }_{\text {sensor }}}\right)
$$

Onde $\alpha_{\text {sensor }}$ é o ângulo do sensor escolhido, direção assume -1 ou +1 dependendo se a curva é para esquerda ou direita, $T$ é a constante $T R A C K$ com o valor da distância entre as rodas no mesmo

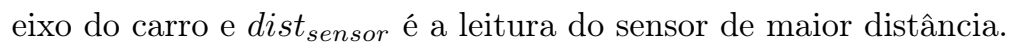

\section{Estabilização}

Após passar pelo ápice da curva em alta velocidade, o carro tem a tendência de cruzar novamente a pista (ponto $\mathbf{C}$ na Figura 5.2). Por isso, o fim da execução de uma curva consiste em estabilizar o carro o quanto antes. Isto é, deixá-lo alinhado com o eixo da pista, independentemente da posição em relação à largura da pista. O responsável em gerenciar o volante nessa tarefa é o controlador stabilizePID, o qual também mantém o setpoint em zero, assim como attackPID, porém o valor de entrada é dado pelo sensor angle (Tabela 1.1).

\section{Curvas em "S"}

Quando o circuito possui duas curvas curtas, seguidas e opostas uma a outra, diz-se que elas são curvas em "S", ou que ambas formam uma chicane. Evidentemente, para identificar essa composição, além do tipo do trecho onde o carro está, é preciso também avaliar o tipo do trecho seguinte. Ao enfrentar uma chicane, o piloto precisa tentar passar pelas curvas seguindo o trajeto com menor desvio possível, idealmente indo em linha reta.

\footnotetext{
2 Para que a roda interna passe exatamente pelo ponto de tangência, o cálculo deveria usar $50 \%$ da largura do carro. Apesar disso, escolhemos usar o valor de $75 \%$ para manter uma margem de segurança e evitar que alguma roda passe por fora da pista, mesmo quando o carro não conseguir seguir exatamente a direção pretendida.
} 


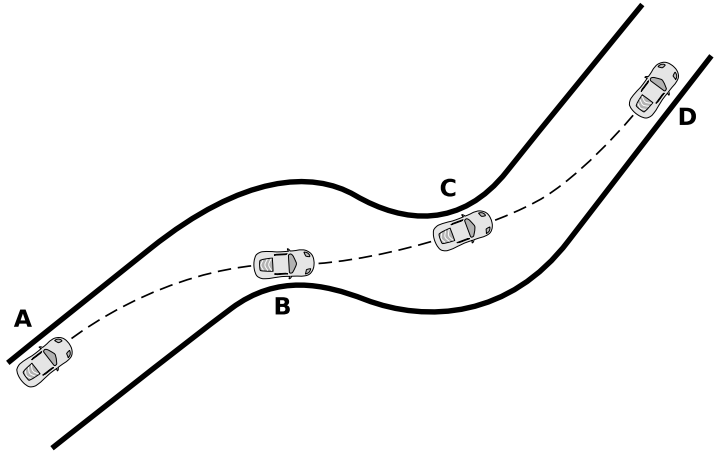

(a) Curva em "S". A. entra na curva B. carro atinge o ápice da curva, mas o carro não continua virando C. mesmo virando o volante, o carro segue em frente $\mathbf{D}$. carro jogado para fora da pista

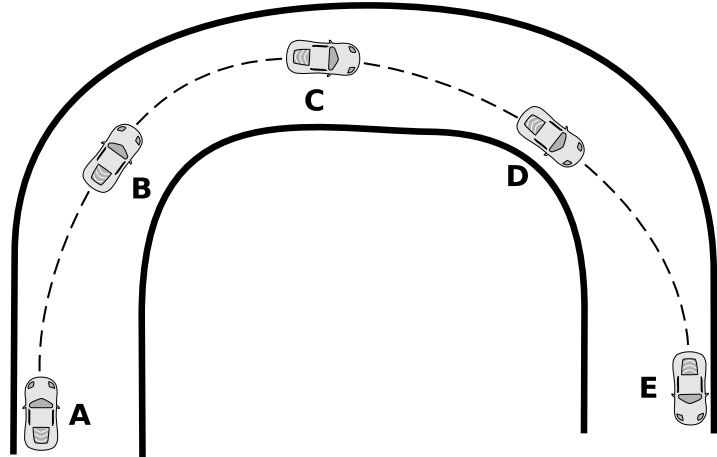

(b) Curva em "U". A. entra na curva B. traseira começa a sair $\mathbf{C}$. carro continua virando em torno do próprio eixo $\mathbf{D}$. carro gira completamente para fora da rota

Figura 5.3: Curvas em sequência.

Considerando os pontos de marcação da Figura 5.3a, na entrada da primeira curva (ponto A) é realizado um ataque simples com o controlador attackPID. Contudo, ao atingir o ápice da primeira curva (ponto B), aciona-se um modificador no controlador e o fator corretivo é desabilitado. Dessa forma, entre o ápice da primeira curva e o início da segunda, tenta-se seguir puramente o sentido mais livre. A partir do momento quando o carro entra na segunda curva, o piloto virtual interpreta que está em uma situação de ataque simples e se comporta de acordo com esse novo cenário.

\section{Curvas em "U"}

Chamamos de curvas em "U" as formações compostas por duas curvas seguidas para o mesmo lado, podendo ou não terem curvaturas distintas. Quando a sequência já começa com uma curva fechada, a estratégia é a mesma do ataque à curva simples, porém repetida duas vezes: ataque até o primeiro ápice, estabilização, ataque ao segundo ápice e estabilização final.

Já quando a primeira curva é mais suave, deve-se tentar manter o carro bem posicionado para virar fechado na segunda. A sequência de ações está exemplificada na Figura 5.3b. Na entrada da primeira curva (ponto A), o piloto inicia o ataque porém depois de percorrer apenas $20 \%$ do comprimento desse primeiro trecho, já usa-se o controlador preparePID com setpoint de 0,2. Assim, em vez de passar pelo ápice no ponto $\mathbf{B}$, o carro faz uma trajetória mais aberta, com mais velocidade, e chega ao fim da primeira curva (ponto $\mathbf{C}$ ) pronto para atacar a segunda com mais chances de conseguir atingir o segundo ápice (ponto $\mathbf{D}$ ) de forma correta.

Definidas as estratégias para responder a cada situação, é preciso realizar o processo de ajuste dos controladores PID como descrito no Capítulo 2. Como resultado, definimos os valores para as contantes de ganho de cada controlador. As Tabelas 5.6, 5.7 e 5.8 apresentam esses valores finais.

Tabela 5.6: Constantes de ganho do controlador de preparação para a curva seguinte.

\begin{tabular}{cc}
\hline preparePID \\
\hline$K_{p}$ & 0,06 \\
$K_{i}$ & 0,0 \\
$K_{d}$ & 3,0 \\
\hline
\end{tabular}

Tabela 5.7: Constantes de ganho do controlador de ataque à curva.

\begin{tabular}{ll}
\hline \multicolumn{2}{c}{ attackPID } \\
\hline$K_{p}$ & 0,4 \\
$K_{i}$ & 0,0005 \\
$K_{d}$ & 1,7 \\
\hline
\end{tabular}

Tabela 5.8: Constantes de ganho do controlador de estabilização do ângulo do carro em relação ao eixo da pista.

\begin{tabular}{cc}
\hline \multicolumn{2}{c}{ stabilizePID } \\
\hline$K_{p}$ & 1,5 \\
$K_{i}$ & 0,0003 \\
$K_{d}$ & 10,0 \\
\hline
\end{tabular}




\subsection{Sistemas auxiliares}

Carros reais, tanto de corrida quanto de passeio, são equipados com uma série de equipamentos e dispositivos de segurança que se dividem em duas categorias: $(i)$ Sistemas passivos, tais como cintos de segurança e airbags; e (ii) Sistemas ativos, como por exemplo o controle de tração. O objetivo dos sistemas passivos é garantir a segurança dos ocupantes do veículo durante acidentes. Em contrapartida, os sistemas ativos visam ajudar o motorista a manter o controle do carro e prevenir os acidentes.

Num ambiente virtual, embora não seja preciso zelar com afinco pelo bem-estar do piloto, é conveniente minimizar a ocorrência de incidentes como colisões e derrapagens. Dessa forma, o emprego de sistemas ativos de segurança se mostra muito interessante. $O$ funcionamento desses mecanismos exige apenas dados simples, como velocidade instantânea do carro, que já são diretamente acessíveis ao nosso agente. Outra vantagem de adotar essas funcionalidades está no fato delas também agirem como filtros, capazes de compensar um pouco a alta granularidade dos comando passados aos atuadores. A seguir, damos detalhes sobre os sistemas auxiliares adicionados ao carro de corridas.

\subsubsection{ABS}

A sigla ABS se refere a expressão Anti-lock Braking System e designa um sistema cujo principal objetivo é prevenir o travamento das rodas durante as frenagens. Quando as rodas estão travadas, o carro derrapa, fazendo com que a desaceleração seja menos eficiente e causando perda do controle de direção. Esse tipo de travamento acontece quando se aciona o freio com mais vigor que o necessário, o que é uma situação recorrente para o nosso piloto virtual. Como vimos anteriormente nesse capítulo, nosso agente só consegue empregar três intensidades de pressão ao pedal (0\%, $40 \%$ e 100\%). Ou seja, sem esse sistema auxiliar, constantemente há derrapagens e o carro fica muito sujeito a sair da pista.

O conceito geral do ABS consiste em monitorar a rotação das rodas, comparando com a velocidade linear do carro, identificando aquelas na iminência de travar e liberando individualmente o freio delas por uma fração de segundo. Em um carro real, muitos componentes estão envolvidos no cumprimento desse dever [Gar05], sendo que a maioria deles não tem paralelo em nosso ambiente de simulação. Apesar disso, ainda é possível produzir um efeito similar mesmo seguindo as restrições impostas pelo TORCS.

Primeiramente, precisamos formalizar a medida de slip, correspondente ao escorregamento. Para tal, seguiremos a Equação (5.2) [Gil92], onde o slip é uma porcentagem calculada em função da diferença entre a velocidade instantânea do carro e a velocidade linear que as rodas estariam proporcionando.

$$
\text { slip }=\frac{V_{\text {carro }}-V_{\text {rodas }}}{V_{\text {carro }}}
$$

Sabendo como medir o escorregamento, poderia-se supor que o ABS trabalharia para manter esse valor o mais próximo de zero possível. Entretanto, uma análise da variação da eficiência da frenagem em relação ao slip revela que uma quantidade moderada de escorregamento dos pneus é essencial para o processo de desaceleração [Gil92].

Mais precisamente, vemos pela Figura 5.4 que o melhor aproveitamento dos freios se dá quando a taxa de escorregamento está por vota de $20 \%$. Contudo, se manter nesse patamar de eficiência só é possível em teoria, pois o sistema como um todo é instável nessa situação [Gil92]: para um dado torque aplicado pelo freio, uma vez que a roda desacelera a ponto de atingir o grau ótimo de escorregamento, qualquer perturbação nessa condição acaba resultando em excesso de torque do freio, causando desaceleração ainda maior na roda. Com o aumento do escorregamento, o torque que o solo gera na roda diminui drasticamente e, por sua vez, a força do freio faz a roda desacelerar ainda mais, provocando o travamento e levando o índice de escorregamento a $100 \%$. 


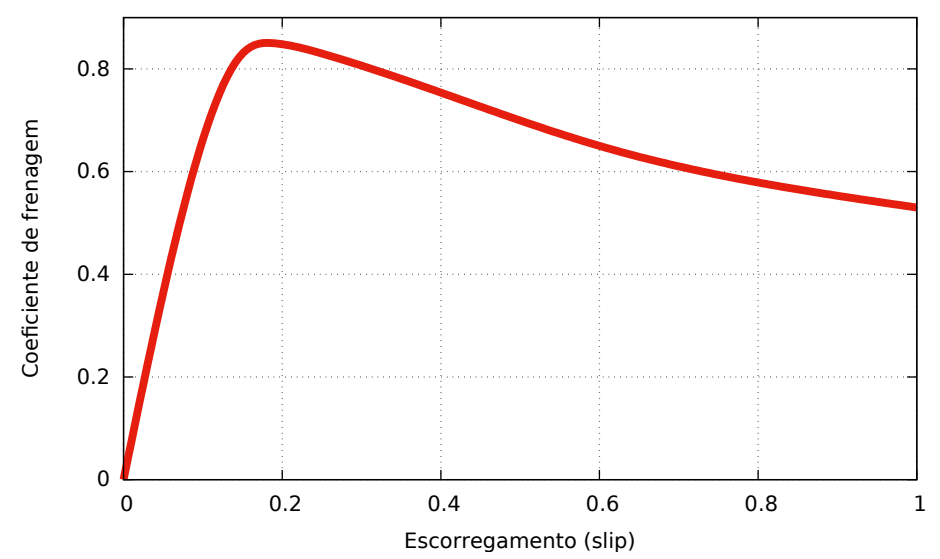

Figura 5.4: Eficiência da frenagem em função da taxa de escorregamento dos pneus.

Pilotos muito bem treinados e experientes são capazes de interpretar o comportamento de seus carros durante as freadas e "sentir" o nível de escorregamento. Com isso, eles conseguem dosar a pressão no freio de modo a manter o carro no limite da aderência, mas sem derrapar. Essa técnica se chama threshold braking e depende de tantas nuances que sua reprodução em um sistema automatizado se torna praticamente inviável. O ABS portanto não almeja prevenir completamente os escorregamentos, mas sim gerenciar o slip para mantê-lo em na faixa aceitável. Quando o valor medido extrapola essa faixa segura, o freio é momentaneamente liberado para o pneu recuperar aderência e, em seguida, volta-se a aplicar a frenagem.

Descrevemos no Algoritmo 11 o método que usamos para reproduzir no ambiente virtual o efeito do ABS. A rotina serve como um filtro, recebendo pela variável freio o valor bruto que o agente usaria para frear e devolvendo uma saída que ajuda a minimizar acidentes.

Dois detalhes adicionais que acrescentamos ao conceito original são as instruções das linhas 14 e 19 do pseudocódigo. O primeiro deles faz com que, no instante seguinte à liberação do freio em função de um travamento, a saída volte com um valor com alta chances de não bloquear novamente as rodas. $\mathrm{O}$ segundo ponto faz com que a intensidade da aplicação do freio cresça gradualmente até o nível desejado. Dessa forma, diminuímos ainda mais o risco de travamentos, pois o freio nunca é acionado abruptamente.

\subsubsection{ESC}

Outro sistema de segurança presente nos carros reais é o controle eletrônico de estabilidade (Electronic Stability Control). Quando o carro não está indo exatamente me linha reta, acelerar demais ou frear demais podem culminar na perda de estabilidade do veículo e falta de controle sobre a direção. Por conta disso, o objetivo do ESC é evitar que o carro não consiga seguir uma rota em curva por decorrência da falta de aderência nas rodas do eixo dianteiro ou do eixo traseiro. Essas duas situações estão ilustradas na Figura 5.5 e são chamadas respectivamente de understeer e oversteer.

\section{Understeer (subesterço):}

O understeer se dá quando o carro mantém uma trajetória quase em linha reta, independentemente das rodas estarem apontando no sentido da curva. Visualmente, o comportamento do carro passa a impressão de que o volante foi esterçado menos do que o necessário, como visto na Figura 5.5a.

Esse cenário está frequentemente associado a entrar com velocidade excessiva em uma curva, fazendo com que a inércia do carro supere o atrito dos pneus dianteiros com o solo. Além disso, o understeer também pode acontecer ao frear intensamente enquanto o volante não centralizado. 
1 ABS (freio)

2 se não estava freando no instante anterior então

3 últimoNívelEstável $\leftarrow 0$

4 últimoFreio gets 0

5 fim

$6 \quad v_{\text {carro }} \leftarrow$ pegaVelocidadeCarro() $\quad \triangleright$ Em metros por segundo.

$7 \quad v_{\text {rodas }} \leftarrow$ RaioRodas $\times \sum_{i=0}^{3}$ pegaRotaçãoRoda $(i)$

$8 \quad$ slip $\leftarrow \frac{v_{\text {carro }}-v_{\text {rodas }}}{v_{\text {carro }}}$

se slip $>0,2$ então $\quad \triangleright$ Derrapando

últimoFreio $\leftarrow 0,05 \triangleright$ Aplica apenas $5 \%$ de freio.

travouRoda $\leftarrow$ Sim

senão

se travouRoda então

$\triangleright$ Quando veio de um travamento, volta a frear em um nível seguro.

últimoFreio $\leftarrow 0,85 \times$ últimoNívelEstável

senão

últimoNívelEstável $\leftarrow$ últimoFreio

fim

se slip $\leq 0,18$ então $\quad \triangleright$ Escorregamento aceitável.

$\triangleright$ Incrementa gradualmente o sinal de saída até atingir o valor de entrada. últimoFreio $\leftarrow \operatorname{Min}(($ últimoFreio $+0,05)$, freio $)$

fim

travouRoda $\leftarrow$ Não

fim

devolva últimoFreio

24 fim

Algoritmo 11: Filtro ABS cuja entrada é o quanto se desejaria estar pisando no freio e a saída é um valor corrigido, que não faz o carro derrapar. 


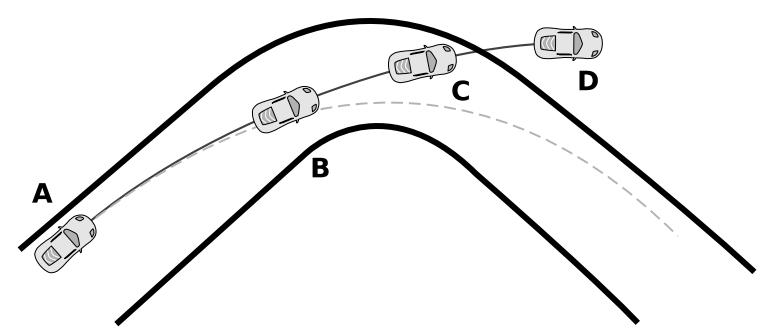

(a) Understeer: A. entrada na curva; B. rodas dianteiras perdem aderência e perde-se completamente o controle da direção; C. mesmo virando o volante, o carro segue em frente; D. carro jogado para fora da pista.

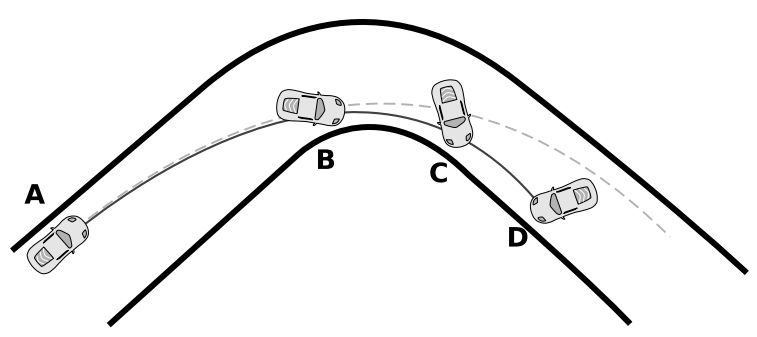

(b) Oversteer: A. entrada na curva; B. rodas traseira perdem aderência e o carro começa a girar em torno do próprio eixo; C. carro desliza lateralmente enquanto gira; D. carro aponta completamente para fora da rota pretendida.

Figura 5.5: Efeitos da perda de aderência nas rodas dianteiras e traseiras.

\section{Oversteer (sobresterço):}

Em contraposição ao item anterior, o oversteer se caracteriza pelo carro virar mais que a trajetória desejada, em um movimento de rotação em torno do próprio eixo (Figura 5.5b). Por conta disso, tem-se a impressão de que o volante foi mais esterçado do que necessário.

O oversteer acontece quando os pneus traseiros ficam sem aderência, deixando de acompanhar a direção ditada pelos pneus dianteiros. Em veículos com tração traseira, como a maioria dos carros de corrida, o oversteer geralmente acontece quando se acelera em demasia durante uma curva ${ }^{3}$.

O funcionamento do ESC se aproveita de muitos dos mecanismos do ABS. O sistema de estabilidade compara o curso desejado pelo motorista (indicado pelo volante) com o movimento real do veículo. Quando se detecta uma condição de instabilidade, o ESC aciona individualmente os freios das rodas que estão no mesmo lado para onde deseja-se virar forçando o carro a girar para a orientação correta. Além disso, o sistema também gerencia a distribuição do torque do motor para as rodas.

Dessa forma, o sistema consegue contribuir muito para a manutenção do controle sobre o carro. Entretanto, apesar da similaridade do ESC com o ABS ser uma vantagem no mundo real, para o uso no nosso ambiente de simulação é uma desvantagem. Como vimos na seção sobre ABS, embora seja possível medir a velocidade angular de cada roda, o piloto virtual não tem meios para comandar o freio de cada roda individualmente.

Dadas as limitações, nosso modo de combater o understeer e oversteer atua de forma mais indireta sobre a rotação do carro. A cada instante, a velocidade de deslocamento perpendicular à direção do carro é medida. Esse parâmetro indica o quanto o carro está escorregando lateralmente e, com base nisso, o acelerador ou o freio, dependendo do casso, recebe um fator atenuante. Em situações extremas, com velocidade lateral maior que $4 \mathrm{~m} / \mathrm{s}$, abdica-se completamente de acelerar ou frear em prol de recuperar a aderência dos pneus.

\footnotetext{
${ }^{3}$ A situação de oversteer pode se tornar relativamente estável quando se vira o volante em contraposição ao sentido de rotação do carro e dosando a pressão no acelerador. Dessa forma, o piloto consegue manter o controle da trajetória mesmo enquanto derrapa. Essa técnica é chamada de drifting.
} 


\section{Capítulo 6}

\section{Experimentos e análises}

Neste capítulo, expomos os resultados dos testes práticos realizados com o agente construído. Na primeira seção, descrevemos o ambiente e as pistas usados nos experimentos. Na segunda seção, retratamos os experimentos para determinar os valores adequados para os parâmetros de aprendizagem. Na seção seguinte, damos detalhes de dois controladores concorrentes também desenvolvidos para o TORCS e comparamos seu desempenho com os resultados de nosso piloto virtual. Por fim, na quarta seção apresentamos uma reflexão sobre as características de nosso agente.

\subsection{Ambiente de testes}

No Capítulo 1, listamos algumas características do simulador de corridas TORCS que são interessantes para propósitos acadêmicos. Por conta dessas qualidades, o jogo tem sido amplamente usado como plataforma de testes para algoritmos de inteligência artificial $\left[\mathrm{OPG}^{+} 12\right]$ e, em decorrência disso, torneios têm sido realizados várias conferências internacionais, tais como $\mathrm{WCCI}^{1}, \mathrm{CEC}^{2}, \mathrm{EVO}^{* 3}, \mathrm{GECCO}^{4} \mathrm{e} \mathrm{CIG}^{5}$.

As competições permitem aos pesquisadores divulgar seus trabalhos e por à prova os controladores desenvolvidos. O primeiro campeonato acadêmico de corridas de carros simuladas usando o TORCS aconteceu em 2008 no IEEE World Congress on Computational Intelligence (WCCI) [LTL ${ }^{+}$08]. No ano seguinte, o torneio recebeu o nome Simulated Car Racing Championship (SCRC) [LLT ${ }^{+}$10], o qual passou a ser usado nas edições posteriores. Nesse novo formato, os organizadores proveem uma interface padrão entre o jogo e os controladores definida por sensores e atuadores (apresentados nas Tabelas 1.1 e 1.2 ) fazendo analogia aos dispositivos encontrados em carros autônomos do mundo real.

Trabalhos com abordagens variadas são submetidos às competições, indo de algoritmos de controle baseados puramente em heurísticas até a agentes com sistemas de IA muito elaborados. A fim de comparar o desempenho de nosso piloto virtual com os controladores desenvolvidos por outros pesquisadores, nosso projeto foi construído com base no software disponibilizado para o SCRC [scr12].

As pistas usadas nos experimentos estão mostradas na Figura 6.1. Todas acompanham a instalação padrão do TORCS e são do grupo de circuitos asfaltados, com características similares às de autódromos reais. O modelo de carro usado foi car1-trb1, com 4,52m de comprimento, 1,9m de largura, massa de $1150 \mathrm{~kg}$ (além de $94 \mathrm{~kg}$ de combustível), motor com potência de $405 \mathrm{~kW}$ (aproximadamente $543 \mathrm{hp}$ ) e tração traseira.

\footnotetext{
${ }^{1}$ http://www2.mae.cuhk.edu.hk/wcci2008

${ }^{2}$ http://www.cec-2009.org

${ }^{3}$ http://www.evostar.dei.uc.pt

${ }^{4}$ http://www.sigevo.org/gecco-2012/competitions.html\#scrc

${ }^{5}$ http://geneura.ugr.es/cig2012/competitions.html
} 


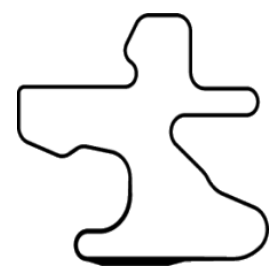

(a) alpine-2

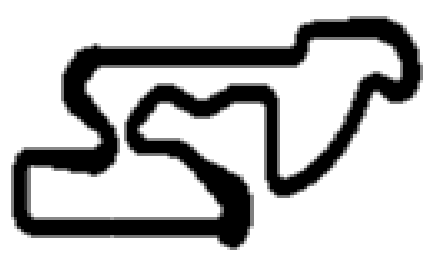

(b) e-track-2

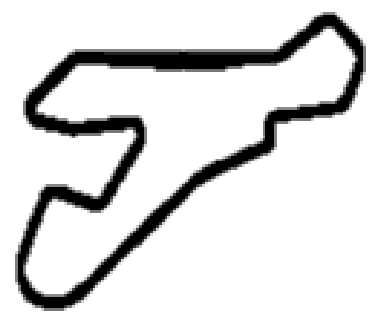

(c) e-track-3

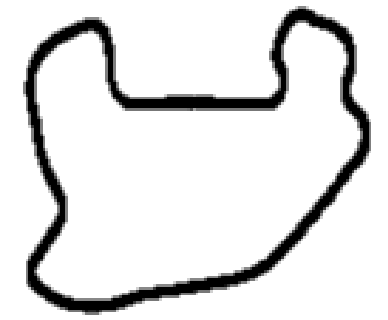

(d) e-track-4

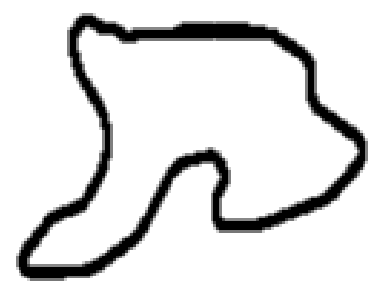

(e) e-track-6

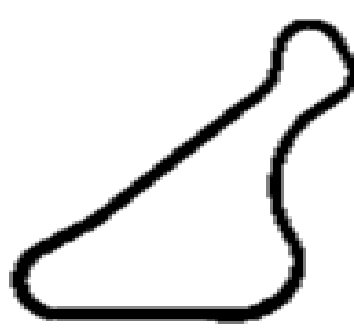

(f) g-track-1

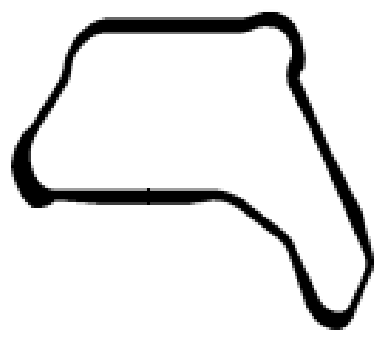

(g) g-track-2

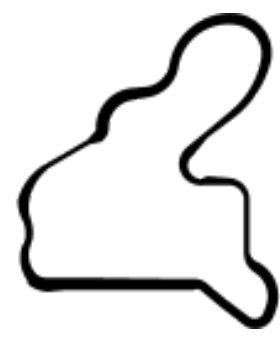

(h) g-track-3

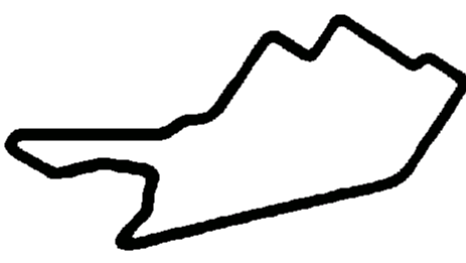

(i) street-1

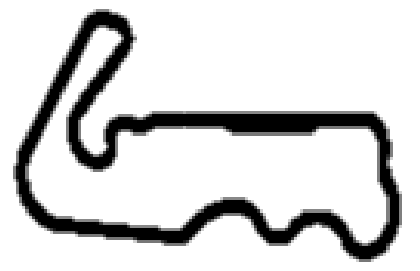

(j) wheel-1

Figura 6.1: Silhuetas das pistas usadas nos experimentos.

Todos os testes foram executados em um computador com sistema operacional Linux, processador com dois núcleos de 2, 27GHz e $4 G B$ de RAM. Além disso, o simulador recebeu dois parâmetros modificadores: -nofuel e -nodamage. A primeira opção desativa o consumo de combustível, fazendo com que o tanque do carro permaneça sempre cheio. A segunda opção desliga a simulação de danos e avarias causados por batidas, bem como o desgaste dos pneus. A motivação para tais escolhas foram principalmente:

- Possibilitar que o carro permaneça correndo na pista por um número arbitrariamente grande de voltas sem a necessidade de entrar nos boxes para reabastecer;

- Manter o desempenho do carro constante durante o processo de aprendizagem de modo que as mudanças de comportamento sejam o único elemento variável influenciando as tomadas de tempo em cada volta.

Com essa estruturação, as baterias de testes consistem em deixar o agente correr por 300 voltas em cada uma das dez pistas citadas. Para esse procedimento, desativamos a interface visual do TORCS a fim de reduzir o tempo dos experimentos. Entretanto, ainda assim a execução de cada sequência de testes consumiu aproximadamente 4 horas. 


\subsection{Experimentos}

No Capítulo 5, descrevemos o cerne do processo de aprendizagem de nosso piloto virtual, onde é possível observar a presença dos parâmetros $\alpha, \gamma$ e $\lambda$. Esses componentes são usados para ajustar as regras de atualização das estimativas de recompensa total esperada por cada ação na matriz $Q$. Abaixo listamos a interpretação dada a esses termos.

$\alpha$ : Representa a taxa de aprendizado. Quanto maior for essa taxa, mais enfase se dá às experiências recém adquiridas. Para valores pequenos, as recompensas recentes pouco alteram as estimativas em $Q$. Quando $\alpha=0$, o aprendizado se interrompe;

$\gamma$ : É o fator de desconto. Ele indica a atenuação que o valor de recompensas futuras recebe por ser avaliado no tempo presente;

$\lambda$ : $\quad$ É o fator de decaimento do traço. Quanto mais distante no histórico estiver uma ação, menor será a fração $\lambda$ que indica seu impacto no presente.

Nota-se claramente que $\lambda$ é um componente variável em relação ao quão longe se retrocede no traço de ações. O termo constante é na verdade o valor de inicialização e decaimento LAMBDA, presente no Algoritmo 10. Por simplicidade de notação, nesta seção usaremos o símbolo $\lambda$ quando estivermos nos referindo à constante LAMBDA.

A fim de determinar os valores para esses parâmetros, investigamos uma série de combinações e analisamos as alterações no comportamento do agente. As avaliações se deram principalmente pela leitura dos registros de tempo de volta e recompensa acumulada por volta. Na Figura 6.2 apresentamos um exemplo de gráfico composto gerado a partir da junção desses registros. A sequência superior de pontos indica, em segundos, o tempo gasto para completar cada volta durante a aprendizagem. Os pontos da camada inferior representam as somas das recompensas que alteraram as estimativas em $Q$, também a cada volta.

Vale salientar que, por conta de nossa estratégia das recompensas terem um caráter quase sempre punitivo, os pontos desse gráfico tentem a ser predominantemente negativos. Assim, quando o aprendizado se estabiliza, as recompensas por volta completada tendem a ser nulas, ou muito próximas a zero. Em casos como esse, dizemos que o aprendizado convergiu e a política resultante é simplesmente a ação de maior valor esperado em cada estado na matriz $Q$ ao final do teste.

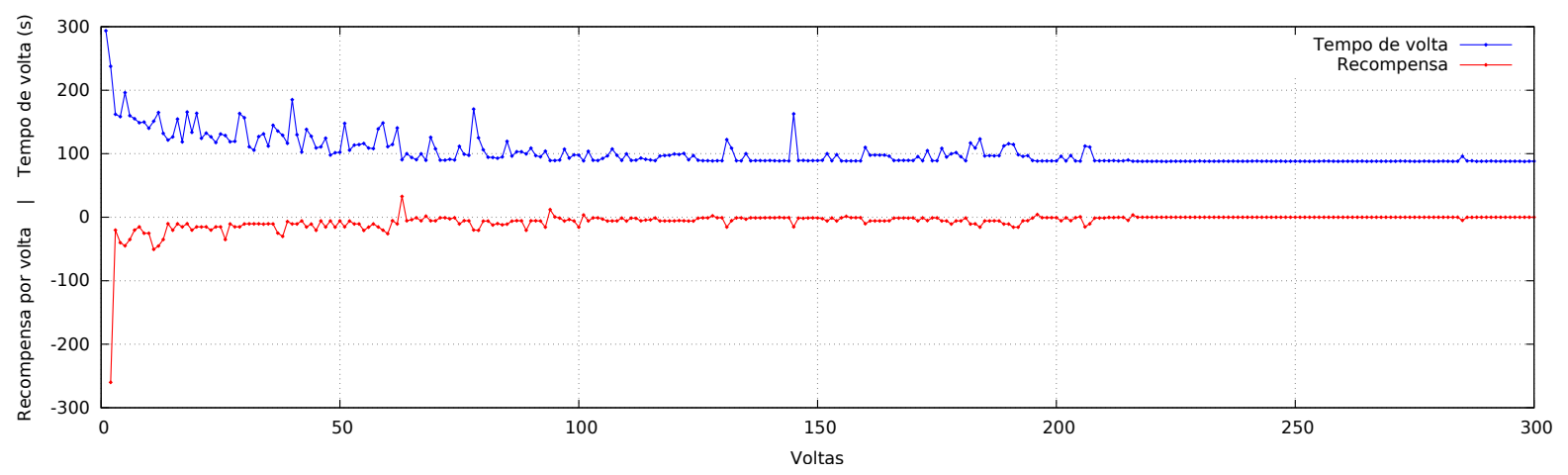

Figura 6.2: Tempo e recompensa acumulada de cada volta na pista e-track-2.

Tendo definido uma ferramenta prática para a análise das seções de aprendizado do piloto virtual, conduzimos experimentos com diversas combinações de valores para $\alpha, \gamma$ e $\lambda$. O objetivo foi determinar qual o conjunto de valores mais adequado ao nosso agente. Os critérios para a avaliação dos resultados em cada pista foram: 
- O aprendizado deve convergir em todas as pistas da bateria de testes. Isto é, ao final de cada experimento, o piloto virtual deve estar dirigindo sem sair da pista e sem grande variação nos tempos das últimas voltas;

- O desempenho do piloto nas últimas voltas deve ser próximo ao de sua melhor volta. Ou seja, o tempo das últimas voltas deve estar estável e próximo ao de sua volta mais rápida;

Pela investigação dos registros de cada seção de testes, observamos que a variação de valores dos parâmetros apresenta pouca influência no desempenho geral do agente. Ou seja, mesmo com diferentes valores em cada termo, não constatamos diferenças significativas no tempo médio das últimas voltas quando o aprendizado convergia. Apesar disso, percebemos que a convergência de nosso método é sensível a mudanças em $\lambda$.

Um caso no qual o aprendizado não conseguiu convergir pode ser visto na Figura 6.3. Os parâmetros desse teste foram $\alpha=0,1, \gamma=0,9$ e $\lambda=0,3$. Acreditamos que a causa desse fenômeno esteja relacionada ao valor de $\lambda$ ser inferior ao ideal. Com isso, o mecanismo de recompensas aplica punições muito atenuadas às ações relacionadas ao carro parar ou sair da pista. Assim, há pouca distinção entre as atitudes que levam a acidentes e aquelas que são punidas simplesmente por não contribuírem para a diminuição no tempo de volta. Consequentemente, o piloto virtual acaba insistentemente escolhendo ações problemáticas.

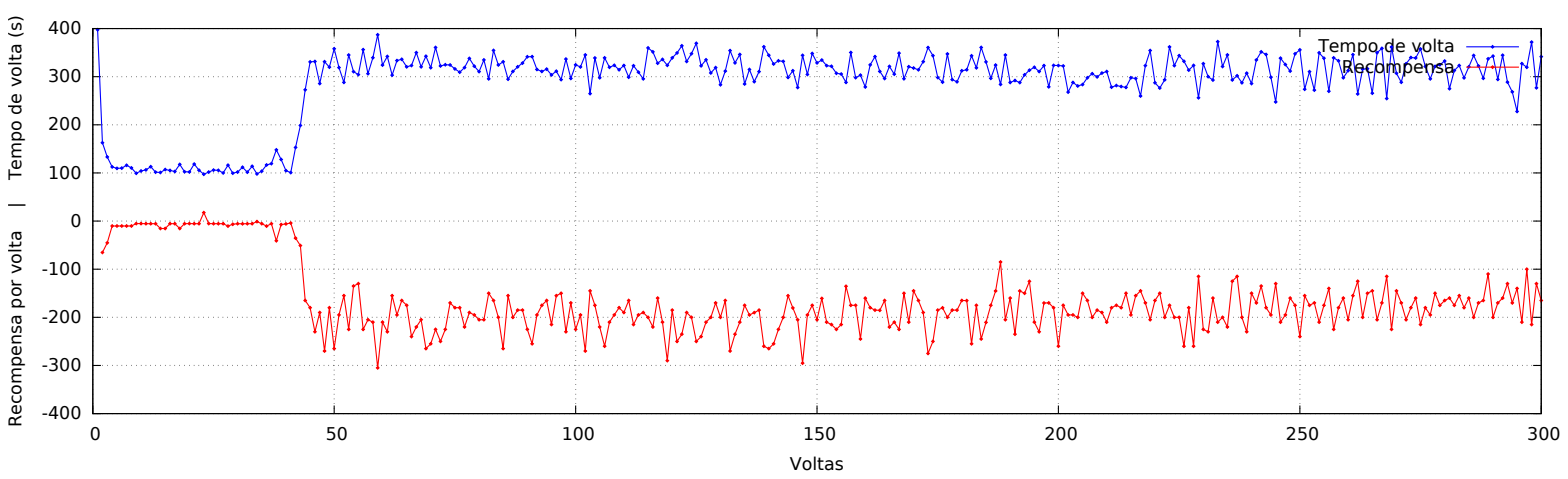

Figura 6.3: Resultado do teste $\operatorname{com} \alpha=0,1, \gamma=0,9$ e $\lambda=0,3$ na pista wheel-1, no qual o aprendizado não convergiu a uma política estável.

Quando $\lambda$ é configurado com valores maiores que o ideal, observamos efeito semelhante de falta de convergência, porém a causa é o inverso do caso anterior. Os acidentes estão associados a várias ações, entretanto nem todas elas são diretamente responsáveis pelo ocorrido. Dessa forma, altos valores de $\lambda$ fazem com que a punição decaia pouco à medida que é aplicada às ações ao longo do histórico. Assim, novamente tem-se um cenário onde muitas ações são erroneamente avaliadas como igualmente ruins.

Como fruto dessas verificações, concluímos que $\lambda=0,4$ é a configuração que torna o aprendizado mais consistente em todas as pistas testadas. Embora impacto das variações nos termos $\alpha$ e $\gamma$ tenha se mostrado muito menos expressivo, os valores que resultaram em tempos médios de volta marginalmente inferiores foram: $\alpha=0,1$ e $\gamma=0,9$.

Por conta do grande volume de registros de tempo e recompensas proveniente da bateria de testes, julgamos não ser interessante sobrecarregar o leitor com toda a massa de dados adquiridos. Porém, apresentamos no Apêndice B todos os gráficos obtidos pelos experimentos realizados com a combinação final de $\alpha=0,1, \gamma=0,9$ e $\lambda=0,4$ em cada uma das dez pistas da Figura 6.1. 


\subsection{Pilotos concorrentes}

Uma das metas deste trabalho é fazer nosso piloto virtual completar voltas o mais rápido possível. Mas quão baixo precisa ser o tempo de uma volta para ela ser considerada "rápida"? Uma forma de responder a essa questão é convocar especialistas e coletar dados sobre seu desempenho no simulador. Entretanto existem desvantagens inerentes a essa solução, dentre elas:

- A dificuldade em se encontrar pessoas que sejam especialistas em pilotar os carros do TORCS, um jogo sem o grande público dos títulos comerciais;

- Os especialistas não estariam sujeitos às mesmas restrições que o piloto virtual, como "enxergar" a pista apenas pelas informações dadas pelos sensores;

- Se as limitações do piloto virtual fossem artificialmente impostas aos especialistas, a situação de uso do simulador seria tão diferente do convencional que provavelmente o desempenho das pessoas seria muito inferior ao esperado de um perito.

Uma alternativa é avaliar outros agentes construídos especificamente para o TORCS, tais como os submetidos para o SCRC. Essa opção contorna as dificuldades listadas acima e foi a escolha tomada para esse projeto. Dentre os concorrentes enviados ao SCRC, dois se destacaram por seu desempenho formidável: AUTOPIA e Mr. Racer. Por essa razão, nós sujeitamos esses competidores aos mesmos testes realizados com nosso piloto virtual e usamos seus resultados como base de comparação. A seguir, apresentamos mais detalhes desses dois controladores.

\subsubsection{AUTOPIA}

A primeira participação do controlador que posteriormente recebeu o nome AUTOPIA deu-se no ano de 2009 [LLT ${ }^{+}$10]. A proposta do trabalho é apresentar uma arquitetura modular onde cada um dos módulos é independente e se encarrega de gerenciar um tipo básico de ação necessária para guiar o carro [OPA $\left.{ }^{+} 09\right]$. Os componentes da arquitetura são:

Controle de marchas: Responsável por monitorar o número de rotações por minuto (RPM) do motor e efetuar a troca de marchas. As trocas são feitas com base em um mapa de valores máximos e mínimos de RPM, de forma semelhante ao método usado em nosso piloto virtual, como apresentado no Capítulo 5;

Velocidade alvo: Este módulo calcula a velocidade desejada em cada trecho da pista usando um sistema de regras baseadas em lógica fuzzy;

Acelerador e freio: Os pedais do acelerador e freio são acionados em função da diferença entre a velocidade alvo e a velocidade instantânea do carro.

Volante: O módulo que guia a direção do carro identifica três situações distintas: (i) andando com marcha ré; (ii) carro do lado de fora da pista; e (iii) carro estando dentro dos limites da pista. No caso mais frequente, item (iii), o volante é regido puramente por uma ponderação entre as leituras das distâncias provenientes dos sensores track;

Gestão de oponentes: O último componente da arquitetura atua como modificador dos controles de acelerador, freio e volante de modo a evitar colisões e efetuar ultrapassagens. 
Além disso, esse controlador também conta com um sistema para se adaptar às particularidades de cada pista: os locais de ocorrência de eventuais acidentes são registrados e tem-se mais cautela ao passar por esses pontos através de uma redução arbitrária da velocidade alvo. Esses fatores em conjunto resultaram na classificação final em segundo lugar na competição de 2009. O projeto então passou a ser continuamente aprimorado com o emprego de algoritmos genéticos para otimizar simultaneamente os parâmetros de controle do volante e velocidades alvo [OPG $\left.{ }^{+} 12\right]$. No ano de 2010, AUTOPIA conquistou o primeiro lugar na disputa e passou a ser considerado o estado da arte, deixando de concorrer no torneio mas ainda sim participando a título de servir como parâmetro de comparação.

\subsubsection{Mr. Racer}

Outro projeto de destaque é o controlador batizado de Mr. Racer, o qual foi apresentado pela primeira vez em um trabalho focado no uso de técnicas de planejamento para pilotar carros no simulador TORCS [QPKR10]. Um requisito forte da abordagem escolhida é ter um modelo acurado da pista. Para atender tal demanda, usa-se intensamente todos os 19 sensores track disponíveis de modo a definir uma série de vetores que descrevem as bordas da pista. Esse modelo é convertido em uma representação abstrata dos trechos da pista. Cada trecho é classificado de acordo com o parâmetro de curvatura, sendo rotulados por:

- Reta;

- Reta próxima a uma curva;

- Curva de alta velocidade;

- Curva de média velocidade;

- Curva de baixa velocidade;

- Curva do tipo grampo(hairpin).

O volante é controlada pela heurística ingênua de seguir a direção do sensor track que devolve o maior valor. O controle do acelerador e freio segue uma função linear para cada um dos seis cenários listados acima. Os parâmetros dessas funções são determinados por uma estratégia evolutiva que precisa ser processada previamente à corrida.

Em sua primeira participação no SCRC, Mr. Racer conquistou a terceira posição da disputa de 2010, competindo diretamente contra AUTOPIA. Nos três anos seguintes, o controlador AUTOPIA participou apenas como elemento comparativo e Mr. Racer recebeu aperfeiçoamentos [QPR11]. A estratégia de evolução do gerenciamento do acelerador e freio passou a ser a Adaptação de Matrizes de Covariância (CMA-ES) e houve melhorias na forma de se lidar com carros adversários. Além disso, o agente também recebeu um novo módulo de aprendizado, responsável por adaptar o comportamento planejado às particularidades de cada pista. Dessa forma, Mr. Racer venceu as competições de 2011, 2012 e 2013.

\subsubsection{Comparações}

Para comparar o desempenho de nosso piloto virtual em relação a AUTOPIA e Mr. Racer, realizamos para cada controlador uma bateria de testes com as dez pistas apresentadas na Figura 6.1. Nosso agente correu por 300 voltas em cada pista. Já AUTOPIA e Mr. Racer passaram por uma etapa de aquecimento antes de cada prova, pois esse é o procedimento realizado no SCRC. As médias dos tempos de volta foram calculadas depois da estabilização do comportamento dos controladores e esses resultados estão condensados na Figura 6.4.

No geral, o desempenho de nosso piloto virtual foi inferior ao de seus concorrentes. Os piores resultados se deram nas pistas e-track-4 e street-1, com diferenças de aproximadamente $60 \mathrm{~s}$ e $40 \mathrm{~s}$ respectivamente. Surpreendentemente, em g-track-3 a diferença foi de apenas $2 s$ e em e-track- 2 fomos $5 s$ mais rápidos que Mr. Racer. Nas demais pistas, a diferença média de tempo foi de aproximadamente $13 \mathrm{~s}$. 


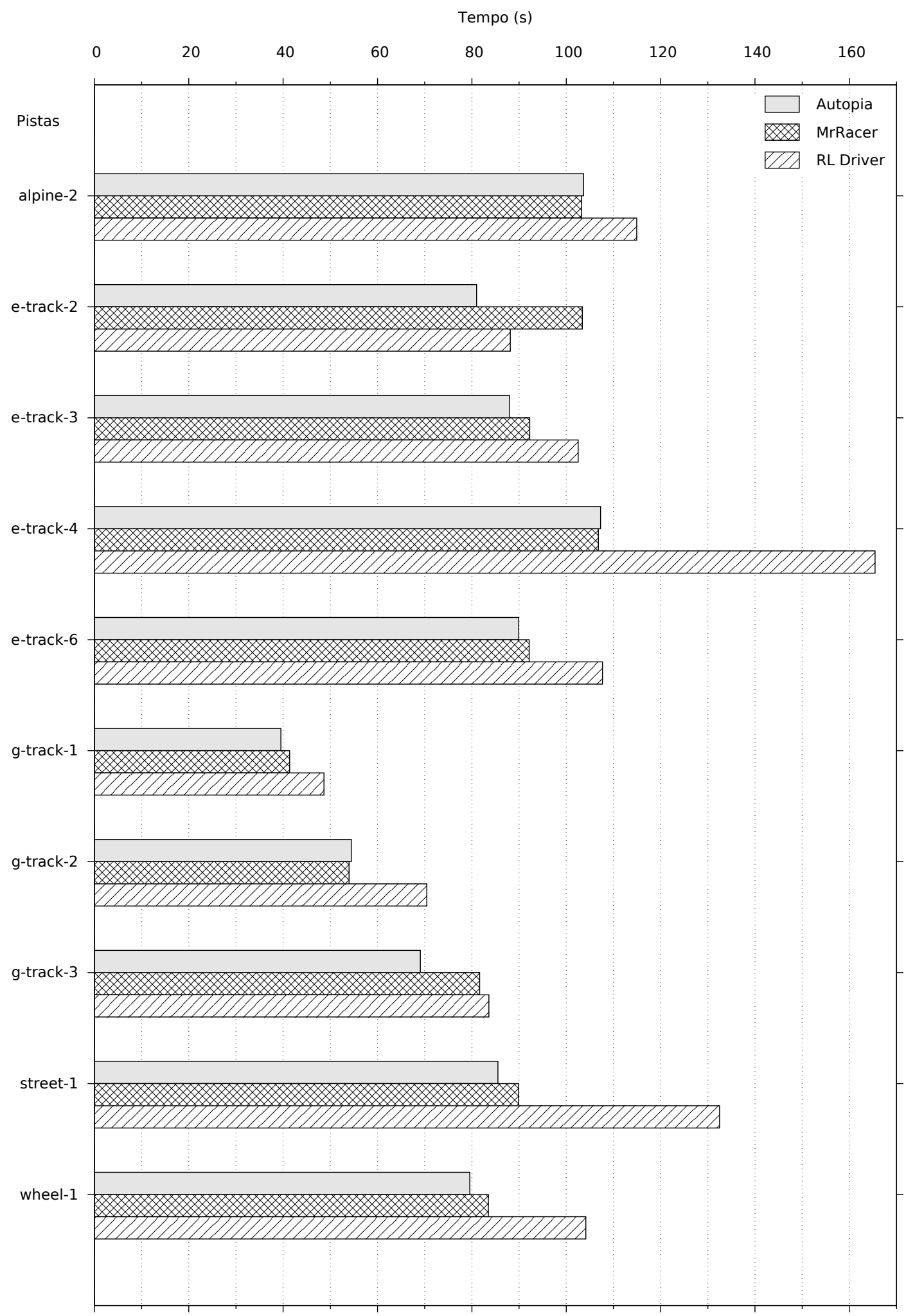

Figura 6.4: Comparação entre os tempos médios de volta dos pilotos analisados. Os resultados referem-se à média de 40 voltas após o aprendizado dos pilotos ter convergido, sendo que "RL Driver" é o nosso agente. 


\subsection{Discussão}

Analisar a evolução do agente durante o processo de aprendizagem, tanto através dos registros de tempo e recompensas quanto pela interface visual do TORCS, nos instigou algumas reflexões. A seguir discutimos sobre algumas questões relacionadas ao comportamento do piloto virtual.

\subsubsection{Aprendizado humano vs. aprendizado de máquina}

Um dos instintos básicos do ser humano é a autopreservação. Por conta disso não é surpreendente notar que pessoas inexperientes na atividade de pilotar carros tendem a ser cautelosas durante suas primeiras experiências em pistas de corrida. Seja conduzindo carros convencionais ou karts, a maior prioridade do aspirante a piloto é manter o carro na pista, evitando assim se machucar ou colocar a própria vida em risco. Fazer voltas velozes é uma etapa secundária em seu aprendizado.

Entretanto, os simuladores eliminam o perigo de ferimentos reais e o temor pela própria segurança deixa de existir. Dessa forma, em seções de corrida simulada, a tendência se inverte e frequentemente observa-se iniciantes acelerando displicentemente e protagonizando grandes colisões. Mas logo as pessoas entendem melhor como controlar o carro virtual e passam para um estado de cautela muito semelhante ao da situação real descrita anteriormente.

Em ambas as condições, uma vez que as pessoas dominam o controle do carro, virtual ou real, elas passam então a tentar diminuir o tempo de suas voltas. Nessa fase, o aprendiz praticamente não se envolve mais em acidentes e tenta ser o mais contante possível em todas as voltas, experimentando mudar de comportamento em poucas curvas, ou em apenas uma. Assim, usa-se a medição de tempo para avaliar os comportamentos e buscar o melhor. Resumidamente, podemos então dizer que o aprendizado das pessoas passa por três etapas: displicência e envolvimento em vários acidentes; cautela e tentativa de controlar o carro para dirigir com segurança; aprimoramento pela busca gradual do melhor tempo.

O piloto virtual, por sua vez, mostrou um processo de aprendizagem completamente diferente. Em vez de passar pelas etapas listadas acima, os registros dos experimentos nos mostram que o agente repetidamente sai da pista ou para o carro até um dado momento quando os acidentes cessam. A partir desse ponto, o piloto virtual já está fazendo suas melhores voltas, não havendo uma melhora gradual nos tempos tomados como inicialmente esperávamos. A Figura 6.2 mostra esse fato: picos nos tempos de volta alinhados a punições acentuadas (associados a ocorrência de acidentes) são frequentes até aproximadamente a volta 220, quando o piloto estabiliza seu desempenho.

Acreditamos que a causa desse fenômeno esteja relacionada aos múltiplos estímulos de feedback que o agente recebe durante toda a volta, além de apenas o tempo total acumulado. Assim, o piloto virtual consegue ponderar sobre seu comportamento sem depender exclusivamente do cronômetro. De certo modo, pode-se entender que em vez de tentar dominar o circuito curva a curva como um humano faria, o agente aprende sobre todos os trechos simultaneamente. Em decorrência disso, quando ações que levam a acidentes param de ser tomadas, a política já está próxima ao melhor conjunto de escolhas que o controlador consegue determinar.

\subsubsection{Topologia das pistas}

Uma questão com a qual nosso piloto virtual não consegue lidar é a eventual ocorrência de elevações e declives nas pistas. Uma vez que nenhum dos sensores disponíveis no carro é capaz de indicar a presença de subidas e descidas, nossa abordagem sempre produz modelos de pista planificados.

Sem informações sobre esse tipo de característica, o agente não consegue diferenciar descidas e retas planas, por exemplo. Isso se mostra um problema, pois esses dois trechos podem receber a mesma classi- 
ficação, porém evidentemente exigem comportamentos distintos. Em uma descida, o piloto precisa chegar ao final da reta com velocidade inferior ao normal a fim de evitar que se saia da pista.

Um desafio especialmente difícil para nosso agente se dá em pistas com uma ocorrência de uma (ou poucas) descida(s) em um tipo de trecho que se repete várias vezes no circuíto, porém com altura constante. Nesses cenários, o mecanismo de aprendizagem se contradiz ao punir ações que levam a acidentes (na descida), como acelerar, e também punir ações que fazem o carro andar muito devagar (nos trechos normais). Dessa forma, todas as alternativas de ação se mostram opções de baixo valor e o agente tente alternar indefinidamente em sua escolha.

Isso faz com que o aprendizado não convirja, resultando em um histórico de tempos de volta e recompensas similar ao apresentado na Figura 6.3. Por conta desse fator, nossa bateria de experimentos com 300 voltas não incluiu algumas pistas usadas nos testes de segmentação e classificação mostrados no Apêndice A.

A princípio, não há formas simples de se identificar elevações e declives em virtude da falta de sensores preparados para essa tarefa. Portanto, uma forma de se lidar com essa questão é seguir a abordagem implementada no AUTOPIA e Mr. Racer: adicionar ao controlador um módulo que monitora a frequência de acidentes em cada trecho e torna as ações mais cautelosas nessa região. Porém isso já é uma solução personalizada para cada pista. Ou seja, mesmo que o agente seja inicializado com uma boa política, ainda sim será preciso passar por acidentes até que essa solução tenha efeito.

\subsubsection{Q-Learning tabular e discretizações}

Uma das restrições impostas pelo uso do Q-Learning tabular baseado na equação de Bellman é a necessidade de se trabalhar com espaços discretos de estados e ações. Neste projeto, os dois principais atributos contínuos que precisaram ser interpretados discretamente foram: a velocidade instantânea do carro, usada para determinar em qual estado se está; e o sinal composto da intensidade de acionamento dos pedais do acelerador e freio. A medição da velocidade foi dividida em 5 intervalos e o sinal para os atuadores dos pedais também foi fragmentado em 5 patamares, como mencionado no Capítulo 5.

Esse tipo de limitação certamente impacta no desempenho do agente, embora essa influência negativa tenha se mostrado menos severa do que estimávamos. No caso do controle do acelerador e freio, acreditamos que o emprego dos sistemas auxiliares descritos no Capítulo 5 contribuiu para mitigar o efeito da discretização. Embora as respostas do mecanismo de aprendizado se restrinjam a 5 alternativas, esses sistemas repassam aos atuadores um sinal filtrado com transições menos abruptas.

Em contrapartida, a avaliação do estado no qual o carro se encontra precisa indicar alguma linha na matriz $Q$. Portanto, a granularidade dos intervalos de velocidade está diretamente relacionada a maldição da dimensionalidade. Uma forma de atacar essa questão é substituir a matriz $Q$ por um aproximador de função valor. Essa abordagem aproveita técnicas de aprendizado supervisionado, tais como redes neurais artificiais, para ajustar os parâmetros do aproximador. Muitos trabalhos têm adotado soluções dessa categoria, inclusive apresentando conclusões positivas sobre a robustez do emprego de aproximadores $\mathrm{CMAC}^{6}$ no Aprendizado por Reforço [Sut96].

Outra opção ainda seria seguir os trabalhos relacionados a Aprendizagem por Reforço em lote, como o Fitted Q-Iteration [EGW05]. Algoritmos dessa categoria reformulam os problemas de Aprendizagem por Reforço como sequências de problemas convencionas de aprendizado supervisiondado. Sua principal característica é o alto aproveitamento dos dados coletados durante o aprendizado, pois todas as transições de estados são armazenadas e a atualização das estimativas de valor é realizada simultaneamente em todo o lote de transições.

${ }^{6}$ Cerebellar Model Articulation Controller 


\section{Capítulo 7}

\section{Conclusão}

Nesta dissertação, apresentamos uma breve introdução aos principais trabalhos no campo da condução autônoma de veículos, dando ênfase àqueles elaborados sobre o simulador de corridas TORCS. Expomos como competições acadêmicas adotando simuladores realistas encorajam pesquisas que podem beneficiar tanto o desenvolvimento de personagens comandados por IA em jogos de videogame quanto técnicas de controle de carros autônomos e robôs móveis.

Mostramos também o funcionamento e implementação de controladores do tipo PID, os quais podem ser usados como componentes que gerenciam atuadores com funções diversas. Destacamos situações delicadas onde esses controladores podem apresentar comportamento indesejado, mas abordamos formas de contornar tais adversidades. Além disso, comentamos sobre os processos de ajuste de parâmetros e um procedimento eficiente para o ajuste manual.

Neste trabalho propomos um método para criação de modelos de pistas usando apenas uma pequena quantidade de sensores. Por esse método, é possível determinar aproximadamente o formato do circuito, o qual pode ser segmentado em trechos. Esses trechos, por sua vez, podem ser classificados formando um conjunto de informações concisas e expressivas para representar a pista.

Expusemos os conceitos fundamentais de Aprendizagem por Reforço, bem como sua adaptação na construção de um piloto virtual. O piloto emprega RL para descobrir como controlar o acelerador e freio visando completar voltas na pista gastando o menor tempo possível. Propusemos também uma heurística baseada em controladores PID, a qual considera a sequência de tipos dos trechos para manejar o volante de modo satisfatório.

Por fim, conduzimos experimentos na maioria das pistas disponíveis no TORCS que são semelhantes aos autódromos convencionais do mundo real. Confrontamos os resultados de nosso piloto virtual com o desempenho de dois dos melhores projetos submetidos à competição SCRC, chamados de AUTOPIA e Mr. Racer. Em cada experimento, os controladores foram isoladamente para a pista, correndo sozinhos por 300 voltas. A medida de desempenho foi o tempo médio das últimas voltas. Nosso controlador se mostrou mais lento que seus concorrentes, mas surpreendentemente foi mais rápido que Mr. Racer em uma das 10 pistas testadas.

Embora não tenhamos conseguido superar os concorrentes, as diferenças de tempo na maioria das pistas testadas ficou entre 10 e 15s. Considerando as limitações de nosso agente, tais como a completa discretização das ações e estados, além da utilização de heurística para guiar o carro, na verdade essas marcas se mostram encorajadoras. Concluímos que o emprego de Aprendizagem por Reforço nesse domínio de aplicação é promissor e acreditamos que a substituição do Q-Learning tabular por um método capaz de lidar melhor espaços de ações e estados contínuos pode trazer melhorias significativas nos tempos de volta. 
O principal ponto fraco da discretização em nossa implementação é o componente velocidade usado como parte da definição dos estados. Existem apenas 5 faixas de velocidade, sendo sua amplitude média aproximadamente $45 \mathrm{~km} / \mathrm{h}$. Essa alta granularidade é um dos fatores que contribuem para o piloto não conseguir conduzir o carro próximo ao limite da aderência dos pneus.

Os experimentos também nos mostraram que o uso da estrutura de histórico análoga a um traço de elegibilidade duplo atenua a sensibilidade do RL aos parâmetros de aprendizagem $\alpha$ e $\gamma$. Entretanto utilizar corretamente esse traço adaptado se mostrou um dos grandes desafios do projeto. Uma vez que o mecanismo de identificação das ações responsáveis pelos acidentes está altamente atrelado ao histórico, existem duas situações que podem comprometer o aprendizado do agente:

- Quando a ação (ou as ações) responsável por fazer o carro sair da pista não está no histórico no momento do acidente, seu valor estimado não recebe a punição. Se isso acontece sistematicamente, o piloto deixa de conseguir fazer voltas limpas e o aprendizado não converge;

- No caso inverso, quando ações "inocentes" ficam no histórico errado ou não são removidas dos históricos, o piloto se torna excessivamente cauteloso. Assim, o carro nunca é levado ao seu limite e os tempos de volta ficam altos.

Outro ponto delicado que merece atenção está relacionado ao processo de segmentação. O método que propomos gera resultados satisfatórios para a maioria dos tipos de trecho. Entretanto, ele não se mostrou consistente em trechos com curvatura inconstante, por exemplo, curvas espiraladas. Essa é uma questão difícil, pois o filtroDePatamar fundamentalmente tenta transformar o sinal da variação angular em um conjunto de "saltos" e "patamares". Uma solução para a identificação desses trechos peculiares seria flexibilizar o filtro para buscar também tendências uniformemente ascendentes ou descentendes, porém essa é uma questão que exige maior reflexão.

\subsection{Trabalhos futuros}

A elaboração deste trabalho nos mostrou que construir um piloto virtual completo demanda muito mais do que apenas implementar algoritmos de Inteligência Artificial. A atividade de dirigir um veículo é na verdade uma composição de tarefas de controle, cada qual com diferentes particularidades. Embora este projeto tange várias dessas tarefas, entendemos claramente que ainda há muito a ser explorado. Assim, listamos a seguir algumas direções que apresentam oportunidades de expansão deste trabalho.

\section{Aumento de robustez}

Dois pontos mencionados anteriormente que podem ser aprimorados são: $(i)$ identificação de curvas em espiral pelo filtro de segmentação; e (ii) a substituição da matriz $Q$ por outro método mais adequado ao uso de espaços contínuos. O primeiro tópico não apresenta alta complexidade técnica, porém a alteração deve ser conduzida com cuidado para evitar que picos no sinal passem a ser considerados trechos de curva.

Já a substituição do método tabular é uma questão que pode ser aborda de diferentes formas de acordo com os objetivo da nova pesquisa. Uma alternativa é usar redes neurais artificiais para atuarem como aproximador de função valor. Outra opção, que exigiria uma reestruturação maior, porém se mostra muito promissora, é adotar um técnica de aprendizado em lote, como o Fitted Q-Iteration.

Com um método mais abrangente no mecanismo de aprendizagem, também seria interessante estudar formas de incluir o controle do volante no espaço de ações. Assim, seria possível dispensar o uso de heurística no piloto virtual, potencialmente tornando-o mais flexível. 


\section{Inicialização com conhecimento prévio}

Neste projeto, o controlador não transfere nenhum tipo de informação entre sessões de teste. Ou seja, a matriz $Q$ sempre é inicializada com valor zero em todas as posições e a política é determinada sem qualquer influência de resultados prévios. Esse método evita a possibilidade do processo de aprendizado ser enviesado por uma inicialização tendenciosa. Em contrapartida, sempre que o piloto virtual é colocado para correr em uma pista, é necessário que ele complete várias voltas até atingir um comportamento estável.

Assim, seria interessante investigar os impactos que a inicialização dos valores de $Q$ tem sobre o aprendizado e o desempenho geral do agente. Caso os efeitos fossem positivos, o estudo poderia seguir no sentido de elaborar uma forma de mesclar as políticas decorrente do treinamento em diferentes pistas. Acreditamos que, com essa política resultante, o controlador seria capaz de ter bom desempenho em novas pistas sem a necessidade de completar várias voltas no circuito.

\section{Condições adversas}

Nossos experimentos foram realizados estritamente em pistas de asfalto. Porém o TORCS também possui circuitos de terra, onde a aderência dos pneus ao solo é muito inferior e controlar o carro passa a ser uma tarefa ainda mais difícil. Portanto, outra alternativa de trabalho futuro é adaptar o piloto virtual para esse desafio adicional, ou até mesmo desenvolver uma solução flexível quanto às condições da pista.

Além disso, o software adaptado para a competição SCRC possibilita introduzir ruídos nas medições realizadas pelos sensores virtuais. Com isso, a analogia entre a simulação e o mundo real fica ainda mais forte já que, na prática, as leituras de sensores estão sujeitas a imprecisões e erros. Dessa forma, testar o desempenho do segmentador quando se tem dados ruidosos e elaborar eventuais modificações no método também é um caminho a ser explorado.

\section{Oponentes}

Em uma corrida com a presença de adversários, as habilidades de efetuar ultrapassagens e de bloquear os outros carros podem ser tão ou mais decisivas do que a capacidade de realizar voltas rápidas em pista livre. Em razão disso, mesmo não sendo o mais rápido, um piloto pode conseguir vencer provas coletivas. Isso é uma motivação para que esforços sejam direcionados em adaptar o comportamento do controlador em função dos oponentes próximos e eventualmente submeter o agente a uma edição do SCRC. 


\section{Referências Bibliográficas}

[ÅH95] Karl J. Åström e Tore Hägglund. "PID Controllers". ISA: The Instrumentation, Systems, and Automation Society, 2nd edição, janeiro 1995.

[AL11] A.A. Abdullahi e S.M. Lucas. "Temporal difference learning with interpolated n-tuples: Initial results from a simulated car racing environment". Em Computational Intelligence and Games (CIG), 2011 IEEE Conference on, páginas 321-328, agosto 2011.

[BCMS08] F. Braghin, F. Cheli, S. Melzi e E. Sabbioni. "Race driver model". Comput. Struct., 86(1314):1503-1516, julho 2008.

[BL09] M.V. Butz e T.D. Lonneker. "Optimized sensory-motor couplings plus strategy extensions for the TORCS car racing challenge". Em Computational Intelligence and Games, 2009. CIG 2009. IEEE Symposium on, páginas 317-324, setembro 2009.

[cig12] "IEEE GIG - IEEE Conference on Computational Intelligence and Games". [Online], 2012. http://geneura.ugr.es/cig2012/.

[CLLB10] L. Cardamone, D. Loiacono, P.L. Lanzi e A.P. Bardelli. "Searching for the optimal racing line using genetic algorithms". Em Computational Intelligence and Games (CIG), 2010 IEEE Symposium on, páginas 388-394, agosto 2010.

[Cor00] Armando B. Corripio. "Tuning of Industrial Control Systems". ISA: The Instrumentation, Systems, and Automation Society, 2nd edição, agosto 2000.

[DdS14] Vinícius K. Daros e Flávio S.C. da Silva. "Identificando e Classificando Trechos de Pistas no Simulador de Corridas TORCS". Apresentado no Simpósio Brasileiro de Jogos e Entretenimento Digital. SBGAMES, 2014.

[Dic07] Ernst D. Dickmanns. "Dynamic Vision for Perception and Control of Motion". Springer London, abril 2007.

[EGW05] Damien Ernst, Pierre Geurts e Louis Wehenkel. "Tree-Based Batch Mode Reinforcement Learning". J. Mach. Learn. Res., 6:503-556, dezembro 2005.

[evo12] "evo* - The main European events on Evolutionary Computation". [Online], 2012. http: //evostar.dei.uc.pt/2012/.

[Gar05] Geraldo J. Gardinalli. "Comparação do desempenho de frenagem simulada x experimental de um veículo de passeio com freios hidráulicos e ABS". Master's thesis, Escola Politécnica da Universidade de São Paulo, 2005.

[gec12] "GECCO - Genetic and Evolutionary Computation Conference". [Online], 2012. http://www. sigevo.org/gecco-2012/index.html. 
[Gil92] Thomas D. Gillespie. "Fundamentals of Vehicle Dynamics". Warrendale, PA, março 1992.

[Han] Jeff Hannan. "Interview with Jeff Hannan". [Online]. http://www.generation5.org/content/ 2001/hannan.asp.

[JPKA95] Todd Jochem, Dean Pomerleau, Bala Kumar e Jeremy Armstrong. PANS: A Portable Navigation Platform. Em "IEEE Symposium on Intelligent Vehicles", páginas 107-112, setembro 1995.

[KTW86] Takeo Kanade, Chuck Thorpe e William Whittaker. Autonomous Land Vehicle Project at CMU. Em "Proceedings of the 1986 ACM Fourteenth Annual Conference on Computer Science”, CSC '86, páginas 71-80, 1986.

[LAC06] Y. Li, K. H. Ang e G. C. Y. Chong. "PID control system analysis and design". IEEE Control Systems Magazine, 26(1):32-41, fevereiro 2006.

[Lec09] S. Lecchi. Artificial intelligence in racing games. Em "Computational Intelligence and Games, 2009. CIG 2009. IEEE Symposium on”, páginas 1-1, setembro 2009.

$\left[\right.$ LLT $\left.^{+} 10\right]$ D. Loiacono, P.L. Lanzi, J. Togelius, E. Onieva, D.A. Pelta, M.V. Butz, T.D. Lönneker, L. Cardamone, D. Perez, Y. Saéz, M. Preuss e J. Quadflieg. "The 2009 Simulated Car Racing Championship". Computational Intelligence and AI in Games, IEEE Transactions on, 2(2):131-147, junho 2010 .

[LPLC10] D. Loiacono, A. Prete, P.L. Lanzi e L. Cardamone. "Learning to overtake in TORCS using simple reinforcement learning". Em Evolutionary Computation (CEC), 2010 IEEE Congress on, páginas 1-8, julho 2010.

$\left[\mathrm{LTL}^{+}\right.$08] D. Loiacono, J. Togelius, P.L. Lanzi, L. Kinnaird-Heether, S.M. Lucas, M. Simmerson, D. Perez, R.G. Reynolds e Y. Saez. "The WCCI 2008 simulated car racing competition". Em Computational Intelligence and Games, 2008. CIG '08. IEEE Symposium On, páginas 119126 , dezembro 2008.

$\left[\mathrm{MBF}^{+} 96\right]$ M. Maurer, R. Behringer, S. Furst, F. Thomanek e E.D. Dickmanns. A compact vision system for road vehicle guidance. Em "Pattern Recognition, 1996., Proceedings of the 13th International Conference on", volume 3, páginas 313-317, agosto 1996.

[MGS09] Jorge Muñoz, German Gutierrez e Araceli Sanchis. "Controller for TORCS created by imitation". Em Proceedings of the 5th international conference on Computational Intelligence and Games, CIG'09, páginas 271-278, 2009.

[MGS10] Jorge Muñoz, German Gutierrez e Araceli Sanchis. "A human-like TORCS controller for the Simulated Car Racing Championship". Em Computational Intelligence and Games (CIG), 2010 IEEE Symposium on, páginas 473-480, agosto 2010.

[MRT12] M. Mohri, A. Rostamizadeh e A. Talwalkar. "Foundations of Machine Learning". MIT Press, agosto 2012 .

[Oga00] Katsuhiko Ogata. "Engenharia de Controle Moderno”. LTC Editora, 3.ed edição, 2000.

[OPA ${ }^{+}$09] E. Onieva, D. A. Pelta, J. Alonso, V. Milanés e J. Pérez. "A modular parametric architecture for the TORCS racing engine". Em Computational Intelligence and Games, 2009. CIG 2009. IEEE Symposium on, páginas 256-262, setembro 2009. 
[OPG $\left.{ }^{+} 12\right]$ E. Onieva, D. A. Pelta, J. Godoy, V. Milanés e J. Pérez. "An evolutionary tuned driving system for virtual car racing games: The AUTOPIA driver". Int. J. Intell. Syst., 27(3):217-241, março 2012.

[PRSI09] D. Perez, G. Recio, Y. Saez e P. Isasi. "Evolving a fuzzy controller for a Car Racing Competition". Em Computational Intelligence and Games, 2009. CIG 2009. IEEE Symposium on, páginas 263-270, setembro 2009.

[QPKR10] J. Quadflieg, M. Preuss, O. Kramer e G. Rudolph. "Learning the track and planning ahead in a car racing controller". Em Computational Intelligence and Games (CIG), 2010 IEEE Symposium on, páginas 395-402, agosto 2010.

[QPR11] Jan Quadflieg, Mike Preuss e Günter Rudolph. "Driving faster than a human player". Em Proceedings of the 2011 international conference on Applications of evolutionary computation - Volume Part I, EvoApplications'11, páginas 143-152, 2011.

[RN94] G. A. Rummery e M. Niranjan. "On-line Q-learning using connectionist systems". CUED/FINFENG/TR 166, Cambridge University Engineering Department, setembro 1994.

[SB98] Richard S. Sutton e Andrew G. Barto. "Introduction to Reinforcement Learning”. MIT Press, março 1998.

[SC09] David Stern e Joaquin Q. Candela. Playing Machines: Machine learning applications in computer games. Em "CIG'09: Proceedings of the 5th international conference on Computational Intelligence and Games", páginas 1-1, setembro 2009.

[scr12] "The 2012 Simulated Car Racing Championship". [Online], 2012. http://games.ws.dei.polimi. it/competitions/scr/.

[Sut96] Richard S. Sutton. "Generalization in reinforcement learning: Successful examples using sparse coarse coding". Em Advances in Neural Information Processing Systems 8, páginas 1038-1044. MIT Press, 1996.

[Thr] Sebastian Thrun. "What we're driving at". [Online]. http://googleblog.blogspot.com.br/2010/ 10/what-were-driving-at.html.

[TLDN07] J Togelius, SM Lucas e R De Nardi. "Computational Intelligence in Racing Games". Em Advanced intelligent paradigms in computer games, number 3. Springer Verlag, 2007.

[Wat89] C.J.C.H. Watkins. "Learning from Delayed Rewards". Ph.d. thesis, Cambridge University, 1989.

[Wil88] M. Williams. "PROMETHEUS-The European research programme for optimising the road transport system in Europe". Em Driver Information, IEE Colloquium on, páginas 1/1-1/9, dezembro 1988.

[WST $\left.{ }^{+} 85\right]$ Richard Wallace, Anthony Stentz, Charles Thorpe, Hans Maravec, William Whittaker e Takeo Kanade. First Results in Robot Road-following. Em "Proceedings of the 9th International Joint Conference on Artificial Intelligence - Volume 2”, IJCAI'85, páginas 1089-1095, 1985.

[ZN42] J. G. Ziegler e N. B. Nichols. "Optimum Settings for Automatic Controllers". ASME Transactions, 64(8):759-768, 1942. 
REFERÊNCIAS BIBLIOGRÁFICAS 


\section{Apêndice A}

\section{Pistas segmentadas}

Neste apêndice, apresentamos as representações de segmentação e classificação das pistas que não foram expostas no Capítulo 3. É importante notar que as figuras não estão em mesma escala.

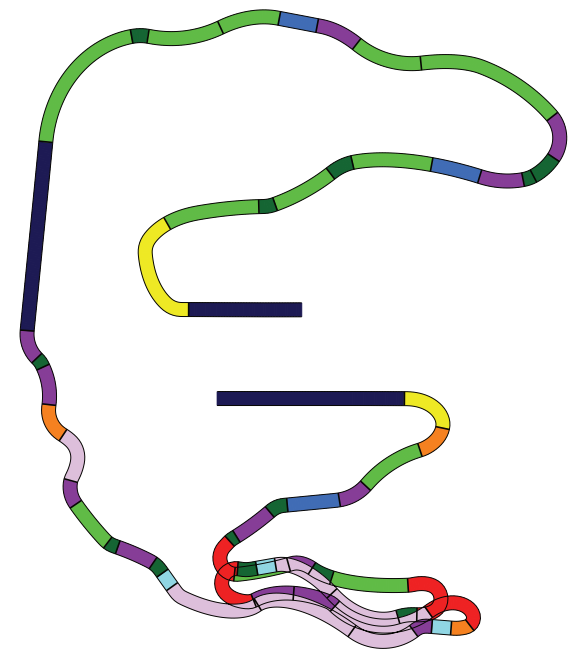

Figura A.1: alpine-1

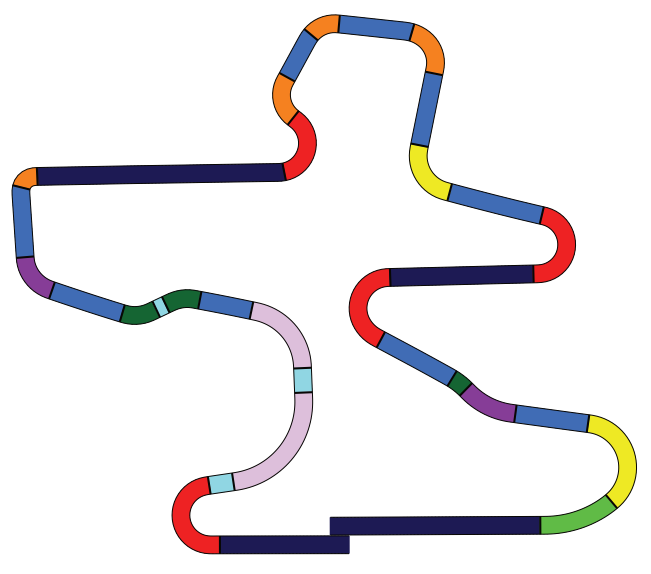

Figura A.2: alpine-2
Legenda

Reta curta

Reta média

Reta longa

Curva hairpin (grampo)

Curva cotovelo

Curva acentuada curta

Curva acentuada longa

Curva moderada curta

Curva moderada longa

Curva leve curta

Curva leve longa 

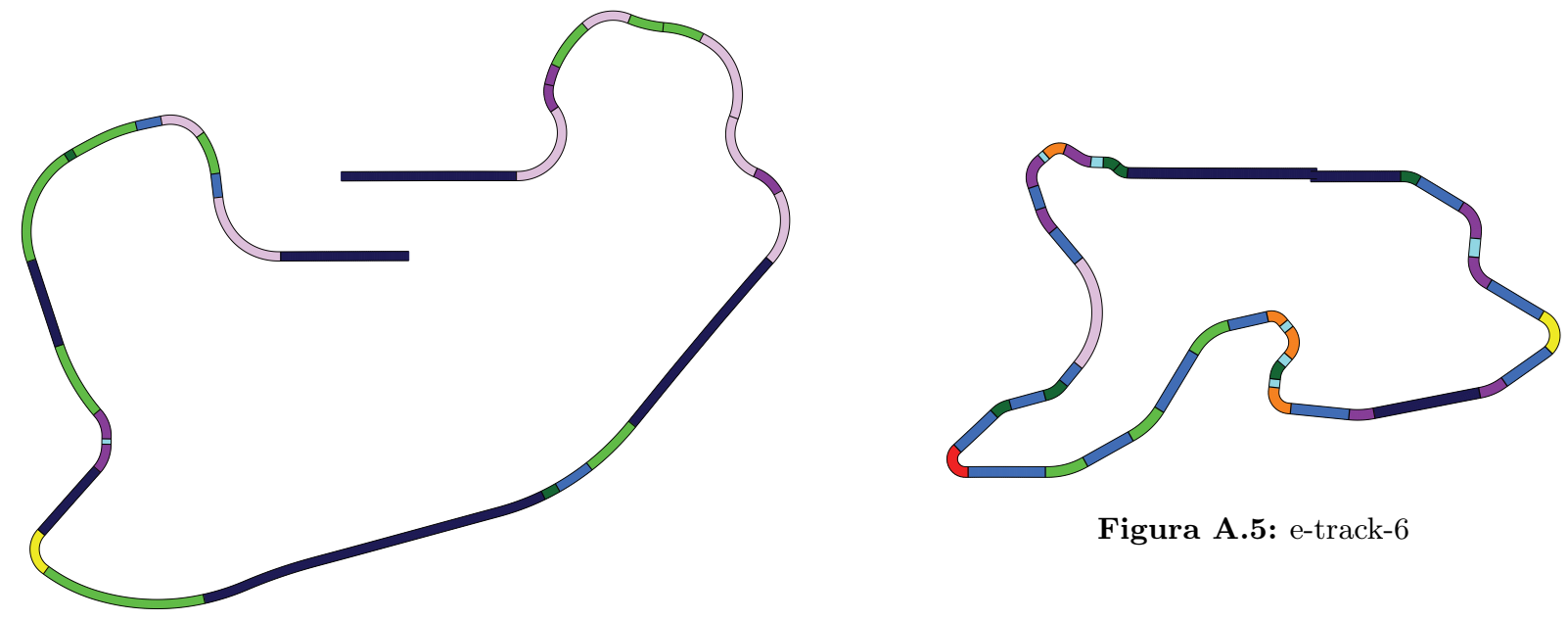

Figura A.5: e-track-6

Figura A.4: e-track-4

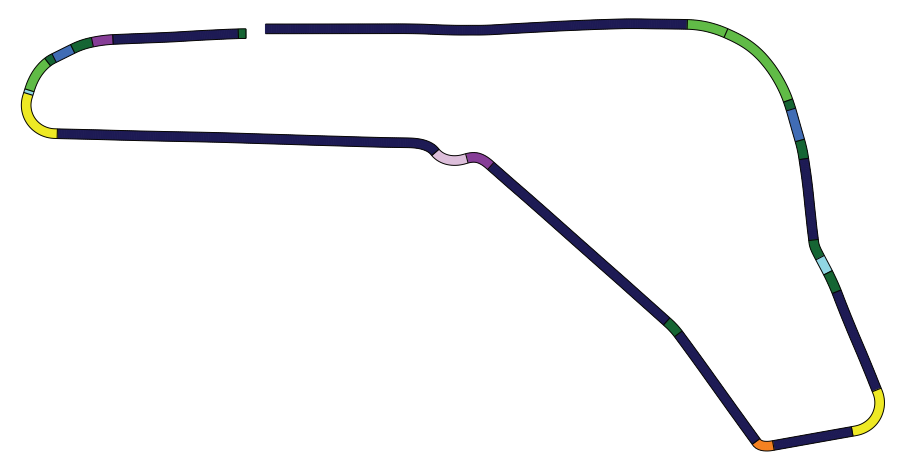

Figura A.6: forza
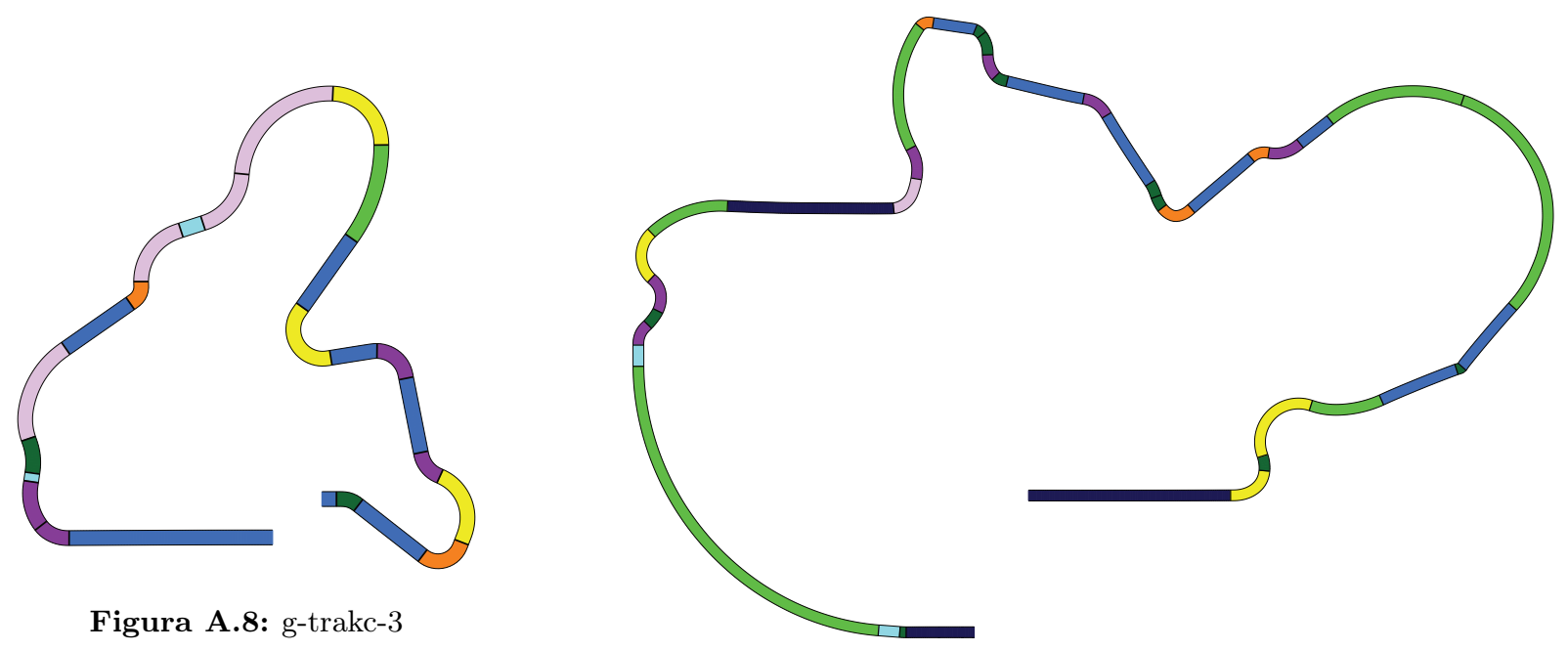

Figura A.8: g-trakc-3

Figura A.9: ole-road-1 
PISTAS SEGMENTADAS

73

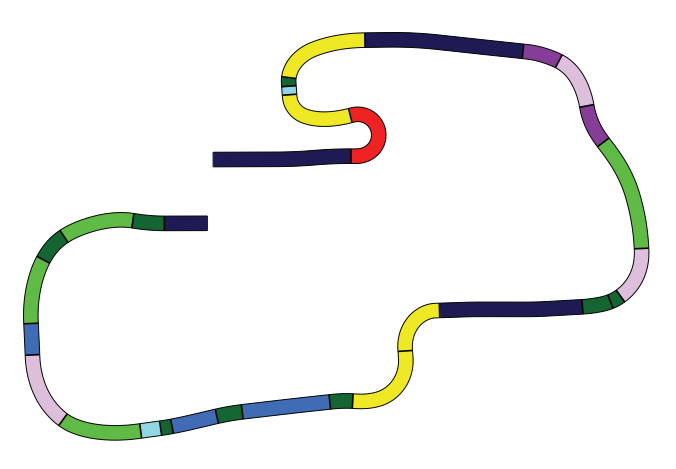

Figura A.10: ruudskogen

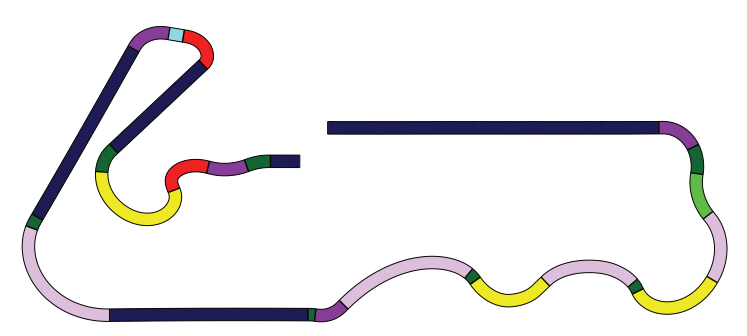

Figura A.12: wheel-1

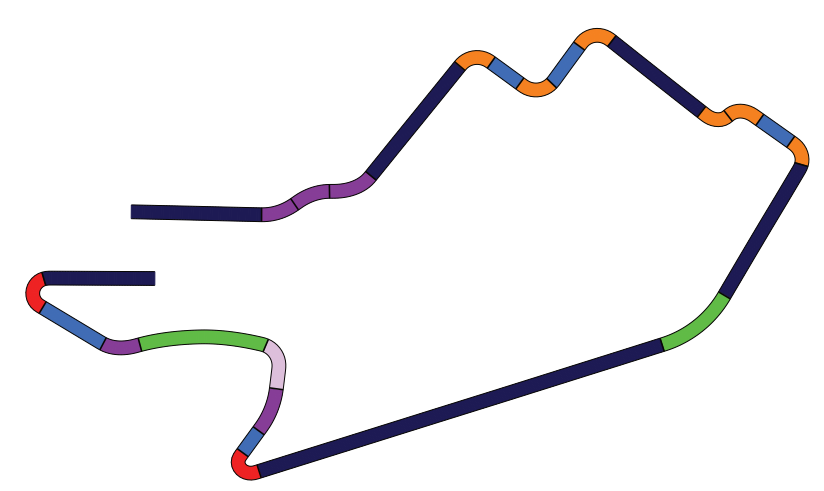

Figura A.11: street-1

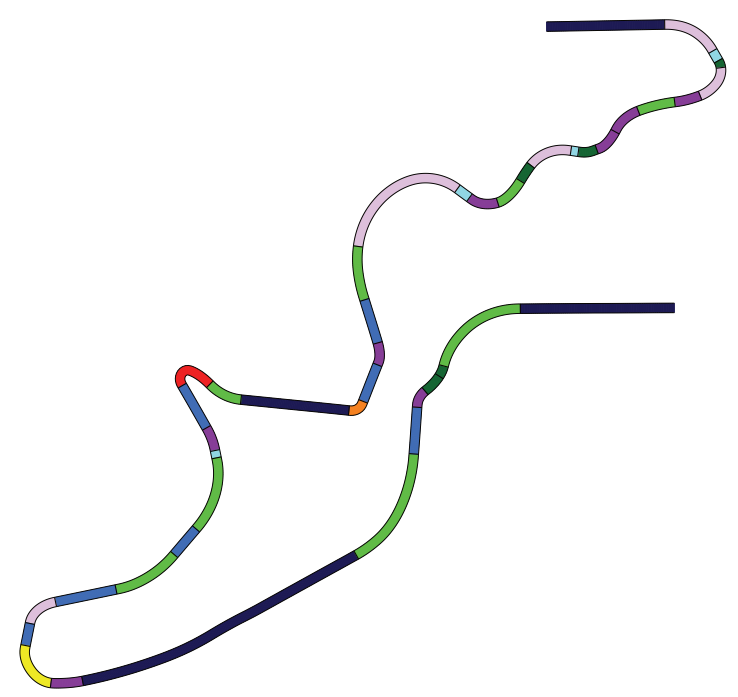

Figura A.13: wheel-2 
APÊNDICE A 


\section{Apêndice B}

\section{Tempos de volta e recompensas}

A seguire apresentamos todos os gráficos dos tempos de volta e recompensas acumuladas resultante dos experimentos com as dez pistas testadas.

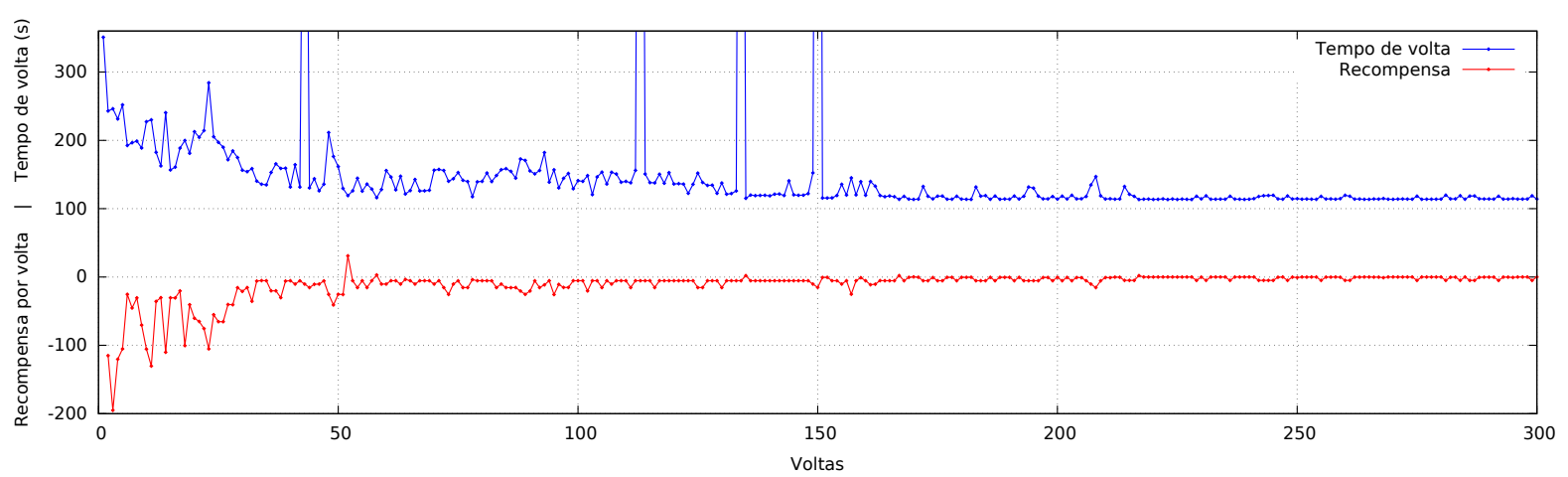

Figura B.1: Tempo e recompensa acumulada de cada volta na pista alpine-2.

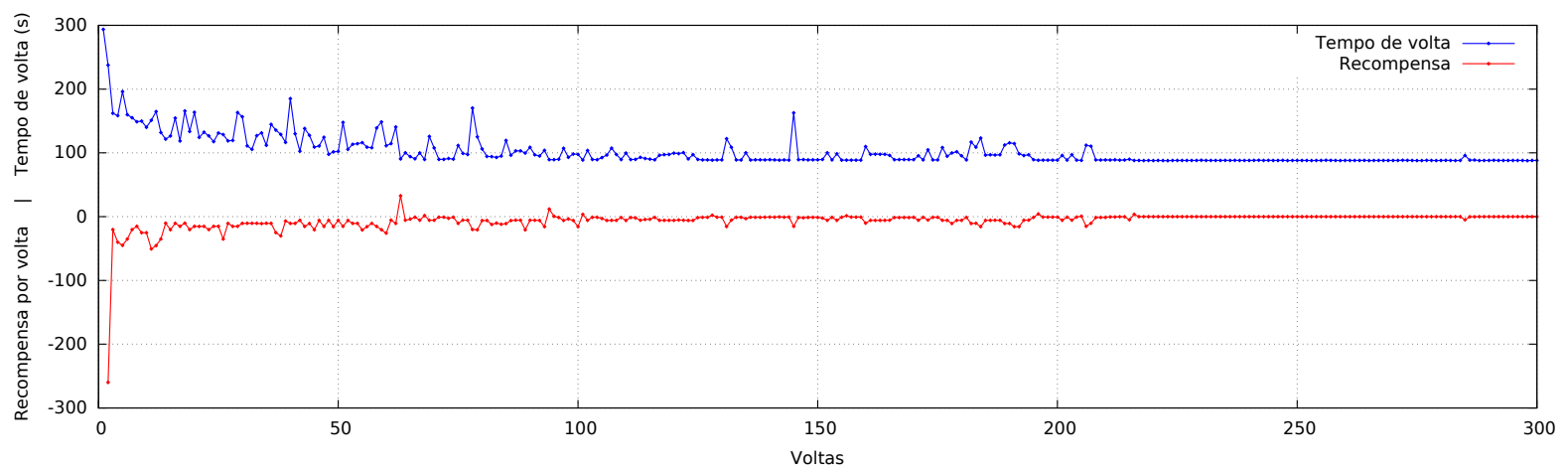

Figura B.2: Tempo e recompensa acumulada de cada volta na pista e-track-2. 


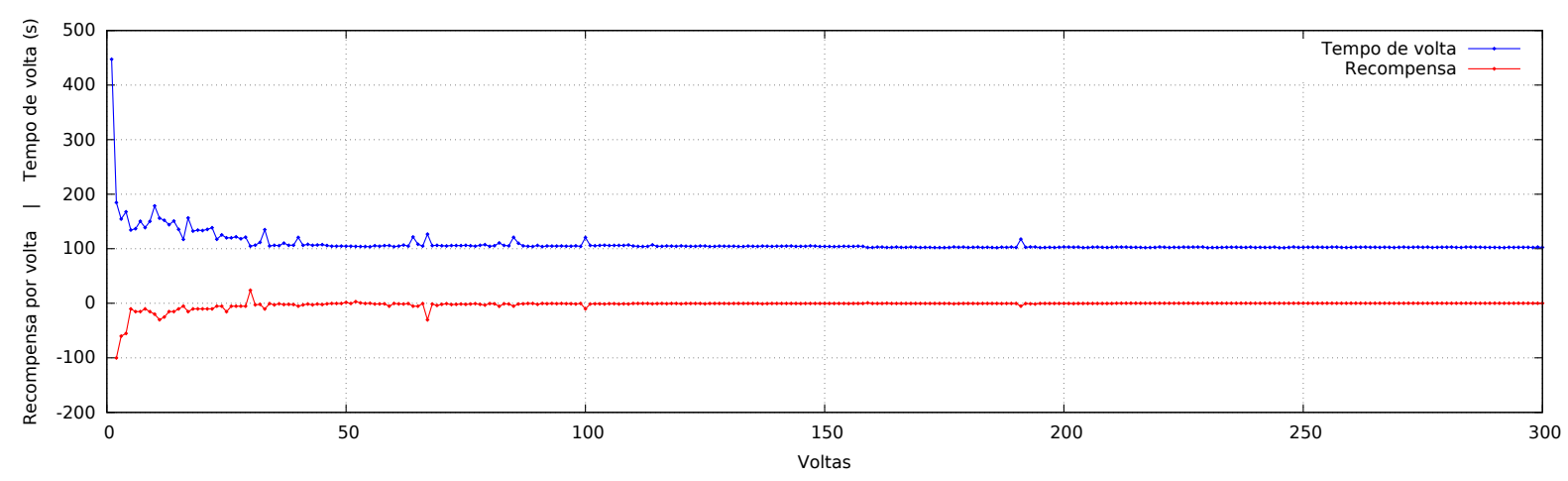

Figura B.3: Tempo e recompensa acumulada de cada volta na pista e-track-3.

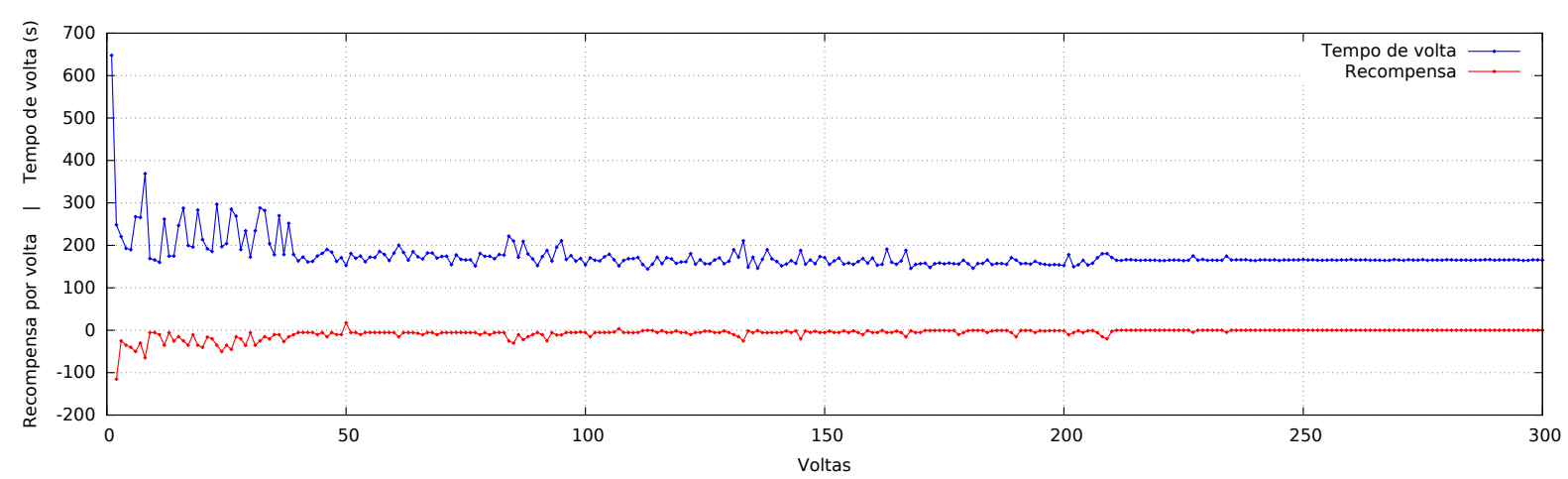

Figura B.4: Tempo e recompensa acumulada de cada volta na pista e-track-4.

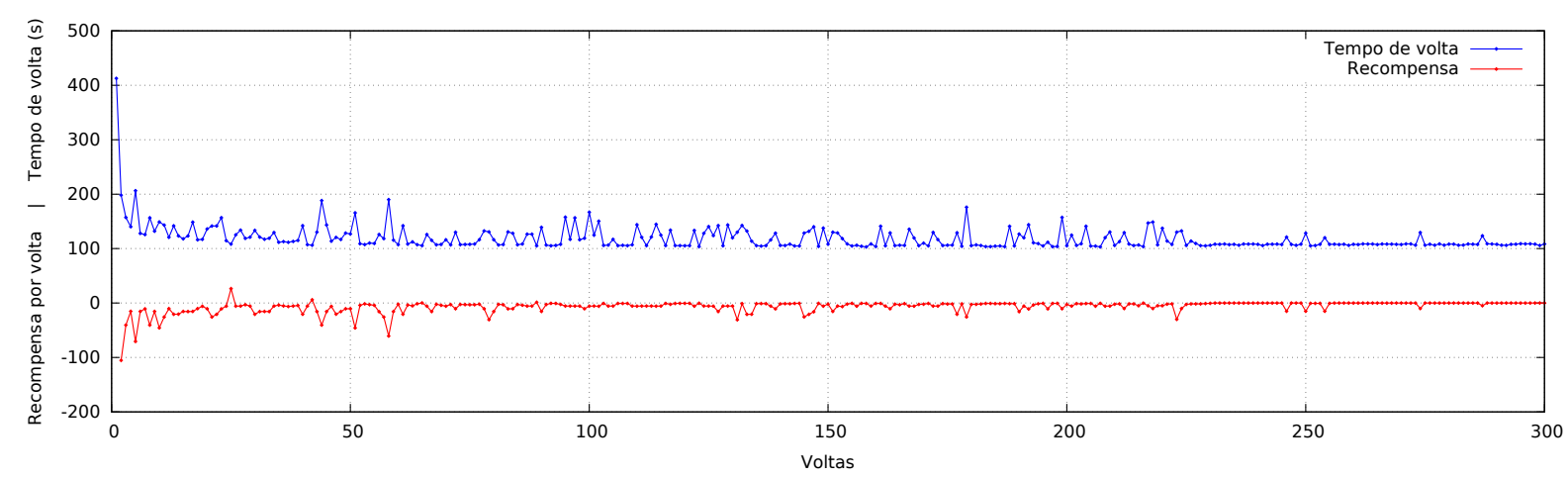

Figura B.5: Tempo e recompensa acumulada de cada volta na pista e-track-6.

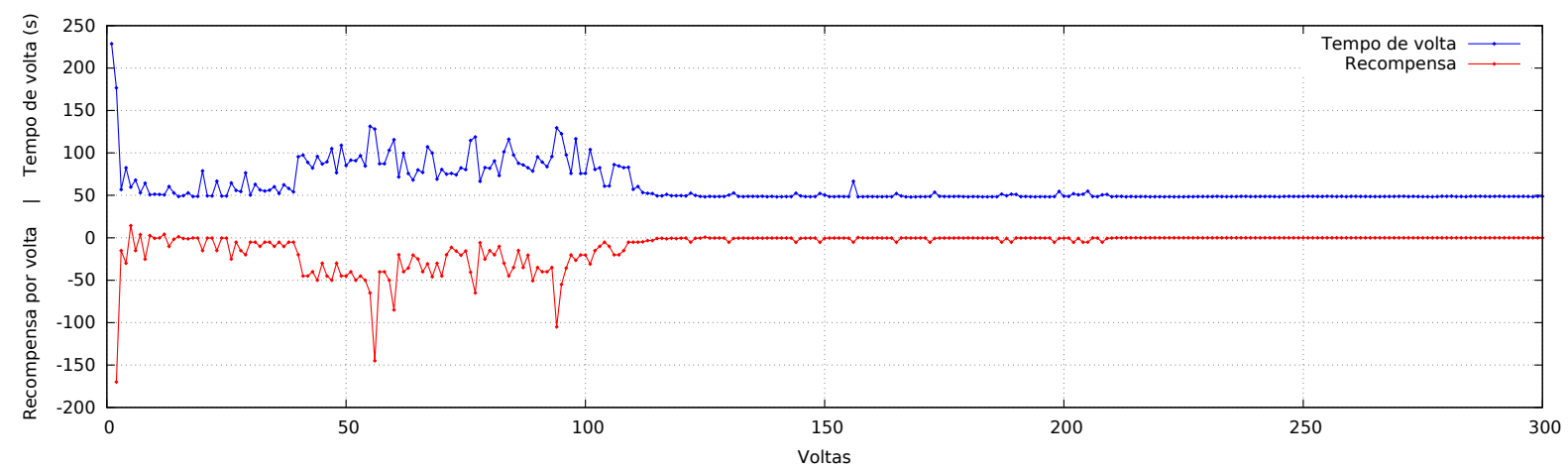

Figura B.6: Tempo e recompensa acumulada de cada volta na pista g-track-1. 


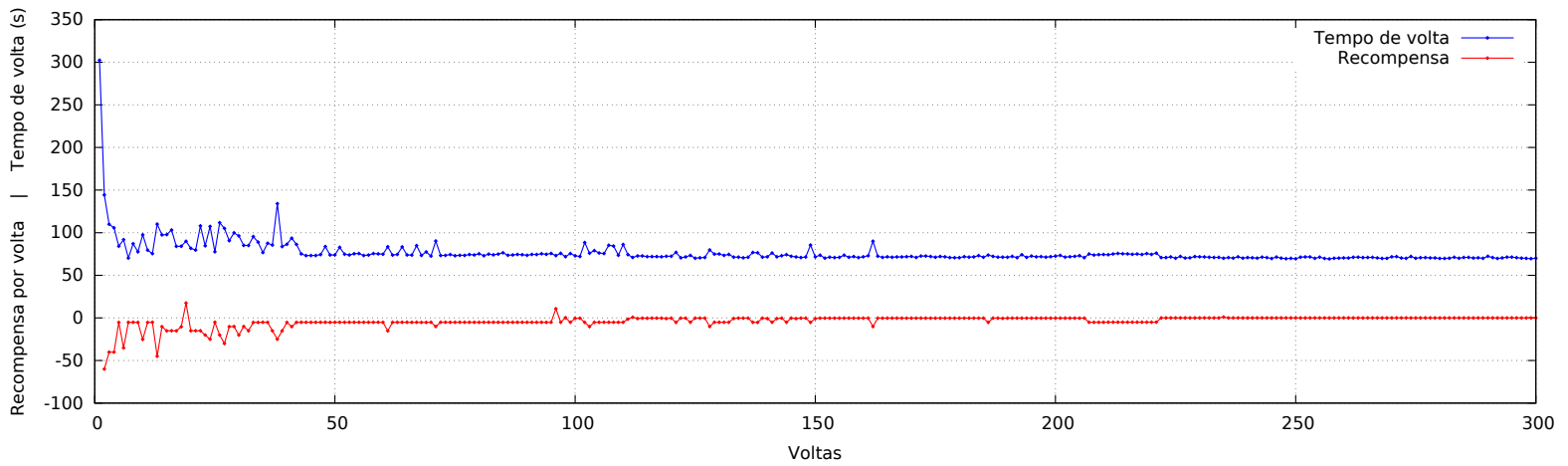

Figura B.7: Tempo e recompensa acumulada de cada volta na pista g-track-2.

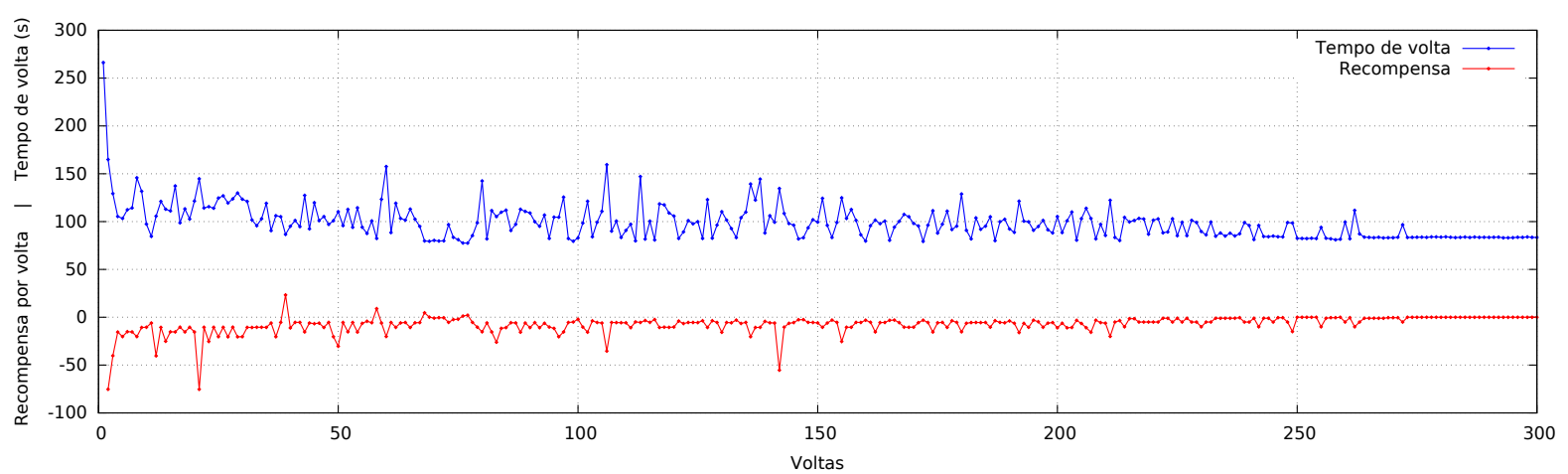

Figura B.8: Tempo e recompensa acumulada de cada volta na pista g-track-3.

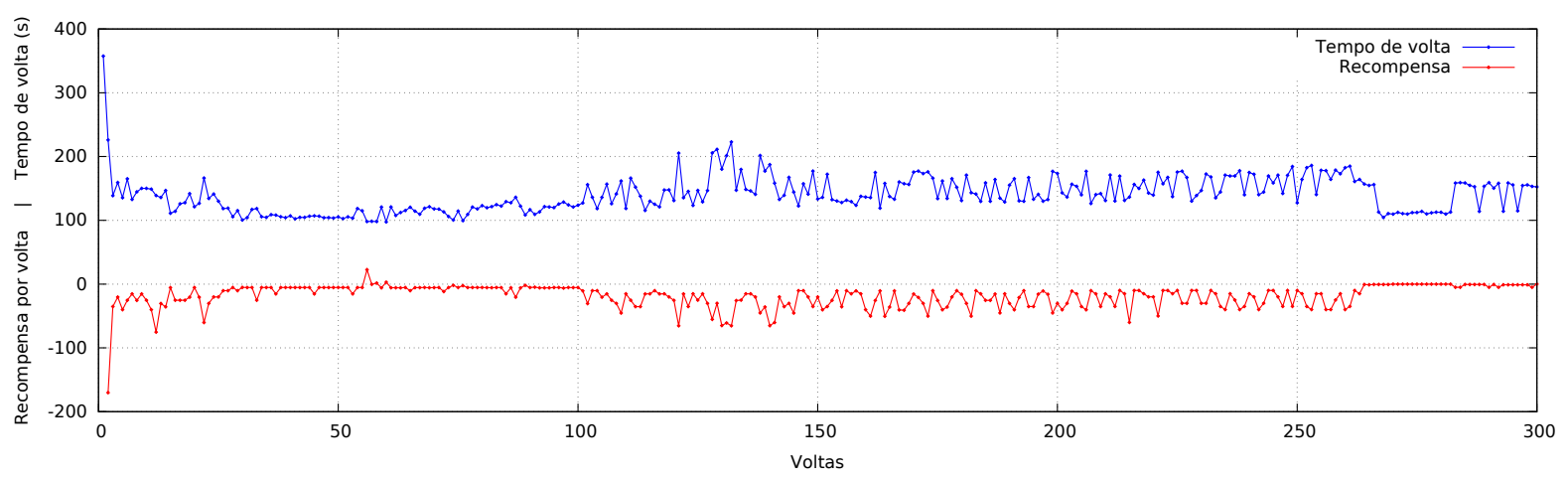

Figura B.9: Tempo e recompensa acumulada de cada volta na pista street-1.

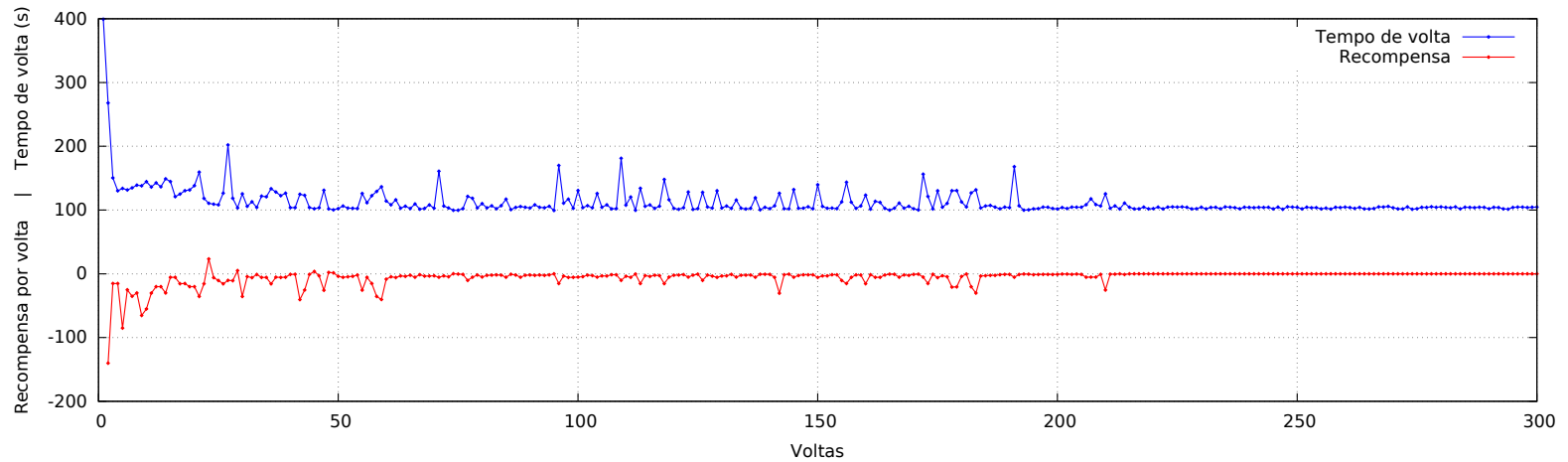

Figura B.10: Tempo e recompensa acumulada de cada volta na pista wheel-1. 